


\title{
Integração de Processamento Distribuído em uma Plataforma de Cidades Inteligentes
}

Dylan Jefferson Mauricio Guimarães Guedes

\author{
DiSSERTAÇÃo APRESENTADA AO \\ INSTITUTO DE MATEMÁTICA E EsTATÍSTICA \\ DA UNiversidade de SÃo PAUlo \\ PARA OBTENÇÃO DO TÍTULO DE \\ Mestre EM CiênCIAS
}

Programa: Ciência da Computação

Orientador: Prof. Dr. Fabio Kon

O presente trabalho foi realizado com apoio do CNPq proc. $465446 / 2014-0$, CAPES - Finance Code 001, FAPESP proc. 14/50937-1, e FAPESP proc. 15/24485-9.

São Paulo

9 de Dezembro de 2019 



\title{
Integração de Processamento Distribuído em uma Plataforma de Cidades Inteligentes
}

\author{
Dylan Jefferson Mauricio Guimarães Guedes
}

Esta é a versão original da dissertação elaborada pelo candidato Dylan Jefferson

Mauricio Guimarães Guedes, tal como submetida à Comissão Julgadora. 
Autorizo a reprodução e divulgação total ou parcial deste trabalho, por qualquer meio convencional ou eletrônico, para fins de estudo e pesquisa, desde que citada a fonte. 
Aos meus familiares e amigos, que sempre me estenderam a mão. 



\section{Agradecimentos}

A pior parte dos agradecimentos é ser injusto e esquecer de alguém importante. Então, prefiro começar dizendo que se fui injusto foi sem intenção.

Agradeço inicialmente aos meus pais, Aureo Jefferson Guimarães Guedes e Patrícia Mauricio Costa, por terem me ensinado as lições mais valiosas e terem sido pais exemplares. Eu ainda não sei explicar como cheguei onde cheguei, mas sei que foi graças a vocês.

Também gostaria de agradecer a todos os outros familiares, principalmente meus primos que cresceram comigo e aos meus tios, que sempre me apoiaram e deram bons conselhos. Também agradeço a minha avó, Zezé, e a Dona Aparecida, que cuidaram de mim quando eu era mais novo para que meus pais pudessem trabalhar.

Aos meus amigos da infância, ensino médio e tempos de graduação, meus mais sinceros agradecimentos pelas resenhas e momentos de descontração. Ainda lembro e conto várias histórias que passamos e espero continuar com essas memórias por muito tempo.

Aos amigos mais próximos da LAPPIS Society, que além de serem algumas das pessoas mais inteligentes que eu já conheci e terem me ensinado tanto, foram sempre pessoas com quem eu pude contar e compartilhar bons momentos. Espero trabalhar com vocês novamente, mas senão for possível, foi uma honra ter trabalhado com cada um de vocês. Aos amigos mais próximos da TFG/Wildlife Studios, que além de serem super competentes são os grandes responsáveis por fazerem meu dia no trabalho melhor.

Deixo os mais sinceros agradecimentos ao Professor Paulo Meirelles, tanto por ter me ensinado muito, tanto como professor quanto como orientador, mas também por sempre ter confiado em mim, desde o início da graduação até o final do meu mestrado. Dos tempos de UnB, deixo meus agradecimentos para a Professora Carla Rocha, por ter confiado em mim e por ter me ajudado diversas vezes no meu processo de vinda para a USP. Também agradeço ao meu orientador, Professor Fabio Kon, pelo apoio e orientação na realização deste trabalho e por depositar sua confiança em mim para seguir com uma parte importante do projeto InterSCity. 
Por fim, deixo um agradecimento especial a todos os amigos de USP que faziam e fazem parte do laboratório de sistemas. Nelson, você é incrível (este modelo LaTeX foi ele quem fez). Higor, muito obrigado por todas as ótimas revisões, conselhos e dicas; sem a sua ajuda e dedicação este trabalho não seria possível.

Por fim, agradeço ao apoio financeiro que recebi durante este trabalho. O presente trabalho foi realizado com apoio do INCT da Internet do Futuro para Cidades Inteligentes, CNPq proc. 465446/2014-0, CAPES código financeiro 001, FAPESP proc. 14/50937-1 e FAPESP proc. 15/24485-9. 


\section{Resumo}

Dylan Jefferson Mauricio Guimarães Guedes. Integração de Processamento Distribuído em uma Plataforma de Cidades Inteligentes. Dissertação (Mestrado). Instituto de Matemática e Estatística, Universidade de São Paulo, São Paulo, 2019.

Nos últimos anos, diversas cidades passaram a disponibilizar e a fazer uso de seus dados de forma eficiente, possibilitando a criação de soluções tecnológicas para cidades inteligentes. Essas soluções podem ser desenvolvidas de uma maneira específica e adhoc, ou podem ser apoiadas sobre uma plataforma de cidades inteligentes, que são mais interoperáveis e padronizadas. Na prática, uma aplicação utiliza a API de uma plataforma de cidades inteligentes para ter garantias de requisitos não-funcionais, como desempenho, escalabilidade e tolerância a falhas. Contudo, quando várias aplicações utilizam a plataforma, o fluxo de dados gerado e consultado é grande e só pode ser atendido com grande poder computacional. Atualmente, uma forma acessível de atingir o poder computacional necessário é aumentar os recursos computacionais horizontalmente, adicionando mais computadores para distribuir as tarefas de processamento. Nesse contexto, as plataformas devem utilizar ferramentas de processamento distribuído para lidar com aplicações intensivas em dados. Porém, a maior parte das plataformas não integram essas ferramentas, e as que integram, não disponibilizam uma forma facilitada de uso. Neste trabalho, apresentamos uma arquitetura que faz a integração entre ferramentas de processamento distribuído e plataformas de cidades inteligentes com ênfase em usabilidade sem gradação de desempenho. Implementamos a arquitetura como um microsserviço chamado DataProcessor, responsável tanto por integrar a ferramenta de processamento em cluster Apache Spark e a plataforma de cidades inteligentes InterSCity, quanto por disponibilizar essa integração através de uma API REST. Assim, desenvolvedores da plataforma InterSCity podem criar novas tarefas de processamento que utilizam os recursos disponíveis de maneira efetiva, mas sem a necessidade de conhecimento específico sobre a ferramenta de processamento em cluster. Avaliamos o DataProcessor em um experimento que utilizou o simulador de larga escala InterSCSimulator para simular dados de trânsito, que nos permitiu concluir que: (1) o uso do DataProcessor para facilitar o uso do Spark não traz perda de eficiência; (2) embora o DataProcessor disponibilize uma API REST, que é uma opção mais difundida que a API do Spark, a quantidade de código necessário é semelhante; e (3) é possível adicionar novas funcionalidades ao DataProcessor facilmente com a adição de poucas linhas de código.

Palavras-chave: processamento-distribuído. processamento-em-cluster. cidadesinteligentes. programação-intensiva-em-dados. Big Data. 



\begin{abstract}
Dylan Jefferson Mauricio Guimarães Guedes. Distributed Processing Integration in a Smart Cities Platform. Thesis (Masters). Institute of Mathematics and Statistics, University of São Paulo, São Paulo, 2019.

In recent years, cities started to provide and use data more efficiently, allowing the creation of new smart cities soluitions. Such solutions can be created either in a more specific and ad hoc way or can be supported by a smart cities platform, which is more interoperable and standardized. In practice, an application should use a smart cities platform API to achieve non-functional requirements needs, such as performance, scalability, and fault tolerance. However, when many applications make use of a platform, the data flow is massive and requires large computational resources. Currently, an effective way to achieve the required power is to increase the computational resources in a horizontal way, through the addition of more computers, to be able to better distribute the processing tasks. In this sense, platforms should use cluster processing tools to better deal with data-intensive applications, yet the majority of smart cities platforms do not integrate such tools. Moreover, the platforms that integrates cluster processing tools do not provide an easy way to use. In this work, we present an architecture that integrates cluster processing tools and smart cities platforms with usability in mind without bringing noticeable performance overhead. We implemented the architecture as a microservice called DataProcessor, which integrates the Apache Spark cluster processing tool and the InterSCity smart cities platform. The DataProcessor also provides the usage of this integration through a REST API. Therefore, InterSCity developers may create new data processing tasks that use available computational resources effectively, without a deep knowledge of cluster processing tools. We evaluated DataProcessor in an experiment that used InterSCSimulator, a large scale simulator, to simulate traffic data, which allowed us to conclude that: (1) DataProcessor usage does not bring noticeable performance degradation; (2) even though the DataProcessor API is easier to use, the required number of lines of code is pretty much the same; and (3) it is possible to add new features to the DataProcessor with a few lines of code.
\end{abstract}

Keywords: distributed-processing. cluster-processing. smart-cities. data-intensiveprogramming. Big-Data. 



\section{Lista de Figuras}

1.1 Tela inicial do aplicativo SmartParking. . . . . . . . . . . . . . . . . 1

2.1 As diferentes formas de replicação. A primeira é a líder e seguidores, a segunda multilíder e a terceira sem líder. . . . . . . . . . . . 7

2.2 Funcionamento do broadcast join. Fonte: XIN et al. (2013). . . . . . . . . 11

2.3 Visão alto nível da arquitetura do Spark. . . . . . . . . . . . . . . . . . 13

2.4 Visualização de um job pela SparkUı. . . . . . . . . . . . . . . . . . . . . 14

2.5 Visão geral dos microsserviços da plataforma InterSCity. Cada um dos blocos dentro da caixa InterSCity Platform é um microsserviço da plataforma. 19

4.1 Visão geral da arquitetura do DataProcessor, com alguns exemplos de uso (como o de consulta SQL). . . . . . . . . . . . . . . 30

4.2 Passo 1 do fluxo de funcionamento do DataProcessor. . . . . . . . . . . 33

4.3 Passo 2 do fluxo de funcionamento do DataProcessor. . . . . . . . . . . . 35

4.4 Passo 3 do fluxo de funcionamento do DataProcessor. . . . . . . . . . 36

4.5 Ordem dos segmentos do código gerado e a proporção de código de cada segmento. . . . . . . . . . . . . . . . . 39

4.6 Carregamento dos resultados pelo Pandas e visualização através do Seaborn. 43

4.7 Tela de preenchimento dos dados do JobScript. . . . . . . . . . . . . 49

4.8 Tela de preenchimento dos dados do JobTemplate. . . . . . . . . . . . 50

4.9 Instanciamento de um novo JobScript para o JobTemplate "Percent is de temperatura". .................... 50

4.10 Listagem dos Processing Jobs. O botão verde dá início ao ProcessingJob, que irá lançar um job do Spark para processamento dos dados. . . . . . . .

5.1 Deslocamento do ônibus 0xABC sobre o grafo da cidade em um formato semelhante ao fornecido pela SPTrans. 
5.2 Transferência dos dados simulados, gerados pelo InterSCSimulator, para o DataCollector do InterSCity, feito através da API produtor-consumidor do RabbitMQ . . . . . . . . . . . . . . . . 56

5.3 Configuração do cluster utilizado. . . . . . . . . . . . . . . . . 57

5.4 Particionamento dos veículos. . . . . . . . . . . . . . . 58

5.5 Estágios definidos para o código gerado pelo DataProcessor. . . . . . . . 61

5.6 Tempo de processamento - DataProcessor vs. Spark. . . . . . . . . . . . 62

\section{Lista de Tabelas}

4.1 Quantidades de linhas utilizadas na implementação. . . . . . . . . . . . . 31

4.2 Lista de endpoints do DataProcessor. . . . . . . . . . . . . . . . 38

5.1 Métricas retornadas pelo Spark após o processamento dos dados. . . . . . 62

\section{Lista de Programas}

2.1 Exemplo de consulta SQL otimizada pelo Spark. . . . . . . . . . . . . . . 10

2.2 Plano de execução traçado pelo Spark para executar a consulta SQL do Programa 2.1. . . . . . . . . . . . . . . . . 10

4.1 Exemplo de requisição REST feita ao DataProcessor para criação do JobTemplate e a resposta recebida. . . . . . . . . . . . . . 34

4.2 Exemplo de requisição REST feita ao DataProcessor para criação do ProcessingJob. . . . . . . . . . . . . . . . . . 34

4.3 Chamada que submete o código gerado para o Spark . . . . . . . . . . . . 35

4.4 Exemplo de extensão do CodeGen. . . . . . . . . . . . . . . . . . . 40

4.5 Visão geral da esquematização dos segmentos e sub-segmentos. . . . . . . 42 
4.6 Criação do JobScript. . . . . . . . . . . . . . . . . . . . . . 47

4.7 Criação do JobTemplate. . . . . . . . . . . . . . . . . . . . . . 47

4.8 Materialização e execução do Processing Job. . . . . . . . . . . . . . . . 47

4.9 Uso do pacote dataprocessor_client. . . . . . . . . . . . . . 48

5.1 Exemplo da função sliding, disponível na linguagem Scala. . . . . . . . 59

5.2 Consulta SQL que calcula métricas de trânsito. . . . . . . . . . . . . . . 60

5.3 Porção 1 do código-fonte que processa as métricas através do DataProcessor. . . . . . . . . . . . . . . . . 65

5.4 Porção do código que define um JobScript do DataProcessor. . . . . . 66

5.5 Definição do JobTemplate utilizado para o processamento pelo DataProcessor. ......................... 66

5.6 Última porção do Código-fonte utilizado para o processamento pelo DataProcessor. ....................... 66

5.7 Primeira porção do código-fonte utilizado para o processamento sem o DataProcessor. . . . . . . . . . . . . . . . 67

5.8 Última porção do código-fonte utilizado para o processamento sem o DataProcessor. . . . . . . . . . . . . . . 68

5.9 Código fonte da estratégia que gera o código k-Means. . . . . . . . . . 70

5.10 Cria o JobScript responsável por executar o k-Means. . . . . . . . . . . 71

5.11 Cria o JobTemplate responsável por calcular o k-Means dos dados de tráfego da cidade. . . . . . . . . . . . . . . . 71

5.12 Criação do Processing Job que tem referencia para o JobTemplate que configura o k-Means. . . . . . . . . . . . . . . 72

5.13 Como carregar um resultado do processamento em formato parquet no Pandas. . . . . . . . . . . . . . . . . . 72 



\section{Sumário}

1 Introdução 1

2 Referencial Teórico 5

2.1 Computação Intensiva em Dados . . . . . . . . . . . . . . . . 6

2.1.1 Replicação . . . . . . . . . . . . . . . 6

2.1.2 Particionamento (Sharding) . . . . . . . . . . . . . 7

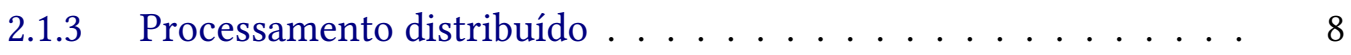

2.1.4 Processamento tardio . . . . . . . . . . . . . . . 9

2.2 spark ................................. 11

2.2 .1 Arquitetura ........................ 12

2.2.2 Estruturas de dados do Spark: RDDs e DataFrames . . . . . . . . . 13

2.2.3 Outras ferramentas de processamento em cluster . . . . . . . . 14

2.3 Microsserviços . . . . . . . . . . . . . . . . . . . . . . 16

2.4 Plataforma InterSCity . . . . . . . . . . . . . . . . . . 18

3 Trabalhos Relacionados $\quad 21$

3.1 Plataformas que integram processamento distribuído . . . . . . . . . . 21

3.2 Frameworks para processamento de Big Data em cidades inteligentes . . 23

3.3 Visão geral dos trabalhos da área . . . . . . . . . . . . . . . . . . 24

4 DataProcessor: Processamento em cluster na plataforma InterSCity $\quad 27$

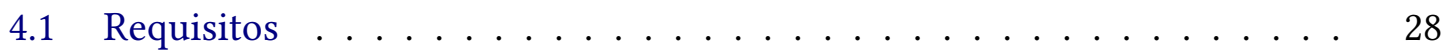

4.2 Arquitetura do DataProcessor . . . . . . . . . . . . . . . . 29

4.3 Implementação do DataProcessor . . . . . . . . . . . . . . . . . . 30

4.4 Interações e funcionamento do DataProcessor . . . . . . . . . . . . . . . 32

4.4.1 Passo 1 - Definição dos parâmetros através do JobTemplate . . . 32

4.4.2 Passo 2 - Definição do ProcessingJob . . . . . . . . . . . . . . 34

4.4.3 Passo 3 - Execução do Processing Job e processamento dos dados. 35

4.4 .4 Endpoints . . . . . . . . . . . . . . . . . 37 
4.5 Integração através de Geração de Código . . . . . . . . . . . . . . . . 39

4.5.1 Segmento Cabeçalho . . . . . . . . . . . . . . . . . 40

4.5.2 Segmento Corpo . . . . . . . . . . . . . . . . . 41

4.5 .3 Segmento Operação . . . . . . . . . . . . . . . . . . . . 41

4.5.4 Segmento Rodapé . . . . . . . . . . . . . . . . . . . . . . . 41

4.5.5 Visão geral do código gerado . . . . . . . . . . . . . . . 42

4.6 Como visualizar percentis de um recurso armazenado na InterSCity? . . 43

4.6 .1 Uso por API Rest . . . . . . . . . . . . . . . . . . . 44

4.6 .2 Uso por JSON-API . . . . . . . . . . . . . . 45

4.6 .3 Uso pelo dataprocessor_client. . . . . . . . . . . . . 48

4.6.4 Uso do serviço dataprocessor-frontend . . . . . . . . . . . . 48

5 Avaliação Experimental 53

5.1 Experimento - Cálculo de métricas do trânsito . . . . . . . . . . . . . 54

5.1 .1 Definições do Cenário . . . . . . . . . . . . . . 55

5.1 .2 Execução da Simulação . . . . . . . . . . . . . . . . . . 56

5.1 .3 Processamento dos Dados . . . . . . . . . . . . . . . . 57

$5.1 .4 \quad$ Resultados . . . . . . . . . . . . . . . . . . . 60

5.1.5 Análise de Desempenho . . . . . . . . . . . . . . 63

5.1.6 Análise de Usabilidade . . . . . . . . . . . . . . . . . . . 63

5.2 Exemplo de Uso - Separar Pontos da Cidade em Regiões . . . . . . . . . . 68

5.2.1 Adição da estratégia que permite a clusterização . . . . . . . . . 69

5.2 .2 Utilização . . . . . . . . . . . . . . . . . . . . . 71

5.2.3 Análise de Extensibilidade . . . . . . . . . . . . . . 72

6 Conclusões $\quad 75$ 
Apêndices

Anexos

Referências 



\section{Capítulo 1}

\section{Introdução}

Nas últimas décadas, observamos um grande aumento da população urbana e do uso de TIC (Tecnologia da Informação e Comunicação) nas grandes cidades (BABAR e ARIF, 2017). Ambos os crescimentos contribuíram para o surgimento do termo cidades inteligentes, que se refere a cidades que utilizam recursos tecnológicos em conjunto com os dados da cidade para melhorar a qualidade de vida dos cidadãos (BATISTA et al., 2016).

O acesso às informações sobre os recursos da cidade possibilita a criação de aplicações que permitem, por exemplo, diminuir o tempo de espera em paradas de ônibus, detectar situações de risco e otimizar o uso de recursos naturais. A Figura 1.1 apresenta o aplicativo de cidades inteligentes SmartParking ${ }^{1}$. O SmarkParting lista os lugares disponíveis para estacionar próximos a uma região de São Paulo, trazendo impacto direto e indireto sobre seus usuários. Direto, pois os motoristas passam a perder menos tempo procurando uma vaga disponível, e indireto pois os motoristas passarão menos tempo com os veículos ligados, diminuindo a poluição da cidade.

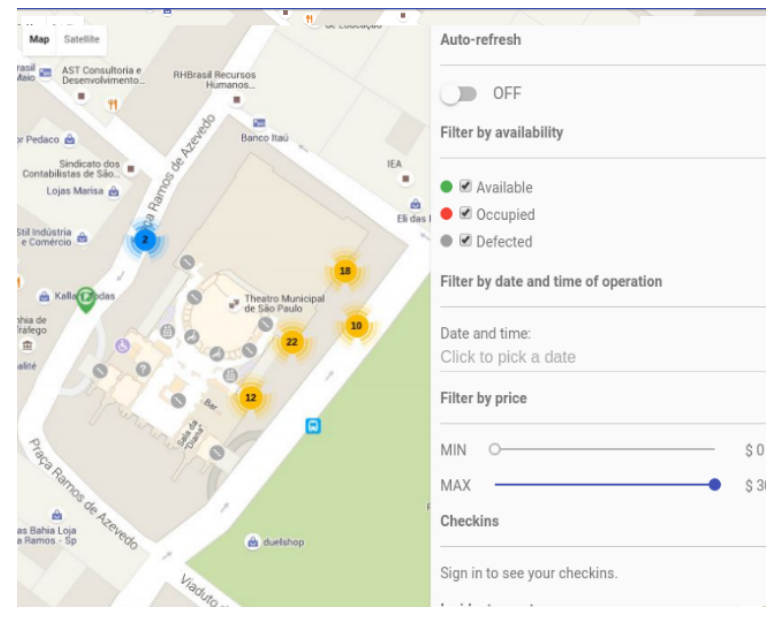

Figura 1.1: Tela inicial do aplicativo SmartParking.

A abordagem ad-hoc é a mais comum para o desenvolvimento de aplicações de cidades inteligentes como o SmartPartking (EsPoste et al., 2017). Ao seguir essa abordagem, que

\footnotetext{
${ }^{1} \mathrm{O}$ código fonte está disponível em: http://gitlab.com/smart-city-platform/smart_parking_api
} 
é vertical por não se preocupar em utilizar ou produzir código reutilizável por outras aplicações, o resultado é uma solução que é bastante específica e pouco interoperável (EsPOSTE et al., 2017). Mais ainda, dois outros problemas surgem: a produtividade é menor, pois é necessário que mais tempo seja gasto com código que é necessário mas que não adiciona funcionalidades aos usuários; e o desperdício de recursos computacionais aumenta, já que os dados dos recursos da cidade devem ser replicados em cada aplicação de cidades inteligentes que queira utilizá-los.

Uma outra abordagem, que é horizontal e trata os dois problemas citados, se baseia em sustentar o desenvolvimento das aplicações sobre uma plataforma. Uma plataforma de cidades inteligentes é um middleware entre os recursos da cidade e as aplicações finais e garante uma série de requisitos funcionais e não-funcionais para os desenvolvedores que as utilizam (BAtista et al., 2016). Ao final, as aplicações têm seu desenvolvimento e planejamento facilitado, ao passo em que apresentam boa interoperabilidade entre si. As plataformas podem ser capazes de atuar em contextos diversos, o que é possível caso a sua arquitetura e implementação sejam flexíveis o suficiente (SANTANA et al., 2017).

Porém, o fluxo e o volume de dados aumenta drasticamente em um cenário onde várias aplicações utilizem uma mesma instância da plataforma ao mesmo tempo (BATISTA et al., 2016). Nesse tipo de cenário, caracterizado pelos 4 Vs do Big Data (grande volume, velocidade, veracidade e variedade), é necessário que diversos computadores trabalhem em conjunto para atender a grande demanda de processamento, caso contrário as tarefas requisitadas podem não ser possíveis ou levar muito tempo para a sua conclusão (ZAMAN et al., 2017). Assim, as plataformas podem apoiar-se na utilização de ferramentas que possibilitem o processamento distribuído em cluster aos seus usuários.

A maior parte das plataformas de cidades inteligentes, conforme exploramos no Capítulo 3, encontram-se em dois cenários: ou (i) não contém qualquer integração com uma ferramenta de processamento em cluster; ou (ii) cuidam somente da configuração da ferramenta de processamento distribuído, mas não se preocupam com a usabilidade e extensibilidade da integração. O primeiro cenário é um problema, pois requer que os desenvolvedores precisem se preocupar em como lidar com o processamento em cluster utilizando os dados da plataforma em questão. Já o segundo cenário é um problema pois requer que os desenvolvedores precisem aprender a utilizar a ferramenta de processamento em cluster definida para uso, que necessita de um conhecimento não tão comum. Um exemplo do impacto que o segundo cenário ocasiona é que, até um engenheiro de software com anos de experiência pode não ser capaz de executar de maneira distribuída tarefas simples utilizando a ferramenta definida para uso.

Nesta dissertação, por outro lado, argumentamos que é possível adicionar suporte ao processamento em cluster a uma plataforma de cidades inteligentes que explore usabilidade e extensibilidade via um middleware. Sistematizamos nossa proposta de middleware através de uma arquitetura e a implementamos como um microsserviço que chamamos de DataProcessor. O DataProcessor integra a plataforma de cidades inteligentes InterSCity e a ferramenta de processamento em cluster Apache Spark e, como resultado prático, permite que os desenvolvedores da plataforma possam utilizar de maneira simplificada um cluster de vários computadores para tarefas tais como:

1. Executar consultas SQL; 
1 | INTRODUÇÃO

2. Treinar modelos de regressão linear;

3. Treinar modelos de floresta aleatória;

4. Calcular estatísticas sobre os dados (como média e desvio padrão).

A InterSCity é uma das plataformas de cidades inteligentes ativas que enquadrase no primeiro cenário citado anteriormente e que surgiu com o propósito de propor sugestões para limitações presentes em outras plataformas desenvolvidas e conceitualizadas anteriormente (Esposte et al., 2017). Embora a InterSCity já tenha sido avaliado em experimentos que simulavam uma grande quantidade de sensores que enviavam dados em tempo real para a plataforma, a plataforma não continha suporte para processamento distribuído, o que limitava as aplicações que a utilizam (M. DeL Esposte et al., 2019).

Assim, o DataProcessor passa a ser o responsável pela integração entre o Apache Spark e a InterSCity, de modo que os desenvolvedores não precisem mais se preocupar com as etapas de extração e carga do pipeline ETL (Extração, Transformação e Carga - Extract, Transform, and Load) (SodT e MARAvić, 2018). A interação entre o DataProcessor e os desenvolvedores é feita através de requisições REST e, caso o usuário deseje executar uma tarefa não oferecida pelo DataProcessor, sua arquitetura prevê a extensibilidade das funcionalidades, evitando que limitações para aplicações não previstas surjam.

Avaliamos o DataProcessor por três perspectivas: desempenho, que serviu para avaliar a degradação de desempenho advinda do uso do middleware; usabilidade, que serviu para avaliar a facilidade advinda da API REST; e extensibilidade, que serviu para avaliar a flexibilidade e facilidade de adição de suporte a novas tarefas ao DataProcessor. Realizamos as avaliações através de dados de um experimento e estudos de caso, onde comparamos duas implementações, uma que utiliza o DataProcessor e outra que utiliza o Apache Spark diretamente. Os resultados, conforme exploramos no Capítulo 5, indicaram que:

- O overhead advindo do uso do DataProcessor é irrelevante em um contexto de Big Data, já que o volume de dados não é levado em conta na requisição enviada ao middleware;

- Em casos mais comuns, a quantidade de linhas necessárias para executar tarefas através do DataProcessor e através do Apache Spark é a mesma, de modo que mesmo que seu uso só precise de conhecimentos bem difundidos, como requisições REST, a quantidade de linhas que devem ser definidas não é maior;

- Em média, um usuário adiciona uma nova funcionalidade ao DataProcessor com cerca de 8 novas linhas essenciais, além das linhas que executam a nova tarefa desejada em si, que é necessário mesmo que fosse feito uso do Apache Spark diretamente. Todas essas linhas tratam-se de adições e não de alterações.

Ao final, realizamos as seguintes contribuições, categorizadas entre técnicas e científicas:

- Entre as contribuições científicas, as principais são: (i) uma revisão do estado-da-arte em processamento em cluster e técnicas de computação intensiva em dados; (ii) a concepção de uma arquitetura que integra processamento em cluster em plataformas 
de cidades inteligentes; (iii) discussões sobre as melhores escolhas para resolver um cenário de computação intensiva em dados em cidades inteligentes.

- Entre as contribuições técnicas, as principais são: (i) a criação do DataProcessor, microsserviço responsável por adicionar suporte a processamento em cluster integrado a plataforma InterSCity; (ii) contribuições para o simulador de cidades inteligentes InterSCSimulator, utilizado no experimento que ajudou a avaliar o desempenho do trabalho.

\section{Organização do Trabalho}

No Capítulo 2, apresentamos o embasamento teórico utilizado na elaboração da proposta do trabalho, onde exploramos: quais técnicas que, quando utilizadas, permitem a computação intensiva em dados; o funcionamento interno do Apache Spark, importante para entender diversos aspectos do DataProcessor, como as métricas que utilizamos para avaliar seu desempenho; características comuns entre microsserviços, que buscamos seguir em nossa implementação, e a arquitetura da plataforma InterSCity, para compreensão da integração.

No Capítulo 3, exploramos os trabalhos relacionados, esclarecendo o que falta nos trabalhos atuais da área e quais ideias aproveitamos em nossa proposta, organizados por assuntos e áreas. Ao final, damos uma visão geral do que o DataProcessor propicia e que não é coberto pelos trabalhos da área.

No Capítulo 4, descrevemos o DataProcessor, nossa proposta de middleware entre o Apache Spark e a InterSCity. Organizamos sua concepção em uma abordagem top-down, partindo das definições de mais alto nível. Começamos com os requisitos e a arquitetura, em seguida apresentamos discussões a respeito das decisões de design possíveis e finalizamos com detalhes importantes da implementação, como os endpoints, e exemplos de uso.

No Capítulo 5, apresentamos a avaliação e análise do trabalho, feito através de um experimento e dois estudos de caso. Em cada um dos três analisamos duas soluções para um experimento, uma solução que utiliza o Apache Spark diretamente e outra que utiliza o DataProcessor, que nos permitiu uma análise do desempenho, usabilidade e extensibilidade da implementação da arquitetura.

Por fim, no Capítulo 6, trazemos nossas conclusões finais e trabalhos futuros, que permitem a extensão do trabalho com o objetivo de diminuir algumas das limitações e ampliar os usos possíveis. Os trabalhos futuros contemplam tanto contribuições técnicas quanto científicas e buscam fortalecer o DataProcessor como um todo. 


\section{Capítulo 2}

\section{Referencial Teórico}

A integração de processamento distribuído em uma plataforma de cidades inteligentes pode ser entendida como a facilitação do uso de ferramentas específicas para processamento distribuído de forma integrada a uma plataforma de cidades inteligentes. Dessa forma, separamos o referencial teórico do trabalho em três partes:

Computação intensiva em dados Conjunto de técnicas que, quando utilizadas, tornam mais efetivas as tarefas que lidam com grande volume de dados. Contudo, como a computação intensiva em dados abrange um grande conjunto de áreas, como mostrado por KLEPPMANN (2017), nos atemos a técnicas que afetam a integração de processamento distribuído. Por exemplo, abordamos particionamento de dados, pois é uma peça chave no desempenho da integração e do processamento em si, mas não abordamos técnicas e estratégias sem tanta relação, como as diferentes formas de garantir atomicidade em transações do banco de dados;

Funcionamento do Spark Apresentamos um apanhado geral que introduz os conceitos mais importantes da ferramenta de processamento distribuído Spark, que é a que decidimos utilizar em nossa integração. Grande parte dos detalhes que mostramos têm relação com as técnicas de computação intensiva em dados e são esses detalhes que utilizamos como base nas comparações relativas ao desempenho, que listamos na Seção 5.1.5;

Arquitetura de microsserviços e a InterSCity Encerramos o referencial teórico com uma visão geral sobre o padrão arquitetural de microsserviços e detalhes da InterSCity, que é a plataforma de cidades inteligentes que utilizamos para implementar a integração com processamento distribuído e que segue esse padrão arquitetural. Cada plataforma de cidades inteligentes tem suas nuances, então aproveitamos para listar alguns detalhes da plataforma que foram essenciais na implementação da integração. 


\subsection{Computação Intensiva em Dados}

Uma tendência dos últimos anos é o investimento em escalabilidade horizontal para suprir necessidades computacionais, em relação a escalabilidade vertical. (OSMAN, 2019). No serviço de nuvem Digital Ocean ${ }^{1}$, por exemplo, um computador na nuvem com $8 \mathrm{~Gb}$ de memória e 4 vCPUs custa $\$ 40$ por mês; já um computador com 16 Gb de memória e 6 vCPUs custa $\$ 80$ por mês ${ }^{2}$, ou seja, o dobro do preço para ter o dobro de memória, mas a quantidade de vCPUs não dobrou de acordo.

Pela ótica do custo benefício, escalar horizontalmente é mais viável, mas, como tirar proveito da troca do computador de 6 vCPUS por dois computadores com 4 vCPUs? Quando mais de um computador precisa ser utilizado em conjunto para realizar uma tarefa, que ocorre no cenário da escalabilidade horizontal, é necessário a utilização de técnicas específicas que tratem da orquestração desses diferentes computadores atuando em conjunto. Num contexto de grande quantidade de dados, uma técnica bem difundida é a replicação de dados, que consiste em criar cópias dos dados em múltiplos computadores para que qualquer um deles possa responder consultas aos dados.

\subsubsection{Replicação}

A replicação baseia-se em criar cópias dos dados em diferentes nós do cluster e tem como principais objetivos a melhora da disponibilidade, latência e vazão. A disponibilidade é melhorada pois caso um nó com o dado necessário fique indisponível, existem outros nós que podem servir a tarefa; a latência é diminuída pois passa a ser possível requisitar dados de um nó mais próximo geograficamente; e a vazão é melhorada pois mais consultas podem ser atendidas ao mesmo tempo desde que mais nós possam responder as consultas desejadas (KLEPPMANN, 2017). Outra funcionalidade que passa a ser disponível com o uso da replicação são os rolling upgrades, que baseiam-se em atualizar poucos nós do sistema por vez, de modo que outros continuem disponíveis durante a atualização

Os três principais modelos de replicação são: (I) líder e seguidores, onde um nó líder fica responsável por escrever novos dados e os replicar nos nós seguidores (que só podem responder consultas), (II) múltiplos líderes, onde vários nós são líderes, e todo líder age como seguidor dos outros líderes e (III) sem líder, onde todos os nós podem escrever novos dados e são responsáveis pela cópia para os outros nós (KLeppMAnN, 2017). A Figura 2.1 ilustra de maneira simplificada cada um desses três modelos, onde na figura, as arestas indicam que o nó origem deve replicar dados nos nós destino.

Contudo, embora a replicação traga uma série de benefícios, como a diminuição da latência, aumento da disponibilidade do sistema ou o aumento da vazão do sistema, a técnica traz situações de inconsistência, independentemente do modelo utilizado. KLEPPMANN (2017) cita uma série de cenários problemáticos que podem ocorrer, como: o que deve ser feito caso o nó responsável pela escrita fique indisponível antes da replicação dos novos dados? O que fazer quando um nó passar de indisponível para disponível,

\footnotetext{
${ }^{1}$ www.digitalocean.com

${ }^{2}$ Preços disponíveis em: www.digitalocean.com/products/linux-distribution/fedora-24-x64/
} 
dado que ele estará desatualizado em relação aos outros? Caso o mestre do cluster esteja indisponível e outro mestre seja eleito, o que fazer quando o primeiro mestre voltar a estar disponível?

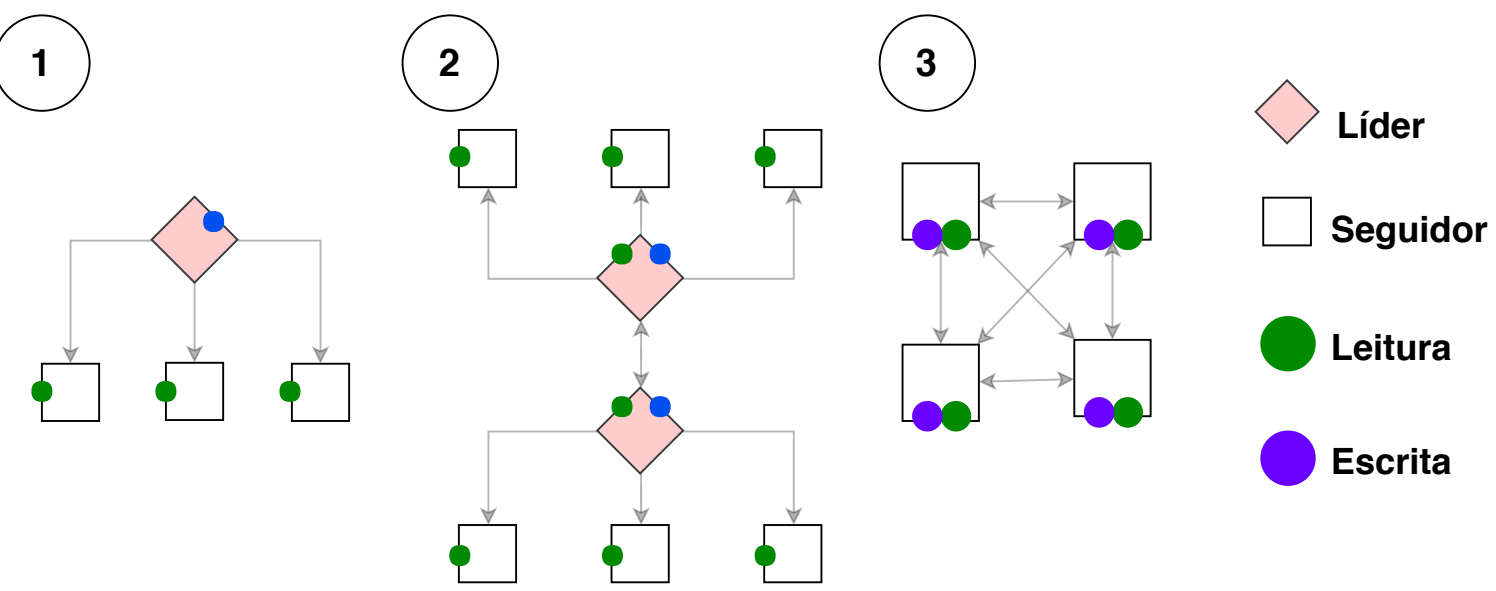

Figura 2.1: As diferentes formas de replicação. A primeira é a líder e seguidores, a segunda multilíder e a terceira sem líder.

Portanto, a replicação é uma técnica essencial e com uma série de benefícios, mas que traz consigo alguns overheads que, a depender do cenário, podem não valer a pena. Ainda assim, é uma técnica chave na computação de um modo geral. A implementamos no simulador que utilizamos no experimento apresentado na Seção 5.1.2; sem a replicação, a simulação era interrompida quando executada em modo distribuído pois haviam situações onde um nó tentava buscar um dado locamente mas que só estava disponível em um outro nó do cluster. Do ponto de vista da integração do processamento em cluster em uma plataforma de cidades inteligentes, a replicação não tem um papel tão crucial: a maior parte dos bancos de dados abstraem a replicação no momento de extração dos dados, que é o ponto onde poderia haver alguma interferência na integração. Já a técnica de particionamento, diferentemente, é chave na integração do processamento distribuído e pode afetar de maneira negativa o desempenho.

\subsubsection{Particionamento (Sharding)}

Também chamado de sharding, o particionamento é uma técnica que envolve classificar os dados entre diferentes grupos, chamados de partições; posteriormente, essa classificação é utilizada para dividir os dados entre diferentes computadores, onde uma partição deve ser alocada em um computador em específico (C. H. Costa et al., 2015). A técnica em si traz uma série de vantagens:

Armazenamento $\mathrm{O}$ particionamento aumenta a capacidade de armazenamento, pois permite que o volume de todas as máquinas disponíveis passem a ser visto como o volume total disponível para uso, como se uma única máquina estivesse disponível mas com um volume disponível maior;

Latência A depender do critério utilizado para o particionamento, os dados necessários podem estar mais próximos, o que diminui a latência para recuperá-los. Por exemplo, 
no caso do Twitter, os usuários podem ser particionados por localização; daí, um usuário que mora no Brasil terá suas requisições submetidas a partição que armazena os dados do Brasil; caso essa partição encontre-se no Brasil, o que costuma ser uma convenção, os dados dos usuários brasileiros passam a ser recuperados em um menor tempo;

Vazão A depender do critério utilizado para particionar os dados, várias partições podem responder diversas consultas ao mesmo tempo, o que melhora a vazão. Com o mesmo exemplo do Twitter, é possível que diferentes países continuem a responder as consultas, mesmo que a partição responsável pelo Brasil esteja congestionada;

Escalabilidade (escrita) É possível adicionar mais computadores ao cluster e fazer partições cada vez mais granulares (mais fragmentadas), melhorando a escalabilidade da escrita. A escalabilidade melhora pois, quando ocorre um pedido de escrita, o pedido é redirecionado para a partição correspondente, entra numa fila de espera e, quando a partição encontra-se disponível, a escrita finalmente ocorre. Com partições mais granulares, mais computadores podem atender mais escritas concorrentemente;

Tolerância a falhas Dado que as partições são isoladas entre si, mais partições melhoram a tolerância a falhas, já que, caso surja problemas em uma partição, as outras partições não são afetadas.

Contudo, esses benefícios variam conforme o modelo de particionamento utilizado. Existem diferentes formas de se definir as partições, e a depender, surgem vantagens (como as citadas) e desvantagens. Uma das estratégias mais comuns para se particionar dados é o particionamento por hash, que determina em qual partição ficarão os dados por uma função de hash (C. H. Costa et al., 2015). Essa estratégia, por exemplo, é boa em alguns cenários, mas ruim em outros: ainda no mesmo cenário de tweets do Twitter, imagine que cada nó do cluster é responsável por armazenar uma partição e que o critério para definir a partição seja a cidade de origem do tweet. Um problema grave pode surgir: A cidade de São Paulo é muito mais populosa que diversas outras cidades do Brasil, logo o nó do cluster responsável pelos tweets da cidade de São Paulo ficará sobrecarregado, também conhecido como key skewness (MYкHALYK, 2019). KLEPPMANN (2017) cita outras estratégias de particionamento, como o particionamento baseado em range.

Um outro ponto importante é o overhead advindo do particionamento, que surge pois é necessária a coordenação das diferentes partições e a classificação da partição responsável para todos os dados. Portanto, não existe um tipo de particionamento melhor em todos os casos, já que um particionamento mais complexo ajuda em alguns cenários mas, por ser mais complexo, aumenta o overhead na classificação da partição. Em todo caso, particionar dados é imprescindível em um cenário de Big Data e tem forte relação com a replicação. As ferramentas que fazem processamento distribuído, por exemplo, costumam particionar os dados para que seja possível processar esses dados de forma isolada e distribuída.

\subsubsection{Processamento distribuído}

Processar de forma distribuída significa quebrar uma tarefa em partes menores e executar essas tarefas de maneira concorrente por diferentes nós. Ao final, o resultado 
atingido é o mesmo que caso um único nó executasse toda a tarefa. No caso de uma consulta SQL, por exemplo, é possível dividir o banco de dados em pedaços menores e espalhá-los entre os nós e executar essa mesma consulta SQL individualmente em cada um desses nós. Ao final, o resultado de cada nó precisa ser mesclado com o resultado dos outros, alcançando assim o resultado desejado da consulta. Um gerenciador de cluster decide como será a organização dessas tarefas pelo cluster e ajuda a coordenar outros aspectos, como o agrupamento dos dados processados.

Atualmente, vários frameworks utilizam a ideia de processamento distribuído para tornar possível a computação intensiva em dados. Contudo, a maneira como esse processamento é implementado e organizado internamente varia. Na Seção 2.2.1, apresentamos detalhes de como o framework de processamento em cluster Spark organiza esse processamento.

Embora os frameworks de processamento distribuídos apresentem nuances quanto à arquitetura e gerenciamento de tarefas, todos utilizam o conceito de shuffling, que chega a ser um dos gargalos mais relevantes advindos do uso da distribuição de tarefas em um cluster (Pu et al., 2019). O shuffling é o ato de redistribuir dados entre os nós do cluster, podendo ser causado pela necessidade de reparticionamento (Apache Spark $R D D$ Documentation 2019) ou de tornar dados disponíveis. De maneira geral, O shuffling é custoso pois envolve I/O, tanto de rede quanto de disco (Pu et al., 2019). Em nosso trabalho, utilizamos o shuffling como uma das principais formas de medir a degradação de desempenho. Pois, caso duas tarefas de processamento recebam a mesma entrada mas em sua execução performem diferentes quantidades de shuffling, é esperado que a tarefa com menos shuffling obtenha melhor desempenho por utilizar menos I/O.

\subsubsection{Processamento tardio}

Se o processamento de uma tarefa só ocorre quando seu resultado é necessário, e não quando ela é submetida ao sistema, dizemos que o processamento executado é tardio. A vantagem de só executar o processamento quando seu resultado é necessário é que otimizações podem levar em conta mais aspectos que passaram a ficar disponíveis, o que permite a remoção de redundâncias, processamentos desnecessários e até a combinação de várias tarefas em uma única. Abaixo listamos algumas otimizações possíveis com a utilização do processamento tardio, ambas utilizadas pelo Spark quando possível, com o intuito de melhorar a latência de processamento.

\section{Pushdown Filter}

O pushdown filter é uma técnica que antecipa filtros de uma consulta SQL de modo que a quantidade de dados utilizado no processamento seja menor. BRAAMs (2018), por exemplo, explora a utilização do pushdown filter durante a operação de $s{ } n^{3}$ do Spark, para que dados que serão descartados não sejam extraídos. O Spark aplica o pushdown filter sempre que possível e de forma automática. No Programa 2.1 é listado um exemplo

\footnotetext{
${ }^{3}$ Operação que analisa e extrai os dados do banco de dados.
} 
de consulta que o Spark tipicamente aplica o pushdown filter: a consulta utiliza join, where e select. O Spark, automaticamente, antecipa a execução do where, mesmo que seja a última operação na consulta, para que a quantidade de dados utilizados no join seja reduzida. O Programa 2.2 apresenta o plano de execução traçado pelo Spark para essa consulta, onde o filtro (que é como o where é interpretado) é executado logo após os dados serem recuperados, enquanto o join ocorre por último.

Programa 2.1 Exemplo de consulta SQL otimizada pelo Spark.

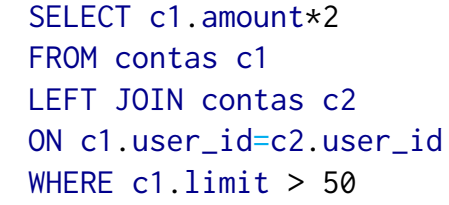

$\overline{\text { Programa 2.2 Plano de execução traçado pelo Spark para executar a consulta SQL do }}$ Programa 2.1.

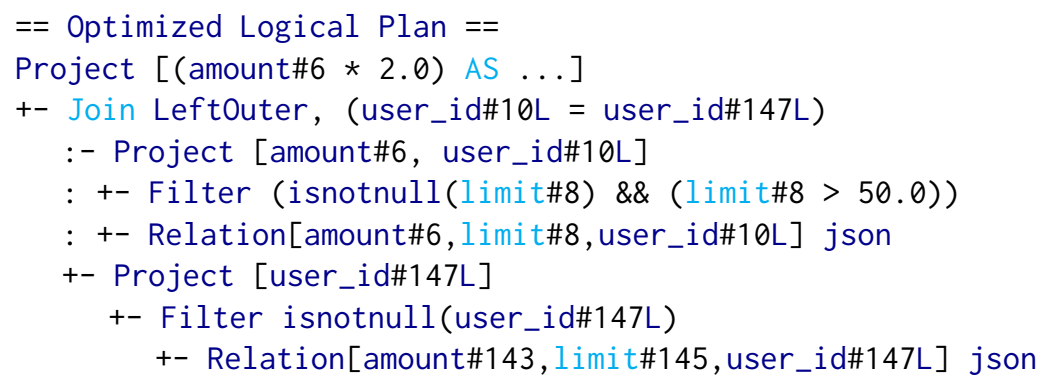

\section{Broadcast Join}

O broadcast join é uma outra otimização disponível no Spark e também possível graças ao processamento tardio. Quando uma operação de join (de assinatura join(t1, t2)) é requisitada, o Spark identifica se a tabela t1 ou t2 tem um volume de dados menor que um determinado limiar (NAIR, 2018). Caso tenha, o Spark aplica o broadcast join, que determina que a tabela com menor quantidade de dados (por exemplo, t1) tenha seus dados copiados para todos os computadores do cluster em que t2 está alocado. Dessa forma, não serão necessários shuffles de dados (XIN et al., 2013).

Na Figura 2.2, é ilustrado o funcionamento do broadcast join. Inicialmente, a Tabela 1 e a Tabela 2 encontram-se em diferentes nós do cluster e precisam ser unidas pela operação de join. Contudo, dado que a Tabela 2 é pequena ${ }^{4}$, uma cópia da Tabela 2 é é feita em todos os nós do cluster que armazenam dados da Tabela 1. Assim, todos os dados necessários estarão disponíveis, de modo que o join entre as tabelas possa ocorrer normalmente. Essa operação é menos custosa que o shuffling tradicional pois nesse, a Tabela 1 precisaria ser movida pelas partições do cluster, enquanto com o broadcast join o particionamento atual não precisa ser modificado. A desvantagem é que, caso a Tabela 2

\footnotetext{
${ }^{4}$ Por exemplo, a Tabela 2 pode ter, no total, $4 \mathrm{Mb}$.
} 
fosse composta de muitos dados, uma grande quantidade de dados precisaria ser replicado sempre, de modo que a técnica tornasse muito custosa (NAIR, 2018).

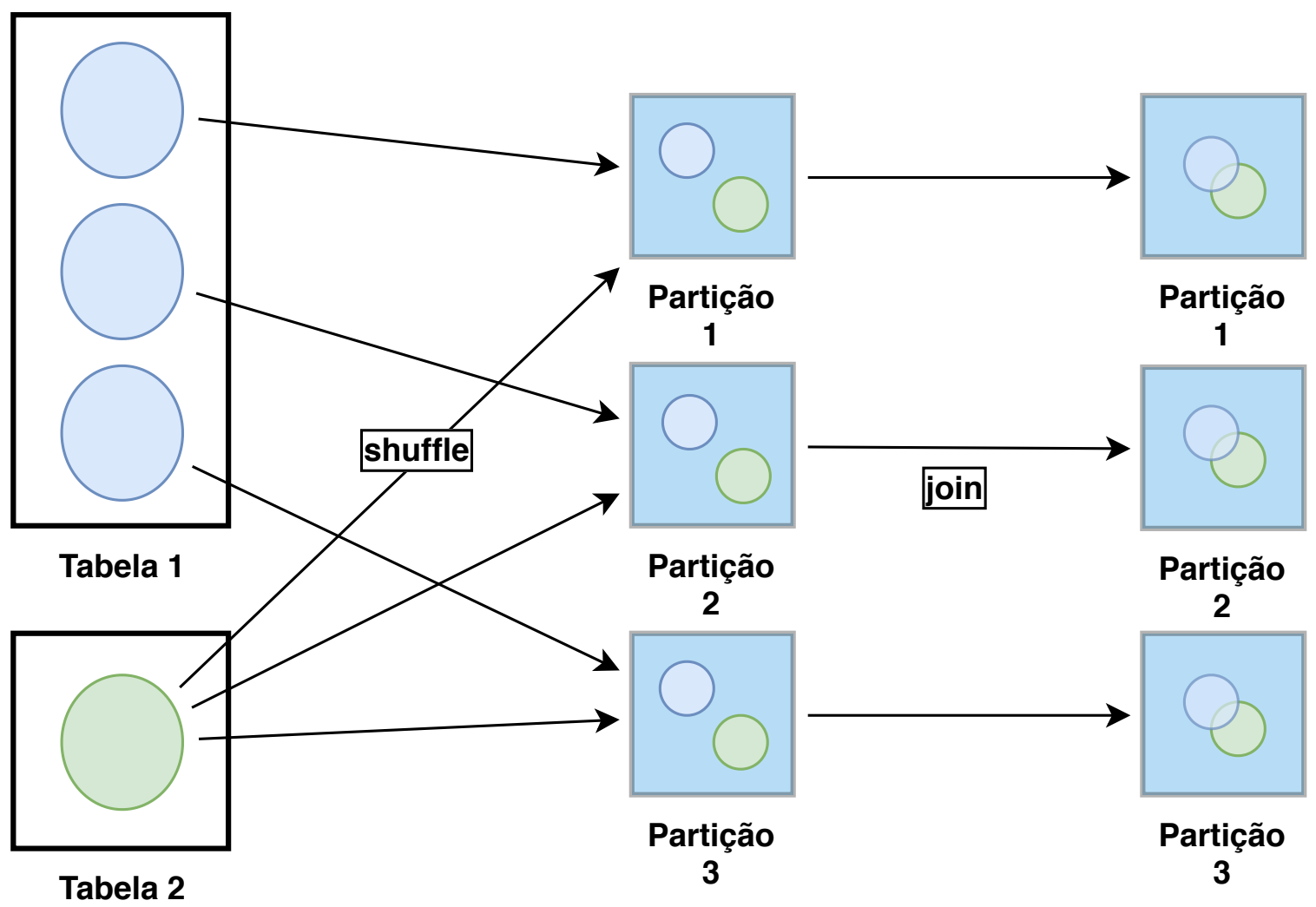

Figura 2.2: Funcionamento do broadcast join. Fonte: XIN et al. (2013).

A maior parte dessas técnicas são utilizadas por ferramentas de processamento distribuído bem difundidas. O Spark, por exemplo, utiliza as técnicas apresentadas, pushdown filter e broadcast join, para atingir menor latência no processamento, além de ter uma arquitetura que gira em torno do processamento tardio, também apresentado anteriormente.

\subsection{Spark}

O Spark é uma ferramenta de processamento em cluster desenvolvida inicialmente pelo AMPLab $^{5}$, UC Berkeley, lançada em 2012 (CHAMBERs e ZAHARIA, 2018). Suas principais funcionalidades são: disponibilização de processamento distribuído em lote e em fluxo; tolerância a falhas; e otimizações diversas, como armazenamento dos dados em memória em situações específicos ao invés de armazená-los no disco.

O uso mais apropriado para o Spark é quando a quantidade de dados a ser processado é maior que toda a memória de um único computador. Nesse cenário, só utilizar o processamento padrão de ferramentas como o Python, Ruby ou Pandas não é suficiente: é

\footnotetext{
${ }^{5}$ en.wikipedia.org/wiki/AMPLab
} 
necessário dividir esses dados em porções menores, e processar essas porções de forma distribuída, utilizando um cluster.

\subsubsection{Arquitetura}

A arquitetura do Spark é composta por quatro componentes: master, workers, driver e executors.

- O executor é o componente responsável pelo processamento dos dados e, na prática, é um processo da JVM (Java Virtual Machine). Os executors são isolados uns dos outros e a ideia é que, para que as tarefas sejam concluídas mais rapidamente, mais executors devem estar disponíveis. Uma convenção é utilizar um executor por thread disponível para uso por máquina. Ou seja, mesmo com uma única máquina, é desejável que vários executors sejam alocados, desde que existam threads o suficiente (ZAHARIA, 2014);

- O driver é um outro processo especial da JVM, mas na arquitetura é o componente responsável por distribuir as tarefas de processamento para os executors e servir de ponto de sincronismo (Chambers e Zaharia, 2018). Por exemplo, caso o usuário requisite o log de todo o processamento, o log de todos os computadores é centralizado no driver.

- Os workers são os computadores do cluster que abrigam os executors (CHAMBERS e ZAHARIA, 2018). Um único worker pode ter diversos executors e, enquanto o executor pode ser visto como um componente mais a nível de software, o worker é visto mais a nível de hardware.

- Por fim, o master é o componente responsável por gerenciar e coordenar os workers e o cluster (Chambers e Zaharia, 2018). Alguns exemplos do papel do master na arquitetura são: quando um novo computador quer fazer parte do cluster, por exemplo, ele o faz através de uma interação com o master; ou, quando um usuário deseja executar uma nova tarefa, é o master que lista quais recursos estão disponíveis.

O processamento que um usuário define para ser executado pelo Spark é interpretado internamente como um job. O Spark analisa o job submetido e monta um plano de execução, que define como o processamento será tratado internamente. Em seguida, o job é dividido em porções menores, chamadas de tasks. Em alguns cenários, Uma task pode depender de outra; o Spark classifica essa dependência entre tasks em dependências narrow, quando basta uma ser encerrada para a outra ter início, e dependência wide, para quando for necessário que outras tasks sejam concluídas. Além disso, o Spark divide as tasks a serem processadas em stages, onde o critério para definir se uma task pertence a um stage ou outro é a necessidade de uma barreira para sincronização.

O exemplo mais comum de barreira utilizada pelo Spark ocorre quando, internamente, é necessário reparticionar os dados alocados (operação de shuffling). Esses três conceitos job, tasks e stages - podem ser visualizados de maneira gráfica por um serviço que o Spark disponibiliza, chamado SparkUI ${ }^{6}$; uma prévia da visualização é apresentada na Figura 2.4.

\footnotetext{
${ }^{6}$ jaceklaskowski.gitbooks.io/mastering-apache-spark/spark-webui.html
} 


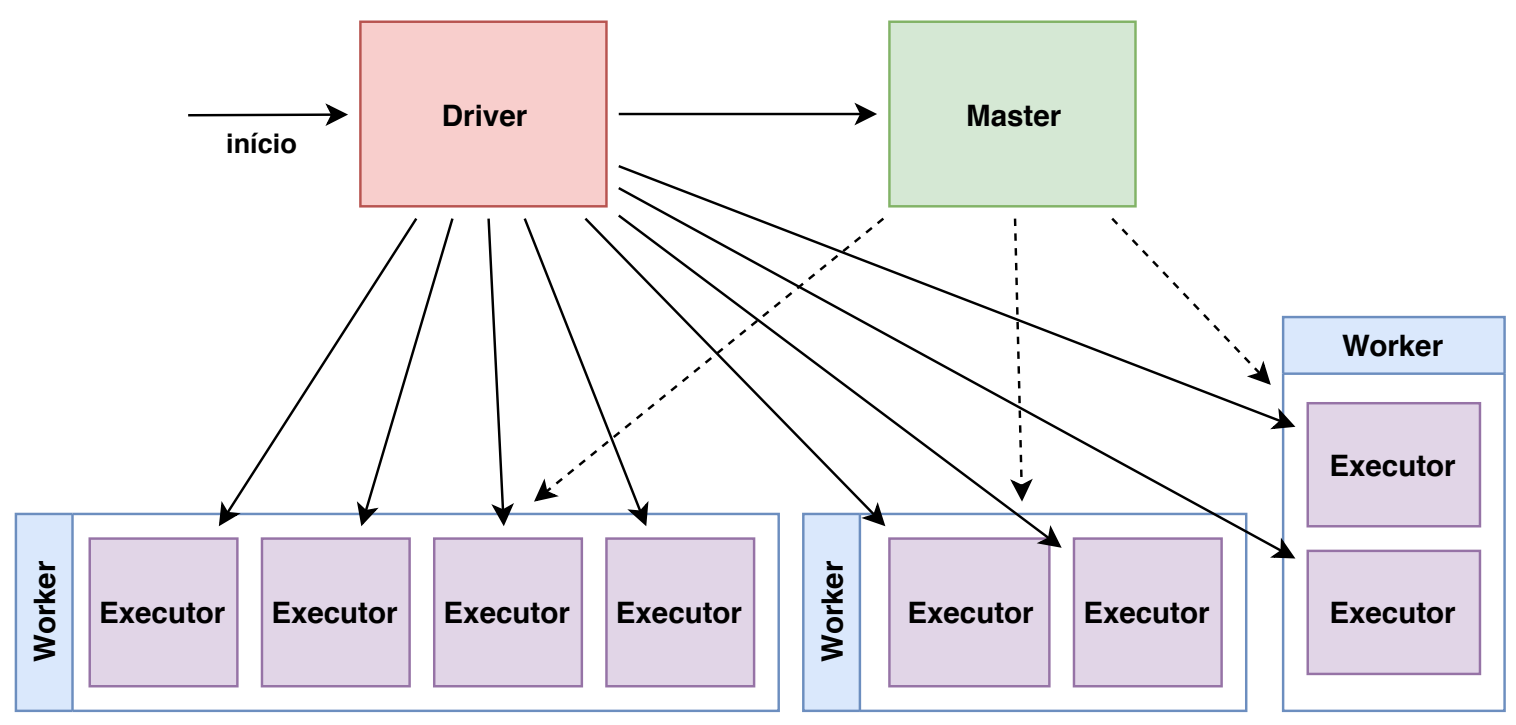

Figura 2.3: Visão alto nível da arquitetura do Spark.

Na figura, é apresentado um job que foi dividido em várias tasks (caixas azuis), onde a task exchange demarca o momento em que a operação de shuffling ocorrerá no processamento (Chambers e Zaharia, 2018).

Contudo, um desenvolvedor que utiliza o Spark não interage diretamente com os conceitos de tasks e jobs; ele o faz através de duas estruturas de dados que o Spark disponibiliza, que são os RDDs e os DataFrames.

\subsubsection{Estruturas de dados do Spark: RDDs e DataFrames}

A estrutura que o Spark utiliza internamente para processar e armazenar os dados são os RDDs (Resilient-Distributed Datasets) (Apache Spark RDD Documentation 2019). Embora existam outras APIs e estruturas de mais alto nível, como os DataFrames, essas também utilizam RDDs internamente. Os RDDs permitem o processamento tardio com tolerância a falhas através de uma API de programação funcional, disponível em Python, Scala, Java e R. Os RDDs são vistos como um grafo-direcionado acíclico (Directed Acyclic Graph - DAG) onde os vértices são as tasks e as arestas são as dependências entre tarefas.

Os DataFrames são uma estrutura de dados que disponibiliza uma API de mais alto nível para os usuários do Spark, compatível com a sintaxe SQL. Internamente, os DataFrames utilizam RDDs, de modo que os mesmos benefícios dos RDDs (como processamento tardio e tolerância a falhas, por exemplo) também se aplicam aos DataFrames. Pelo DataFrame ser uma API que utiliza os RDDs, é comum concluir que os DataFrames apresentam desempenho inferior, mas, na prática, ocorre o contrário. O Spark conta com um motor de otimização de consultas SQL, o Catalyst ${ }^{7}$, e um motor de otimização e geração de código, o Tunsgten ${ }^{8}$. Ao final, os DataFrames são capazes de alcançar desempenho superior que os RDDs em vários cenários, mas ainda assim, os RDDs continuam tendo espaço

\footnotetext{
${ }^{7}$ databricks.com/glossary/catalyst-optimizer

${ }^{8}$ databricks.com/blog/2015/04/28/project-tungsten-bringing-spark-closer-to-bare-metal.html
} 


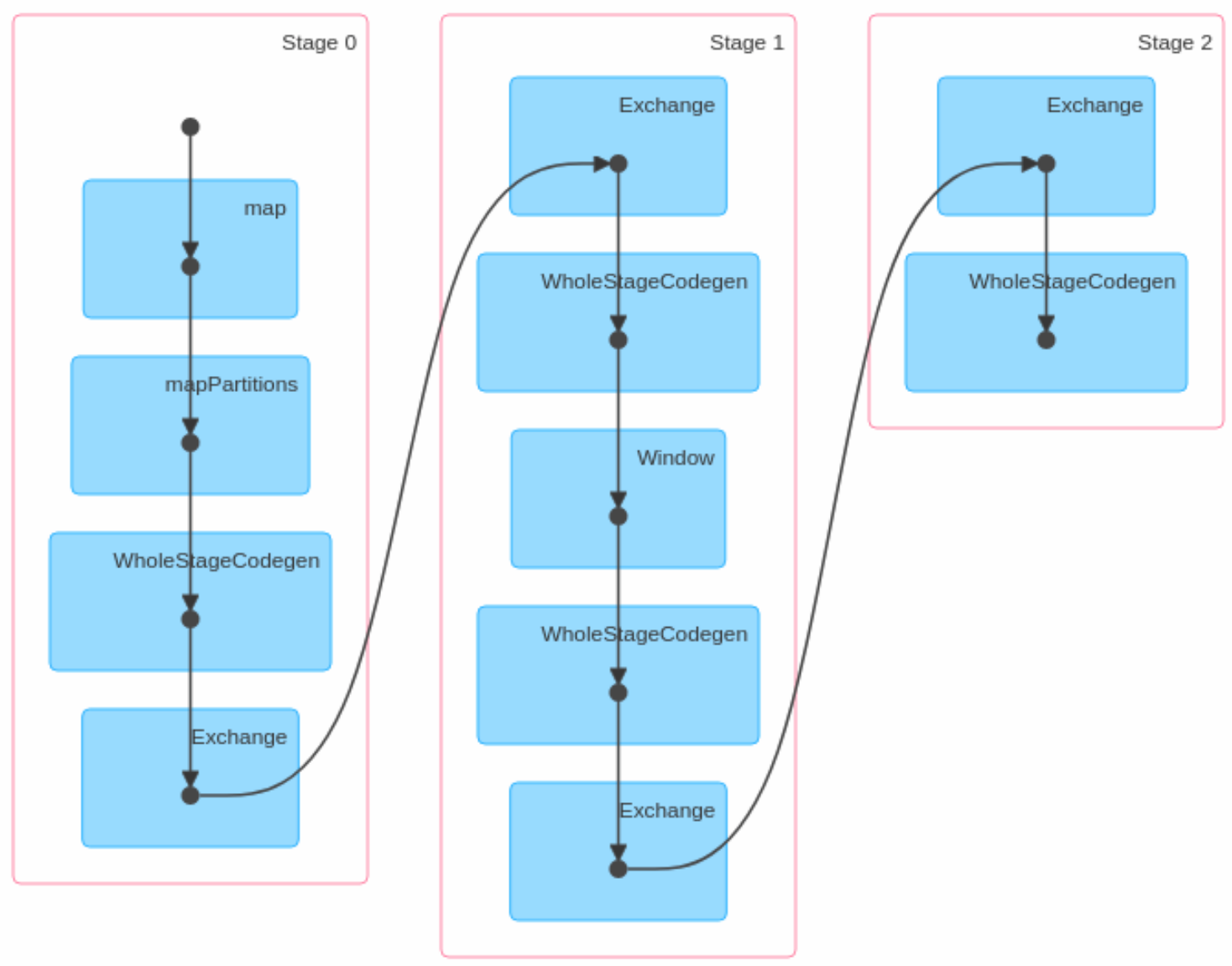

Figura 2.4: Visualização de um job pela SparkUI.

pois, diferente dos DataFrames, permitem que o desenvolvedor particione os dados da maneira que ele preferir (WARREN e KARAU, 2017).

\subsubsection{Outras ferramentas de processamento em cluster}

Embora o Spark seja uma das ferramentas mais bem estabelecidas atualmente para processamento distribuído, existem outras boas ferramentas que seguem propostas diferentes. Antes de decidirmos utilizar o Spark para processar os dados da InterSCity, o comparamos com outras tecnologias também bem difundidas. Como ambos os tipos de processamento, em lote e em fluxo, são de grande uso no contexto de cidades inteligentes (Al NuAimi et al., 2015), comparamos com tecnologias que atuem nessas duas frentes.

As três principais ferramentas que levamos em conta para comparar com o Spark foram o Hadoop MapReduce, Flink e Storm. As três são grandes projetos de software livre da Apache, utilizadas em larga escala em produção e também seriam boas escolhas de ferramenta.

\footnotetext{
${ }^{9}$ hadoop.apache.org
} 
Hadoop MapReduce (Hadoop MR) ${ }^{9}$ O Hadoop MR é uma implementação do modelo de programação map reduce apresentado por DEAn e GHEMAWAT (2004), que traz um novo paradigma para o processamento distribuído de dados em lote. O Hadoop MR foi desenvolvido em grande parte pela Yahoo e faz parte da pilha de ferramentas Hadoop, que contempla: o HDFS, que é um sistema de arquivos distribuído, imutável e tolerante a falhas; o HBase, que é um banco de dados não-relacional que implementa o Google Bigtable; e o Hadoop Yarn, que é um gerenciador de arquivos (BAPpalige, 2014).

A característica mais marcante do Hadoop MR em relação ao Spark e as outras duas ferramentas que analisamos é que, durante o processamento das tarefas, todo resultado preliminar deve ser armazenado no Hadoop HDFS. Na prática, isso significa que após toda iteração de processamento, deve ocorrer uma escrita e uma leitura em disco. Essa prática apresenta uma alta garantia de tolerância à falhas, graças ao modelo de replicação que o Hadoop HDFS propicia, contudo, o desempenho sofre um grande impacto negativo. Outra característica que ressaltamos é que a API do Hadoop MR é escrita toda em função das duas funções, map e reduce, o que limita quais tipos de tarefas podem ser feitas e tem como resultado um código prolixo (ZAHARIA, CHOwdhury, DAs et al., 2012).

Portanto, consideramos o Spark uma opção mais apropriada que o Hadoop MR, já que: o Spark apresenta desempenho superior na maior parte dos cenários (ZAHARIA, Chowdhury, DAs et al., 2012); a API de uso do Spark é, em grande parte, menos prolixa que a do Hadoop MR; e o Spark apresenta um modelo único para processamento em lote e em fluxo, enquanto o Hadoop MR só permite processamento em lote. Por outro lado, utilizar o Hadoop MR pode fazer sentido caso o projeto já utilize o Hadoop MR de maneira integrada e sólida, de modo que uma troca de tecnologia pode não trazer os ganhos esperados e ser arriscada. Mas, dado que não é o cenário em que nos encontramos, consideramos a escolha pelo Spark mais apropriada.

Apache Storm ${ }^{10}$ O Apache Storm é uma ferramenta de processamento em fluxo distribuído desenvolvida em grande parte pelo Twitter e foi uma das primeiras ferramentas de processamento em fluxo utilizadas em larga escala, como apresentado em TosHniwal et al. (2014). É uma ferramenta que, assim como o Spark, tem como principais características a escalabilidade, resiliência, extensibilidade, eficiência e administrabilidade (TosHNIWAL et al., 2014), mas o segue através de uma abordagem e arquitetura diferentes.

A diferença entre o processamento em fluxo que o Storm e o Spark propiciam é que, enquanto no Storm os dados são processados à medida que são recebidos, graças a um polling contínuo de alta frequência, o Spark processa dados à medida que uma janela de tempo fixa é alcançada. Ou seja, a escolha pelo modelo de processamento em fluxo trata-se de uma troca entre vazão e latência: o Spark atinge maior vazão por utilizar micro-lotes, enquanto o Storm atinge menor latência por fazer polling com maior frequência.

Chintapalli et al. (2016) compararam o Storm, o Spark e o Flink e chegaram a conclusão que o Spark, embora apresente pior latência, de fato apresenta uma vazão bem maior. Ao final, optamos pelo Spark pois a diferença de vazão é mais expressiva na maior parte dos cenários de cidades inteligentes e, recentemente, o Spark disponibilizou a utilização de

\footnotetext{
${ }^{10}$ storm.apache.org
} 
processamento contínuo ${ }^{11}$, que permite atingir menor latência no processamento, que torna o Spark uma escolha mais flexível que o Storm. Outro fator determinante é o fato do Spark ter suporte para processamento em lote e em fluxo através da mesma API, enquanto o Storm só disponibiliza processamento em fluxo, o que traria a necessidade de uso de outra ferramenta só para o processamento em lote.

Apache Flink ${ }^{12}$ O Apache Flink é uma ferramenta que, assim como o Spark, tem suporte para ambos, processamento em lote quanto em fluxo, mas os enxerga de uma forma diferente: enquanto o Spark enxerga o processamento em fluxo como um caso específico do processamento em lote, o Flink enxerga o processamento em lote como um caso específico do processamento em fluxo (CARBone, KATsifodimos et al., 2015). O maior diferencial do Flink é a atenção e o preparo dado para manutenção de uso de operações com estado (CARBone, EWEn et al., 2017), onde é possível que um fluxo de processamento acesse o estado de um outro fluxo, que não recebe tanta atenção pelo time do Spark. De fato, em sistemas distribuídos só permitir operações sem estado facilita diversos problemas, já que o estado de uma entidade passa a não poder ser afetado por outros agentes.

GARCíA-Gil et al. (2017) compararam o processamento em lote do Flink e do Spark e, pelos resultados obtidos, concluíram que o Spark é mais refinado em diversos cenários, embora tenham deixado claro que não foi levado em conta na comparação o processamento em fluxo, que é a principal força do Flink. Dessa forma, pelo Spark ser um projeto mais maduro em cenários expressivos ${ }^{13}$, optamos por ele. Assim, concluímos que ambos, Spark e Flink, tratam-se de boas opções de ferramenta de processamento em cluster híbridas, mas preferimos o Spark por ser mais maduro e ter um ecossistema maior.

\subsection{Microsserviços}

Microsserviços é um estilo arquitetural para construção de um sistema onde as responsabilidades de um projeto são distribuídas entre serviços menores e que colaboram entre si através de mecanismos leves de comunicação, como protocolo AMQP ou requisições REST (Fowler, 2014). Enquanto uma aplicação monolítica cuida de todo o sistema de maneira centralizada, microsserviços tratam partes diferentes do sistema de forma independente, de modo que uma atualização em um microsserviço não cause indisponibilidade em outros. De acordo com Fowler (2014), as principais características de sistemas que seguem esse estilo arquitetural são:

Componentização por Serviços Existem duas formas de componentizar um sistema: por serviços e por bibliotecas. O que costuma definir qual a melhor escolha a seguir são as prioridades do sistema, pois a componentização por serviços tem a vantagem

\footnotetext{
${ }^{11}$ spark.apache.org/docs/latest/structured-streaming-programming-guide.html\# continuous-processing

12 flink.apache.org

${ }^{13} \mathrm{Um}$ desses cenários é quando, no processamento em fluxo, diversos eventos ocorrem em diferentes janelas ao mesmo tempo. Fonte: medium.com/gradiant-talks/big-data-applied-spark-vs-flink-5c54a55957fa
} 
de permitir a implantação de maneira isolada, enquanto componentização por bibliotecas apresenta melhor desempenho, já que a interação com a biblioteca é feita dentro do mesmo processo.

Organização guiada por negócio Equipes são organizadas por microsserviços, que são organizados por lógicas de negócio, ao invés de equipes que focam somente numa parte da tecnologia. Ou seja, ao invés de um time especialista em uma única coisa, como especialistas em modelagens de bancos de dados, os times são organizados pelos componentes do sistema, como o time responsável pela parte de pagamentos ou pela parte de perfis de usuário, por exemplo.

Produtos, não Projeto Uma equipe deve desenvolver um produto, e não todos focarem em um projeto grande, onde cada um faz uma parcela do projeto. Assim, a responsabilidade do produto passa a ser do time que o desenvolveu, de modo que seus desenvolvedores devam se preocupar com tudo que envolva seu produto.

Endpoints inteligentes e fluxos simples Sistemas que seguem o padrão de microserviços costumam implementar seus sistemas com base nos princípios Unix ${ }^{14}$. Ou seja, o mais comum é que um microsserviço receba um dado, o transforme e retorne o dado transformado para ser reutilizado por outra tarefa de outro microsserviço.

Governança descentralizada Cada microsserviço tem uma liderança descentralizada, de modo que diferentes escolhas podem ser tomadas para cada um dos microsserviços, que provavelmente têm necessidades diferentes. Se um é melhor com uma tecnologia e outro com outra, então, que utilizem tecnologias diferentes e tomem escolhas de design diferentes.

Gerenciamento descentralizado dos dados Cada microsserviço tem seu próprio banco de dados, ao contrário de todos utilizando um banco centralizado. Isso permite que sejam utilizados diferentes tecnologias de bancos de dados, que cada banco seja escalado de forma independente e pode melhorar a disponibilidade do sistema, pois caso um banco sofra algum problema, outros não serão afetados.

Automatização da infraestrutura A automatização da infraestrutura é bem comum em microsserviços pois é essencial para a implantação contínua, que permite avaliar de maneira ágil o estado do microsserviço conforme novas versões são desenvolvidas. O movimento DevOps tem bastante relação com essa característica, onde desenvolvedores passam a se preocupar com automatizar os processos do sistema.

Desenhado para falhar Microsserviços, além de serem desenhados com cenários em que falhas podem ocorrer, são isolados de modo que falhas em um microsserviço não torna todo o sistema indisponível. Além disso, certas tecnologias podem ser utilizadas para ajudar na recuperação de falhas (embora também possam ser utilizadas em sistemas monolíticos).

Desenho evolucionário O desenho do sistema deve facilitar a evolução do produto como um todo, focando em extensibilidade. Além disso, novos desenvolvedores passam

\footnotetext{
${ }^{14}$ en.wikipedia.org/wiki/Unix_philosophy
} 
a poder evoluir o sistema com maior produtividade, quando o design do sistema é planejado com a evolução em mente.

Portanto, as principais vantagens de um sistema que utiliza uma abordagem de microsserviços é a facilidade de manutenção, isolamento entre funcionalidades distintas, possibilidade de escolhas de tecnologias diferentes para cada serviço e escalabilidade pontual, onde é possível escalar somente um microsserviço em específico. Contudo, o padrão de microsserviços também traz desvantagens, como: em times pequenos, manter vários microsserviços é pouco efetivo, a complexidade do sistema pode aumentar, é mais complicado depurar sistemas distribuídos, dentre outros.

A plataforma de cidades inteligentes que escolhemos para implementar a integração com processamento distribuído, a InterSCity, segue esse padrão arquitetural. Os microsserviços dessa plataforma utilizam tanto protocolo AMQP quanto requisições REST para comunicação e utiliza tecnologias diferentes para alguns microsserviços, a depender da sua necessidade.

\subsection{Plataforma InterSCity}

A InterSCity ${ }^{15}$ é uma plataforma de cidades inteligentes nascida a partir de estudos científicos que buscam abordar os principais desafios encontrados no desenvolvimento de infraestruturas de cidades inteligentes (BATISTA et al., 2016). A plataforma utiliza uma arquitetura de microsserviços que permite armazenamento, análise, processamento, atuação, composição e integração de dados de recursos de cidades inteligentes e tem como principal objetivo prover os serviços e integrações necessárias para a construção de aplicações de cidades inteligentes complexas (Esposte et al., 2017).

Plataformas de cidades inteligentes surgiram num contexto onde a maior parte das aplicações eram feitas com abordagem adhoc e não se preocupavam com interoperabilidade ou reaproveitamento das soluções. Por outro lado, aplicações que se apoiam em uma plataforma como a InterSCity, são interoperáveis entre si e podem fazer reuso de código, já que a maior parte das chamadas serão as mesmas, só alterando alguns parâmetros.

\section{Arquitetura}

A arquitetura da InterSCity era composta por seis microsserviços: DataCollector, ResourceCataloguer, ResourceAdaptor, ResourceDiscoverer, ActuatorController e ResourceViewer. Após este trabalho, a arquitetura passa a ter mais um microsserviço, o DataProcessor.

Os microsserviços da InterSCity buscam ter responsabilidades pontuais e bem definidas, comum em arquiteturas de microsserviços (Fowler, 2014), princípio chave para que a plataforma atenda os requisitos funcionais e não-funcionais disponibilizados para as

\footnotetext{
15 interscity.org
} 


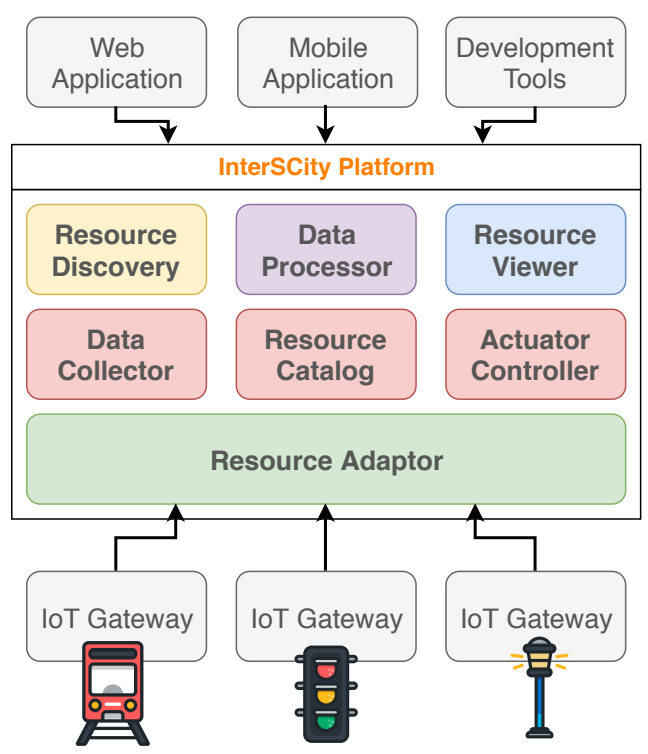

Figura 2.5: Visão geral dos microsserviços da plataforma InterSCity. Cada um dos blocos dentro da caixa InterSCity Platform é um microsserviço da plataforma.

aplicações. A Figura 2.5 apresenta uma visão geral da plataforma com todos os 6 microsserviços originais mais o novo microsserviço que desenvolvemos, o DataProcessor. Os microsserviços são todos configurados como contêineres do Docker ${ }^{16}$ e disponibilizam configuração automatizada.

A plataforma se apoia em duas abstrações: recursos e capacidades. Os recursos representam os recursos físicos da cidade (como sensores e semáforos), enquanto as capacidades representam quais são as atribuições de um determinado recurso. Os dados dos recursos são classificados em dois tipos: dados estáticos (como o estado de funcionamento e descrição do recurso) e dados não-estáticos (quais valores foram medidos ao longo de um dia por um sensor de temperatura, por exemplo).

Embora a plataforma tenha vários microsserviços, os sensores da cidade só precisam se comunicar com o microsserviço proxy da plataforma, chamado ResourceAdaptor. O DataCollector e o ResourceCataloguer são os microsserviços responsáveis por gerenciar os dados dos recursos da cidade, sendo o ResourceCataloguer responsável pelos dados estáticos e o DataCollector responsável pelos dados não estáticos (de medição). Essa separação é importante pois, em certos cenários, ocorre um grande número de registros de recursos (de modo que a demanda por mais recursos computacionais só é necessária para o ResourceCataloguer), enquanto em outros cenários não há qualquer mudança em dados estáticos, mas uma grande quantidade de medições é feita (de modo que só o DataCollector precise de mais recursos computacionais).

Para ajudar a encontrar os recursos da cidade através de consultas complexas, como forneça a lista de todos os recursos que podem medir temperatura num raio de 50 metros perto da minha casa, é utilizado o ResourceDiscoverer, que internamente interage com o ResourceCataloguer. Ou seja, o desenvolvedor até pode utilizar o ResourceCataloguer diretamente para encontrar os recursos desejados, mas o ResourceDiscoverer fornece uma

\footnotetext{
${ }^{16}$ www.docker.com
} 
API mais poderosa.

Os dois microsserviços restantes estão em fase preliminar de desenvolvimento, mas já apresentam alguma funcionalidade: o Actuator Controller é responsável pela atuação em recursos da cidade e o Resource Viewer apresenta para o usuário final uma camada de visualização dos recursos da cidade. Por fim, o DataProcessor, que é a nossa contribuição, passa a fazer parte da lista de microsserviços da plataforma, com o objetivo de facilitar para os desenvolvedores o processamento de Big Data.

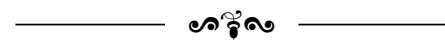

Neste capítulo apresentamos o referencial teórico referente a este trabalho, que tem como principais tópicos o processamento distribuído de Big Data e seu uso no contexto de cidades inteligentes. No próximo capítulo falaremos dos trabalhos relacionados, que contemplam principalmente outras plataformas de cidades inteligentes e sua integração de processamento distribuído. Do que vimos, vários pontos positivos são atingidos, mas consideramos que todas pecam em um aspecto ou outro dessa integração. 


\section{Capítulo 3}

\section{Trabalhos Relacionados}

O uso dos dados das cidades possibilita uma série de aplicações, que vão desde auxiliar a tomada de decisões por gestores da cidade até facilitar a vida das pessoas (GANDOMI e HAIDER, 2015). Porém, a grande quantidade de dados gerados requer que tenha-se disponível grande poder computacional, que costuma ser mais viável com a escalabilidade horizontal que com a vertical (KleppMAnN, 2017). Al NuAimi et al., 2015 apresentam um apanhado geral sobre alguns trabalhos realizados na área. Alguns governos já começaram a utilizar a grande quantidade de dados disponível das cidades mas diversos desafios da área continuam em aberto (BATisTA et al., 2016).

Portanto, fica claro que a área já conta com trabalhos que se preocupam com a utilização de Big Data no contexto de cidades inteligentes. A seguir listamos alguns trabalhos que lidam com processamento distribuído em cidades inteligentes, mas, pelos trabalhos da área só tratarem de alguns dos desafios, também adicionamos trabalhos não relacionados com cidades inteligentes. Por isso, separamos os trabalhos em diferentes tópicos: o grupo das plataformas de cidades inteligentes que, de alguma forma, lidam com processamento distribuído; o grupo dos frameworks de processamento de dados que se classificam como reutilizáveis em diferentes aplicações; e o grupo das ferramentas que facilitam o uso do processamento distribuído, independente do contexto.

\subsection{Plataformas que integram processamento distribuído}

\section{CIVITAS - VILLANUEVA et al. (2013)}

VILLANUEva et al., 2013 apresentam a plataforma CIVITAS, que tem como propósito permitir o suporte para o desenvolvimento de serviços de cidades inteligentes. A plataforma utiliza a ideia de plugs, onde todo hardware que deseja consumir ou produzir dados para a plataforma é visto como um plug por meio de um software que deve ser instalado previamente. Ao final, todo plug é visto como um objeto distribuído que faz parte da plataforma, o que facilita na padronização dos diferentes recursos e facilita a sua integração, 
que passa a ser responsabilidade do software da CIVITAS e não do recurso em si. O trabalho traz argumentos sobre a não utilização de protocolos baseados em texto e compila uma série de funcionalidades que podem ser usadas no contexto de Big Data, mas sem trazer inovação. $\mathrm{O}$ trabalho cita que a CIVITAS processa dados mas não apresenta como ocorre a distribuição e o processamento em si, ou detalhes maiores sobre ou replicação dos dados. Outro problema é que o trabalho não traz avaliações, então não é possível concluir qual seu estado quanto ao desempenho e escalabilidade.

\section{CiDAP - Cheng et al. (2015)}

Cheng et al., 2015 apresentam a plataforma de Big Data CiDAP (City Data and Analytics Platform), que funciona sobre a plataforma SmartSantander. São apresentadas desde a arquitetura da plataforma, quanto lições aprendidas, discussões sobre as decisões tomadas e avaliação de desempenho. Entre os pontos mais interessantes do trabalho destacam-se a divisão de processamento entre interno e externo - processamento interno seria um processamento mais simples feito pelo próprio banco de dados ${ }^{1}$, enquanto o processamento externo seria todo processamento feito de fora do banco. O trabalho cita o uso do Spark para o processamento externo, mas não foca tanto na questão do processamento distribuído. Um outro ponto interessante é que consultas SQL podem ser especificadas através de API REST para o processamento interno, semelhante ao DataProcessor. Contudo, o trabalho não se atenta à questão da usabilidade em si no processamento externo e só é avaliado na perspectiva de quantos usuários é possível atender ao mesmo tempo.

\section{FiWARE}

O FiWARE ${ }^{2}$ é uma das maiores iniciativas de cidades inteligentes dos últimos anos e um dos trabalhos mais conhecidos e utilizados da área. A iniciativa por trás do projeto foca em padronizar algumas questões da área e propor uma plataforma de cidades inteligentes de uso geral, também chamada FiWARE, que pode ter módulos ativados e desativados conforme as necessidades do usuário. A plataforma disponibiliza o Cosmos, um módulo que possibilita o processamento de dados da plataforma por meio de ferramentas de processamento distribuído já difundidas, como o Spark e o Flink. Pela documentação, a arquitetura não contempla questões de usabilidade ${ }^{3}$, mas apresenta uma forma de interação com o gerenciamento de recursos via API REST. ARAUjo et al. (2019) avaliam o desempenho do FiWARE em diversos aspectos e levantam que uma das limitações da plataforma é o fato dos agentes IoTs serem escritos em Node.js, o que limita o uso do paralelismo e afeta a escalabilidade vertical.

\footnotetext{
${ }^{1}$ No trabalho, utilizam o banco de dados NoSQL CouchDB, que disponibiliza uma API map-reduce para processamento de seus dados.

${ }^{2}$ www.fiware.org/

${ }^{3}$ fiware-cosmos.readthedocs.io/en/latest/
} 


\section{Ma e Liang (2015)}

MA e LiANG (2015) apresentam uma arquitetura focada em processamento distribuído que utiliza o Kafka, Storm e Spark, e seu uso no contexto de cidades inteligentes. O trabalho mapeia uma série de problemas e desafios da área e quais são as demandas de uma plataforma de Big Data. Diferente de alguns dos trabalhos vistos, esse se preocupa com a avaliação do desempenho e escalabilidade, mas de uma ótica já muito explorada: o trabalho foca em avaliar quão boas são tecnologias como o Kafka e o Spark, o que têm pouca relevância para a área, pois são tecnologias difundidas e que já provaram sua excelência (Zaharia, Chowdhury, Das et al., 2012).

\subsection{Frameworks para processamento de Big Data em cidades inteligentes}

\section{SCDAP - OSMAN (2019)}

O trabalho de Osman (2019) apresenta o framework para processamento de Big Data SCDAP (Smart City Data Analytics Panel). O trabalho foca bastante em seguir princípios de design baseado em outros trabalhos da área e, de maneira no geral, propõe basicamente um conjunto de ações que deveria ocorrer em alto nível para o funcionamento de uma plataforma e quais ferramentas utilizar para processar os dados. De maneira geral, é difícil reutilizar as ideias do trabalho: não é descrito como reproduzir ou como é o uso do framework, não foi feita uma avaliação do trabalho e questões como usabilidade e extensibilidade, que são alguns de nossos focos, não receberam atenção.

\section{BASIS - C. Costa e SAntos (2016)}

C. Costa e SAntos (2016) apresentam o BASIS, uma arquitetura de Big Data para cidades inteligentes. Sua arquitetura traz como diferencial uma divisão em três camadas: uma de mais alto nível, chamada de camada conceitual; uma mais focada nas ferramentas utilizadas para processamento dos dados, chamada camada tecnológica; e uma camada de infraestrutura, que foca nas ferramentas que gerenciam a infraestrutura da plataforma. A arquitetura é avaliada através de um experimento que classifica algumas informações sobre voos por meio de aprendizagem não-supervisionada. O trabalho não cita extensibilidade ou usabilidade, mas apresenta um serviço de visualização para os resultados do processamento.

\section{Khan, Anjum, Soomro et al. (2015) e Khan, Anjum e Kiani (2013)}

Khan, Anjum, Soomro et al. (2015) e Khan, Anjum e Kiani (2013) propõe um serviço de nuvem que tem como objetivo final ajudar gestores da cidade na tomada de decisões. 
O serviço utiliza como base uma arquitetura composta de três camadas: uma de mais baixo nível, que lida com a aquisição dos dados advindos principalmente de sensores; uma camada de nível médio, responsável pela mesclagem de dados de fontes distintas; e uma camada de nível mais alto, responsável pelo processamento, análise e visualização dos dados. No trabalho, apresentam um experimento que utiliza dados diversos da cidade de Bristol, como o nível de educação, transporte e infraestrutura de algumas regiões da cidade. O experimento consistiu em cruzar e relacionar esses dados e foi feito de duas maneiras: uma utilizando Spark e outra utilizando o Hadoop MapReduce. Ao final, fizeram uma comparação entre ambas as ferramentas e concluiram que o Spark tem desempenho superior.

\section{Amini et al. (2017)}

Amini et al. (2017) apresentam uma arquitetura para análise de dados de trânsito que utiliza o Kafka como ferramenta chave para seu funcionamento. De maneira breve, sensores e atuadores da cidade publicam e recebem dados do Kafka, que atua como o middleware do sistema. Os dados enviados são também armazenados no Hadoop HDFS e o log é replicado em um banco NoSQL, para análises futuras. Para validar o trabalho, executaram um estudo de caso que utiliza o simulador de trânsito $\mathrm{SUMO}^{4}$ para gerar dados.

\subsection{Visão geral dos trabalhos da área}

Embora haja uma quantidade considerável de trabalhos na área que focam especificamente no processamento de Big Data, fica claro que diversos desafios da área continuam em aberto. Um ponto que chamou nossa atenção foi a similaridade entre os trabalhos na proposta: a maior parte propõe uma arquitetura que define uma série de ferramentas para seu uso e avaliam preliminarmente essa arquitetura em um contexto bem específico e (às vezes) avaliam o tempo necessário para o processamento dos dados.

Mas, uma ressalva importante é que, não faz sentido o governo de uma cidade fazer um grande investimento em infraestrutura computacional para possibilitar grande processamento para cidades inteligentes se o uso desse processamento não é acessível. Por exemplo, a maior parte dos trabalhos apresenta uma arquitetura que utiliza alguma ferramenta como Spark ou o Hadoop MapReduce, mas questões como a integração entre essa ferramenta e outras partes do sistema, a usabilidade de uma ferramenta de processamento distribuído, a extensibilidade do trabalho proposto, dentre outros desafios, não são explorados, o que dificulta sua adoção.

Ainda, as avaliações são relativamente superficiais: a maior parte dos trabalhos foca em nos provar que ferramentas como o Spark são boas, e o pior, em cenários muito simples, o que não tem relevância; essas ferramentas já são usadas há anos em contextos críticos por empresas que só utilizam as melhores soluções.

\footnotetext{
${ }^{4}$ sumo.sourceforge.net/
} 
Nesse sentido, nos guiamos pelos requisitos de usabilidade, desempenho e extensibilidade, que são os pontos mais negligenciados e pouco explorados dentre os trabalhos que vimos, para propor nossa arquitetura, apresentada no capítulo a seguir. A usabilidade, que tem papel chave em permitir que uma grande infraestrutura seja utilizada para processar a grande quantidade de dados de uma cidade sem que o usuário tenha conhecimento de ferramentas específicas. A extensibilidade, para permitir a longevidade da solução e permitir o uso do trabalho em cenários que não previmos (o que é inevitável). E o desempenho, pois as outras duas características tem um preço e, se esse preço for muito alto, a solução deixa de fazer sentido.

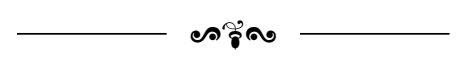

Neste capítulo apresentamos de maneira geral o estado-da-arte em processamento distribuído em cidades inteligentes, bem como um panorama geral do que os trabalhos da área contemplam ou não. Ainda, mostramos suas forças e fraquezas, no que pecam e no que estaremos contribuindo. No próximo capítulo, apresentamos o DataProcessor em detalhes, indo do mais alto nível, com a arquitetura e os requisitos, até os níveis mais baixos, com seu funcionamento e exemplos de código. 



\section{Capítulo 4}

\section{DataProcessor: Processamento em cluster na plataforma InterSCity}

Aplicações de cidades inteligentes que utilizam Big Data precisam, de alguma forma, lidar com requisitos essenciais advindos da área de cidades inteligentes ou da área de Big Data; dentre esses, o uso de uma plataforma de processamento apropriada (AL NUAIMI et al., 2015). A plataforma InterSCity, introduzida com maiores detalhes na Seção 2.4, não continha suporte integrado a processamento de grande quantidade de dados e é neste contexto que este trabalho se insere.

Uma tentativa inicial de adição de suporte a processamento em cluster na InterSCity ocorreu com uma versão preliminar do DataProcessor em $2016^{1}$, no contexto de uma disciplina de pós-graduação. Nessa primeira versão, o DataProcessor tratava-se de um código escrito em Python que utilizava o Spark para calcular a velocidade de trechos do trânsito armazenados no DataCollector. Contudo, o projeto não recebeu contribuições após o término da disciplina nem nunca foi utilizado em modo distribuído, caindo em desuso. A InterSCity, desde então, continuou sem um suporte apropriado para processamento em cluster integrado à plataforma, de modo que os desenvolvedores de aplicações de cidades inteligentes fossem os responsáveis por lidar com o processamento de Big Data dos dados da cidade.

Com o intuito de adicionar uma nova versão do suporte ao processamento distribuído integrado à plataforma, iniciamos no contexto do meu trabalho de conclusão de curso, em 2017, um projeto chamado Shock ${ }^{2}$. O Shock permitia a criação de um pipeline de processamento onde o usuário deveria especificar todo o ETL, que posteriormente era transformado em um pipeline do próprio Spark. Contudo, O Shock baseava-se em decisões de design que se mostravam pouco efetivas, como por exemplo, (1) o usuário deveria construir o pipeline de processamento através de mensagens enviadas a um determinado barramento do Kafka e (2) toda operação do Spark que fosse ser utilizada deveria ser

\footnotetext{
${ }^{1}$ A primeira versão está disponível em: gitlab.com/interscity/interscity-platform/data-processor-old ${ }^{2}$ github.com/DylanGuedes/py_shock.git
} 
implementada no Shock previamente, o que limitava sua extensibilidade.

A partir das lições aprendidas com o Shock e após um melhor estudo dos trabalhos relacionados, observamos meios de permitir, através desta nova versão do DataProcessor, que desenvolvedores pudessem finalmente ter acesso ao processamento em cluster de maneira integrada à plataforma e com boa usabilidade e extensibilidade. Neste capítulo exploramos essa nova abordagem, que iniciamos com a definição de requisitos a serem seguidos pela arquitetura e a sua implementação.

\subsection{Requisitos}

Definimos quatro requisitos para serem seguidos por uma integração de processamento distribuído a uma plataforma de cidades inteligentes: integração adequada e efetiva, desempenho, usabilidade e extensibilidade. Consideramos esses quatro requisitos como essenciais pois, ao serem seguidos, retiram os impeditivos que fazem com que aplicações evitem utilizar a integração. Em maiores detalhes, listamos a seguir os quatro requisitos:

Integração Adequada e Efetiva (seamless integration) A integração adequada e efetiva é importante pois permite que funcionalidades sejam adicionadas e estendidas sem trazer ao projeto o risco de instabilidade. Em nosso contexto, uma maneira de seguir esse requisito é promovendo somente extensão e adição de código, ou em termos práticos, através da criação de um novo microsserviço isolado para a InterSCity. Consideramos esse requisito essencial pois permite a adesão de uso a uma plataforma sem que seja necessário uma grande revisão do funcionamento do sistema, já que na prática não haverá alteração de comportamento, não prejudicando também a retrocompatibilidade de diferentes versões da plataforma.

Usabilidade (usability) O conhecimento técnico necessário para configurar e utilizar uma ferramenta de processamento distribuído é grande ao ponto de um desenvolvedor experiente não ser capaz de executar tarefas simples sem que um tempo razoável seja dedicado para aprender a usá-la. Através de uma boa usabilidade, é possível permitir que desenvolvedores não precisem se preocupar em aprender uma nova tecnologia ou que, pelo menos, esse processo seja feito com uma menor curva de aprendizagem, mas que ainda assim tenham acesso ao benefício de processar os dados de forma distribuída. Seguimos esse requisito ao disponibilizarmos meios de interação comuns e bem difundidas entre desenvolvedores, como requisições REST.

Extensibilidade (extensibility) Não é possível prever todas as funcionalidades que os desenvolvedores de aplicações de cidades inteligentes necessitam. Dessa forma, é necessário que formas de estender a integração entre a plataforma e suas aplicações estejam disponíveis, para possibilitar sua evolução sem trazer instabilidade ao projeto, de modo que mais cenários de uso possam ser atendidos em um momento posterior. Seguimos esse requisito ao propor abstrações que esperam e facilitam a extensão de trechos, mas que também promovem o reuso de código.

Desempenho (performance) Toda a motivação para se utilizar uma ferramenta de processamento em cluster só faz sentido se a degradação de desempenho ao utilizar a 
integração não for expressiva. Seguimos esse requisito ao utilizarmos abordagens que evitam a degradação de desempenho, mesmo com o grande volume de dados, seja essencial.

A partir das definições dos requisitos, definimos quais abstrações e ideias utilizaríamos na arquitetura e na implementação do DataProcessor. Tratamos o requisito de extensibilidade em nível de entidades da arquitetura, onde elaboramos abstrações que buscavam facilitar a extensão nos níveis mais baixos da implementação. Os requisitos de usabilidade e desempenho foram tratados em nível de comunicação de componentes da arquitetura. $\mathrm{O}$ requisito de integração adequada e efetiva não foi trabalhado a nível de arquitetura, mas sim de implementação.

\subsection{Arquitetura do DataProcessor}

A arquitetura do DataProcessor foi guiada pelos requisitos definidos na Seção $4.1 \mathrm{e}$ teve como principal preocupação a utilização de componentes que fossem extensíveis e reaproveitáveis para cenários não previstos. De maneira geral, os elementos da arquitetura trabalham em conjunto para prover a integração entre a plataforma e o processamento distribuído através de geração de código, detalhada mais à frente na Seção 4.5. A ideia geral é que um usuário, através da utilização do DataProcessor, gere um código apropriado para processar os dados de forma distribuída.

A arquitetura do DataProcessor é composta de três componentes: JobTemplate, JobScript e Processing Job. De maneira geral, os três componentes atuam em conjunto para permitir a integração desejada e o fazem através de (1) interações com o usuário, que especifica qual o tipo de processamento a ser feito; e através da (2) geração de código, que gera o código nativo responsável por processar os dados de maneira distribuída de acordo com as orientações do usuário.

- O JobScript define qual estratégia deve ser utilizada para gerar código que integra a ferramenta de processamento e a plataforma de cidades inteligentes. Dessa forma, o JobScript é quem contém, por exemplo, a lógica para a execução de consultas SQL, treinamento de um modelo de regressão linear, dentre outras tarefas de processamento.

- O JobTemplate personaliza o comportamento de um JobScript através de parâmetros definidos pelos usuários. Por exemplo, caso o Usuário A deseje processar uma consulta SQL e o Usuário B deseje processar uma outra consulta SQL, eles devem personalizar JobTemplates diferentes que atendam suas necessidades, mas ambos os JobTemplates utilizarão o mesmo JobScript, que define como uma consulta SQL é executada pela ferramenta de processamento em cluster. Ainda, dado que JobTemplates são, portanto, simples armazenadores de chave-valor, um usuário que não deseja preencher todos os campos novamente tem a opção de clonar um JobTemplate existente, de modo que só seja necessário alterar poucos parâmetros do JobTemplate clonado.

- Por fim, o ProcessingJob é uma abstração para tarefas e tem como responsabili- 
dades utilizar o JobScript para gerar o código que será submetido à ferramenta de processamento em cluster, injetar no código gerado os parâmetros personalizados e submeter o código gerado à ferramenta de processamento em cluster.

Uma visão geral da arquitetura é apresentada na Figura 4.1. Partindo da esquerda para a direita, temos inicialmente os JobScripts que possibilitam o processamento das tarefas. Em seguida, aparecem os JobTemplates, que contém setas que referenciam os JobScripts. O primeiro JobTemplate da figura contém a consulta select * from cars e faz referencia ao JobScript que processa consultas SQL. Por fim, os últimos itens são os ProcessingJobs, que referenciam um JobTemplate pois utilizarão os parâmetros definidos para a geração de código personalizado. O Processing Job PJ 1, por exemplo, é relativo à consulta select * from cars.

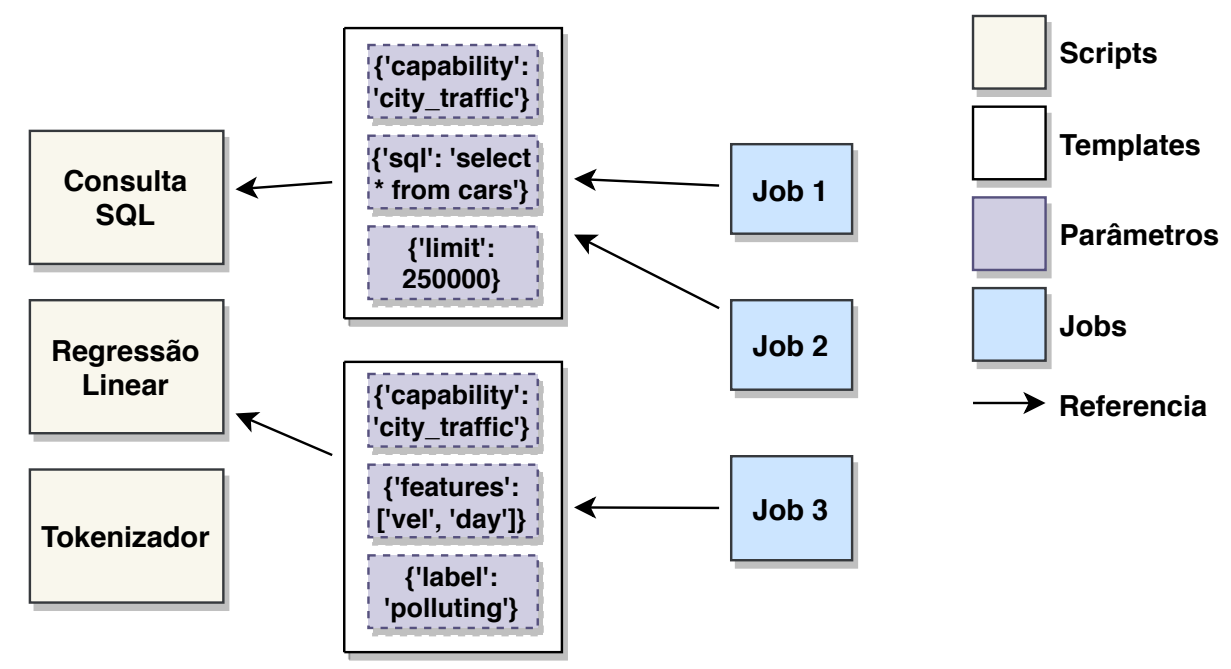

Figura 4.1: Visão geral da arquitetura do DataProcessor, com alguns exemplos de uso (como o de consulta SQL).

Após a definição da arquitetura, focamos nas escolhas mais concretas do DataProcessor, relativas a implementação. Optamos por tecnologias abertas e utilizadas em larga escala nos mais diversos contextos e que estavam de acordo com os princípios de design seguidos pela InterSCity, apresentados em Esposte et al. (2017).

\subsection{Implementação do DataProcessor}

Implementamos o DataProcessor em cerca de 2000 linhas de código Elixir ${ }^{3}$ apoiado no framework web Phoenix ${ }^{4}$ e o código-fonte do projeto encontra-se temporariamente em github.com/dylanguedes/data-processor-backend. Detalhamos na Tabela 4.1 a quantidade de código que utilizamos para a implementação da arquitetura e de algumas estratégias para processamento de dados. Escolhemos o Elixir para a implementação pois:

\footnotetext{
3 elixir-lang.org/

${ }^{4}$ phoenixframework.org/
} 
- Tem uma sintaxe inspirada na linguagem Ruby, que é utilizada por quase todos os microsserviços do InterSCity, o que facilita a manutenção do código;

- Utiliza a máquina virtual Erlang - a BEAM, que é própria para operações paralelas, ao contrário do Ruby, que tem o paralelismo como uma de suas principais limitações (STORIMER, 2013);

- Suporte para tolerância a falhas, que é importante para melhorar a disponibilidade do DataProcessor. O Ruby não apresenta suporte para esse tipo de situação, enquanto a Beam o trata através de uma abstração apropriada ${ }^{5}$.

\begin{tabular}{r|r|r|r|r|r} 
Linguagem & Arquivos & $\begin{array}{c}\text { Linhas } \\
\text { totais }\end{array}$ & $\begin{array}{c}\text { Linhas de } \\
\text { código }\end{array}$ & Comentários & $\begin{array}{c}\text { Linhas em } \\
\text { branco }\end{array}$ \\
\hline Dockerfile & $<5$ & $<15$ & $<10$ & $<5$ & $<5$ \\
\hline Elixir & $<70$ & $<2600$ & $<2000$ & $<260$ & $<380$ \\
\hline JSON & $<5$ & $<25$ & $<25$ & 0 & 0 \\
\hline Markdown & $<5$ & $<55$ & $<60$ & 0 & 0 \\
\hline Python & $<5$ & $<150$ & $<150$ & $<5$ & $<30$ \\
\hline Shell & $<5$ & $<5$ & $<5$ & 0 & 0 \\
\hline YAML & $<5$ & $<70$ & $<55$ & $<10$ & $<10$ \\
\hline Total & $<\mathbf{8 0}$ & $<\mathbf{2 9 0 0}$ & $<\mathbf{2 3 0 0}$ & $<270$ & $<\mathbf{4 5 0}$
\end{tabular}

Tabela 4.1: Quantidades de linhas utilizadas na implementação.

Como tecnologia de processamento em cluster para o InterSCity, optamos pela ferramenta Apache Spark ${ }^{6}$. O Spark permite ambos os tipos de processamento, em lote e em fluxo, apresenta garantias de tolerância a falhas, tem um ecossistema bem ativo e já foi utilizado em grande escala em produção (ZAHARia, Chowdhury, Franklin et al., 2010). Dentre outras funcionalidades importantes, destacam-se a boa diversidade de APIs, disponíveis em Python, Scala, Java e R, pacotes de aprendizagem de máquina, como o SparkML, pacotes de processamento de grafos, como o GraphX e várias outras iniciativas pela comunidade.

Tanto as interações entre usuários e o DataProcessor, quanto entre o Spark e o DataProcessor são feitas através de requisições REST. Escolhemos REST pois a maioria das linguagens contém algum pacote que permite seu suporte, de modo que, caso um dia o Spark adicione suporte para outras linguagens, o DataProcessor pode ser adaptado para gerar código nessa nova linguagem. Além disso, a maior parte dos frameworks front-end são feitos com base em requisições REST, facilitando a criação de camadas com melhor usabilidade para o DataProcessor.

Para comunicação entre o DataProcessor e o DataCollector utilizamos consultas diretas ao MongoDB, já que extrair dados pela API do DataCollector seria inviável com um grande volume de dados pois o DataCollector contém um limite de dados retornados e pagina os resultados da consulta, além do fato do Ruby on Rails armazenar os dados requisitados em memória. Outro problema é a falta da funcionalidade pipeline presente ao consultar

\footnotetext{
${ }^{5}$ A BEAM disponibiliza a abstração Supervi sors. Sua documentação está disponível em https://hexdocs. pm/elixir/Supervisor.html

${ }^{6}$ spark.apache.org
} 
o MongoDB diretamente. O pipeline permite filtrar os dados diretamente na consulta ao MongoDB, o que ajuda na latência das operações.

Em resumo com as novas informações apresentadas nesta seção, disponibilizamos a integração entre a InterSCity e o Spark através da geração de código, especificada pelo usuário através de requisições REST. Na próxima seção mostramos o fluxo de funcionamento do DataProcessor, com o propósito de indicar em que ordem devem ocorrer as diferentes interações entre usuário e o sistema e como o DataProcessor lida com essa interação internamente.

\subsection{Interações e funcionamento do DataProcessor}

Após definirmos a arquitetura, planejamos como o DataProcessor deveria funcionar; nesta seção apresentamos esse funcionamento através de um exemplo que segue o fluxo de uso do DataProcessor. O exemplo tem um fluxo de funcionamento separado em três passos e ilustra o uso por um desenvolvedor que deseje executar uma consulta SQL aos os dados da InterSCity que tenham a capacidade city_traffic. Durante as interações entre sistemas e usuários, utilizaremos a notação $<\mathrm{V}, \mathrm{E}, \mathrm{P}>$ para indicar a requisição REST enviada, onde:

V trata-se do verbo definido para a requisição REST. Atualmente, são permitidos os verbos POST, GET, DELETE e PATCH.

E trata-se do endpoint da requisição. Listamos na Seção 4.4 .4 os endpoints disponibilizados pelo DataProcessor.

P trata-se dos parâmetros da requisição, que seguem a notação $\{\mathrm{K}: \mathrm{V}\}$, ou chave-valor.

Por exemplo, a requisição <POST, /job_templates, $\{$ 'id': 5$\}>$ indica uma requisição REST com verbo POST que deve ser recebida no endpoint job_templates utilizando id=5 como parâmetro.

A resposta das requisições utilizam a assinatura $\langle R, B>$, onde:

$\mathbf{R}$ trata-se do código da resposta da requisição. O DataProcessor utiliza atualmente dois códigos: 200 para sucesso e 404 para erros.

B trata-se do corpo da resposta da requisição. O corpo segue uma estrutura de chave-valor semelhante ao valor de $\mathrm{P}$ enviado na requisição $\langle\mathrm{V}, \mathrm{E}, \mathrm{P}\rangle$.

Por exemplo, a resposta $<200$, \{'uuid' : 'abcde' $\}>$ indica que a requisição enviada teve sucesso (código 200) e retornou um uuid.

\subsubsection{Passo 1 - Definição dos parâmetros através do JobTemplate}

O primeiro passo para a execução de uma tarefa que utiliza processamento distribuído integrado ao InterSCity é a criação de um JobTemplate, feito através de uma requisição 
REST enviada ao servidor do DataProcessor. O DataProcessor cria o JobTemplate com os parâmetros desejados e retorna para o usuário um código que identifica a instância criada, que será utilizada. A Figura 4.2 ilustra esse primeiro passo. Na figura, o usuário faz uma requisição <POST, /job_templates, $\{1\}>$, onde $\{1\}$ é a versão abreviada do conjunto de parâmetros \{'capability': 'city_traffic', 'sql': 'select * from cars', 'job_script': 3$\}^{7}$. Neste exemplo, o DataProcessor espera três parâmetros para a criação do JobTemplate.

1. O identificador do JobScript responsável pela consulta SQL. Na figura, o JobScript que cuida de consultas SQL tem o identificador id=3, mas note que existem outros JobScripts disponíveis, como o de identificador id=4, que treina um modelo de regressão linear.

2. A consulta SQL em si. Neste exemplo, a consulta recebe todos os campos da tabela cars através da consulta 'select * from cars'.

3. A capacidade dos recursos que será analisada, de acordo com a plataforma InterSCity. Esse parâmetro é importante pois, cada capacidade tem seus próprios campos e tipos, que podem ser dinâmicos. Ao definir a capacidade previamente, o DataProcessor pode, por exemplo, inferir o schema dos dados, de modo que o usuário não precise se preocupar com esse tipo de definição, o que contribui com a usabilidade da solução.

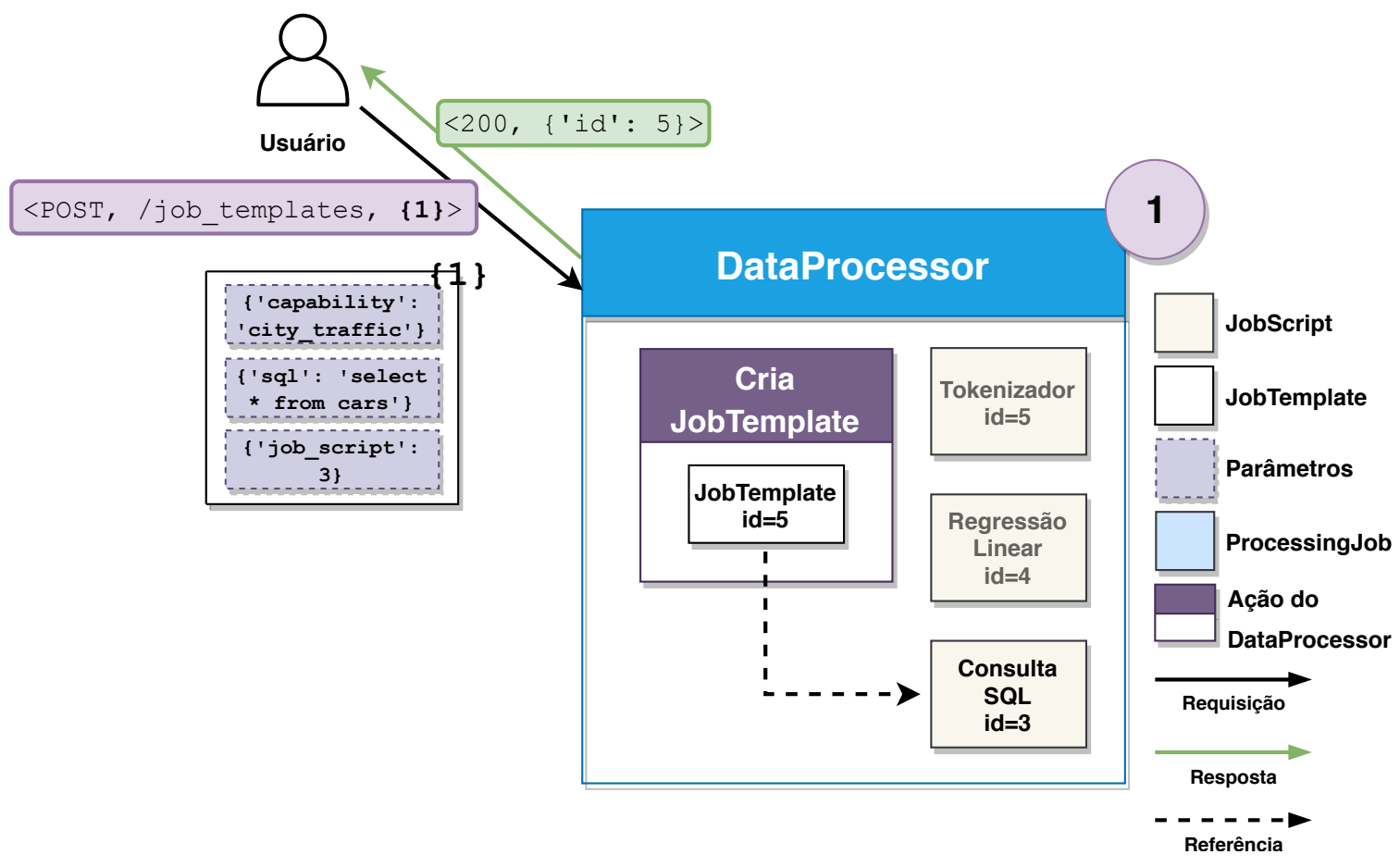

Figura 4.2: Passo 1 do fluxo de funcionamento do DataProcessor.

Após receber a requisição e criar o JobTemplate corretamente, o DataProcessor retornará ao usuário o identificador do JobTemplate. O identificador é usado pelo usuário posteriormente para execução das próximas tarefas do fluxo e, neste exemplo, tem valor

\footnotetext{
${ }^{7}$ Utilizamos essa notação para diminuir a poluição visual nas figuras.
} 
id=5. O Programa 4.1 traz o exemplo da chamada REST esperada pelo DataProcessor para a definição de um JobTemplate e utiliza a notação $\{\mathrm{V}, \mathrm{E}, \mathrm{P}\}$ mencionada anteriormente. Nessa requisição mostramos somente o primeiro parâmetro e truncamos os outros, onde o parâmetro mostrado define qual capacidade da InterSCity será utilizada. O DataProcessor deve responder com sucesso (código 200) e retornar o corpo do JobTemplate criado. No exemplo, só mostramos um parâmetro (título do JobTemplate) e truncamos os outros.

Programa 4.1 Exemplo de requisição REST feita ao DataProcessor para criação do JobTemplate e a resposta recebida.

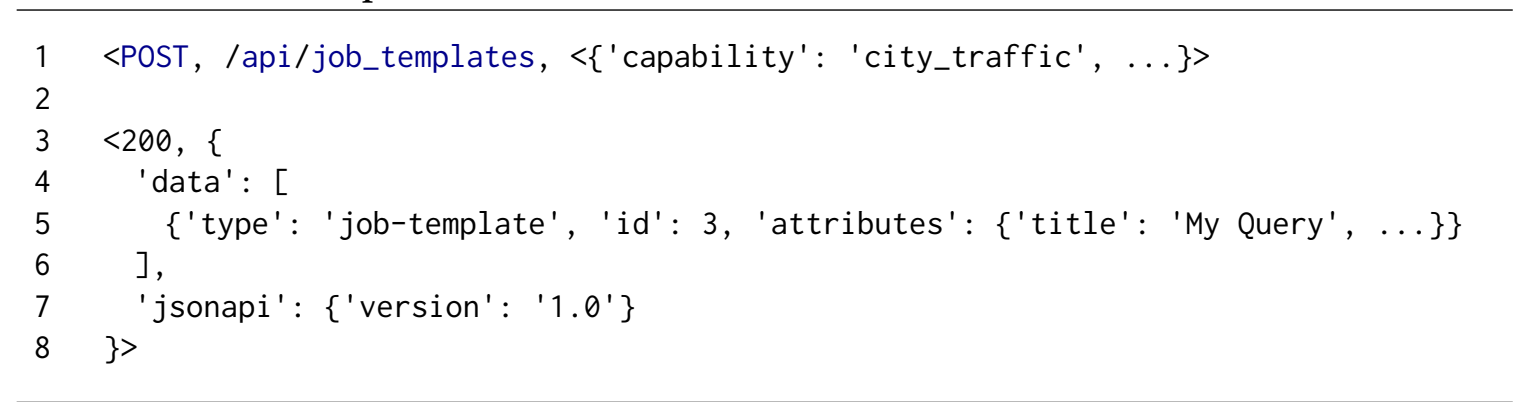

\subsubsection{Passo 2 - Definição do ProcessingJob}

Na etapa seguinte, descrita na Figura 4.3, ocorre a criação de um ProcessingJob, feito através de uma requisição REST ao endpoint job_templates/schedule, responsável por escalonar e materializar um novo ProcessingJob. O único parâmetro necessário na requisição é o identificador do JobTemplate que contém os parâmetros desejados, que em nosso cenário trata-se do identificador recebido no passo descrito em 4.4 .1 e tem valor $i d=5$.

O DataProcessor receberá a requisição e criará o Processing Job correspondente - neste exemplo, o ProcessingJob recebe id=2. Pela Figura 4.3, note que o novo ProcessingJob contém uma referência para o JobTemplate de id=5. Como esse JobTemplate tem referência para o JobScript de id=3, o ProcessingJob passa a ter acesso ao JobScript. Após a criação do Processing Job, ele passa a estar disponível para ser iniciado, o que dará início ao processamento dos dados pelo Spark. O Programa 4.2 contém a requisição REST esperada pelo DataProcessor.

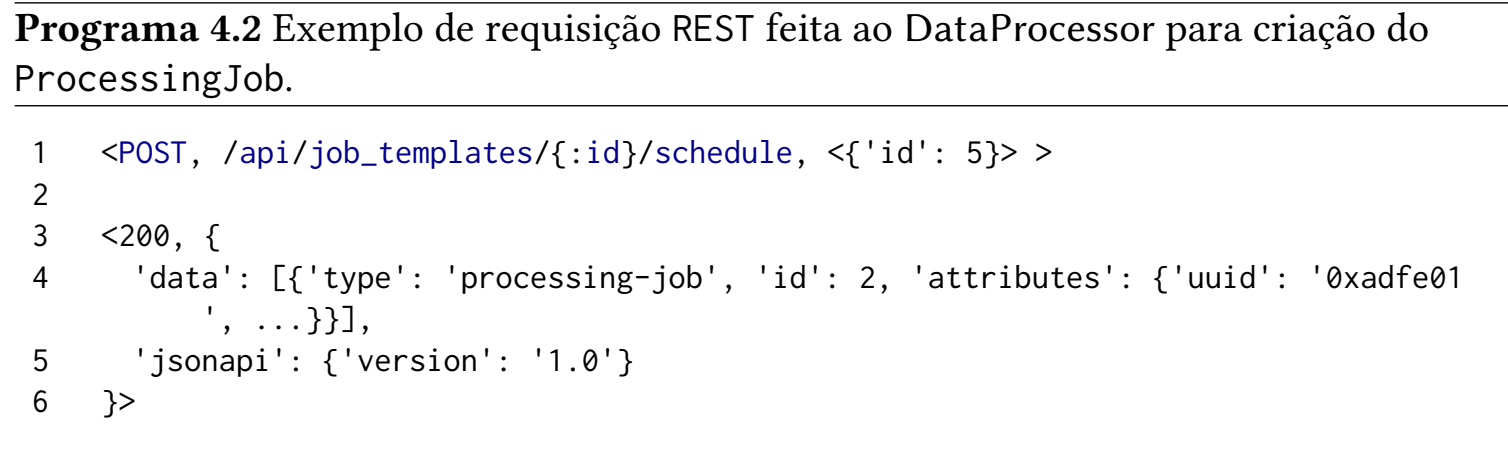




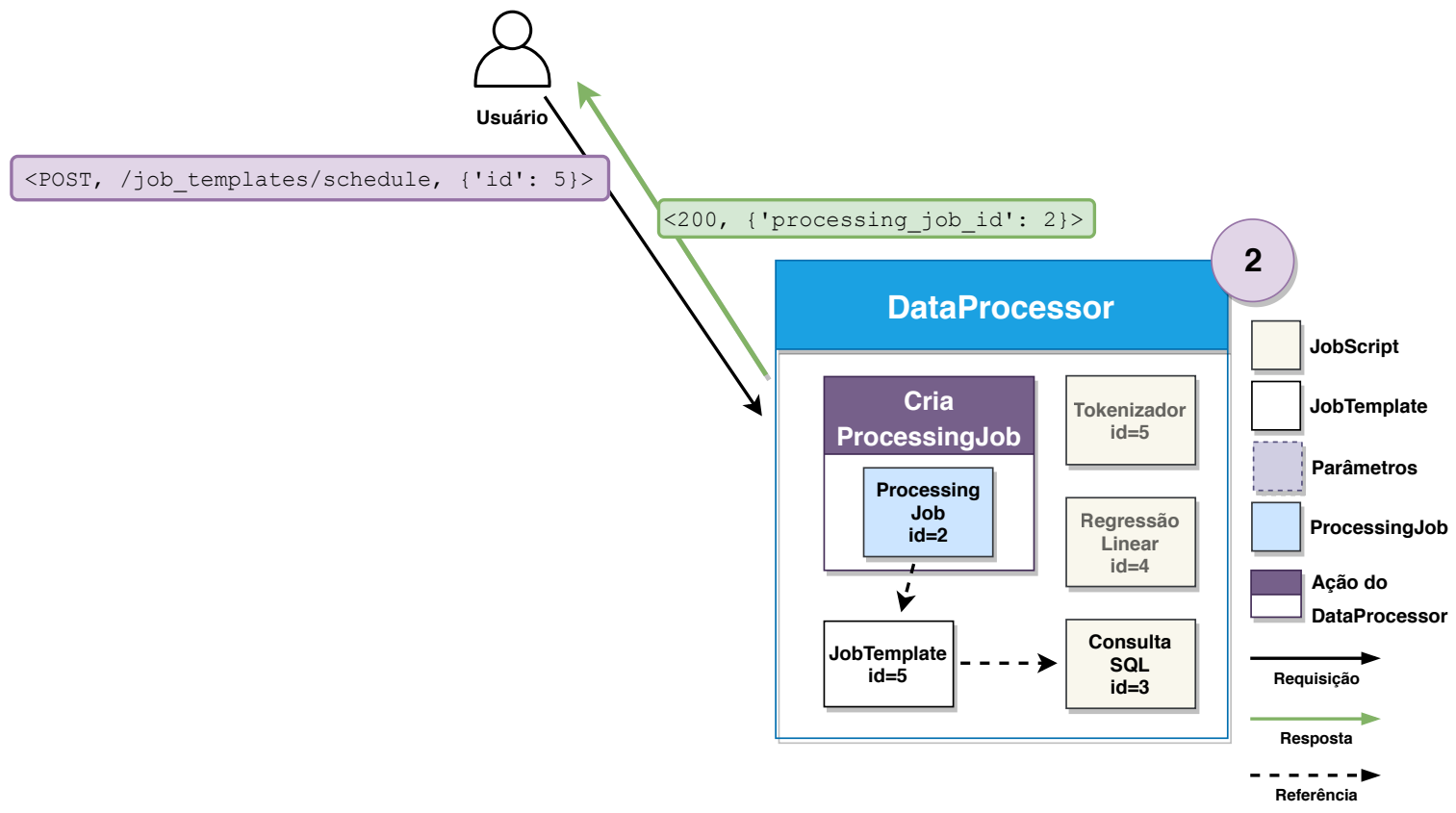

Figura 4.3: Passo 2 do fluxo de funcionamento do DataProcessor.

\subsubsection{Passo 3 - Execução do ProcessingJob e processamento dos dados.}

Este último passo é ilustrado na Figura 4.4 e, por ser maior, o dividimos em sub-passos. O seu início é marcado com o usuário iniciando o Processing Job através de uma requisição REST. O DataProcessor recebe a requisição no Passo 3.1 e, através do JobScript de id=3, gera o arquivo com o código nativo que executa a consulta SQL de forma distribuída (Passo 3.2). Em seguida, o Processing Job submete o código gerado para a ferramenta de processamento em cluster - em nosso caso, o Spark - para que a sua execução tenha início (Passo 3.3). O DataProcessor utiliza o código listado no Programa 4.3 para submeter o código, onde :mongodb_package, :generated_file e : job_template_id são parâmetros que serão alterados com o tempo. O primeiro desses parâmetros é qual a versão do conector do MongoDB, o segundo qual o caminho para o arquivo gerado através do JobScript e o terceiro é o identificador do JobTemplate.

Programa 4.3 Chamada que submete o código gerado para o Spark.

1 spark-submit --packages $\{$ :mongodb_package $\}$ : generated_file $\}$ : job_template_id\}

Após receber o código gerado, o Spark materializa e inicia o ProcessingJob que executa a tarefa requisitada. O Processing Job, durante sua execução, faz uma requisição REST ao DataProcessor para recuperar os parâmetros (Passo 3.4). O DataProcessor, ao receber a requisição, define neste momento qual o schema dos dados através do MongoDB e, em seguida, retorna o JobTemplate com os parâmetros e o schema dos dados (Passo 3.5). No Passo 3.6, o Spark extrai dados do MongoDB utilizando os parâmetros recebidos, materializa um DataFrame a partir dos parâmetros definidos e aplica transformações sobre ele conforme o código gerado pelo JobScript. Ao final, o DataFrame resultante 


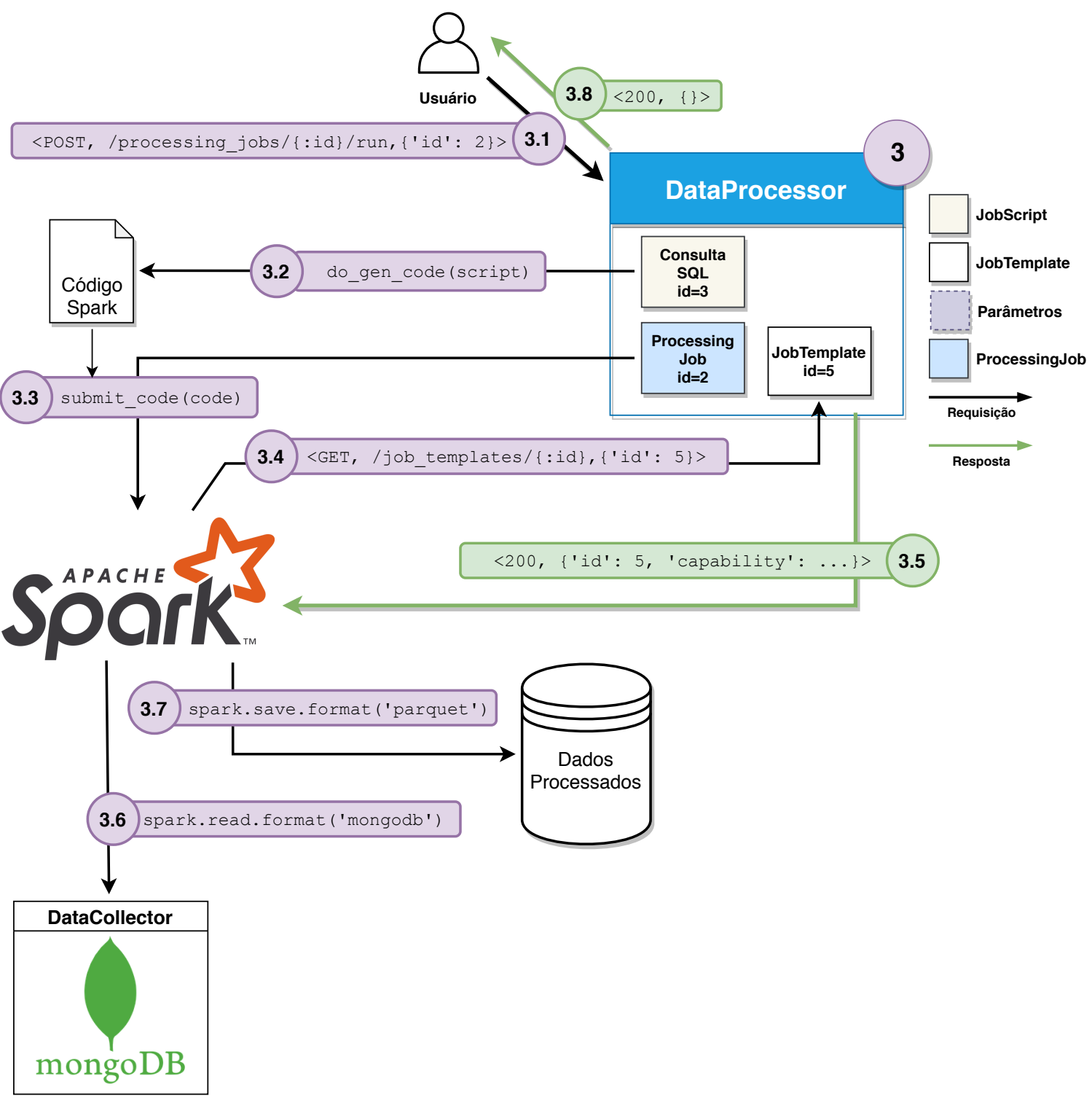

Figura 4.4: Passo 3 do fluxo de funcionamento do DataProcessor. 
é armazenado no sistema de arquivos utilizando a estratégia especificada pelo usuário anteriormente (Passo 3.7) e o DataProcessor retorna para o usuário o resultado do processamento (Passo 3.8). Na próxima seção, detalhamos melhor os endpoints disponibilizados pelo DataProcessor e quais as respostas esperadas.

\subsubsection{Endpoints}

A seguir sumarizamos os principais endpoints disponibilizados pelo DataProcessor, bem como suas responsabilidades, os parâmetros esperados e o retorno pelo servidor. Utilizamos a especificação JSON-API ${ }^{8}$ na maior parte dos endpoints, o que proporciona boa interoperabilidade com diversas ferramentas por tratar-se de uma especificação bem difundida. Os poucos endpoints que não o seguem são demasiadamente simples e não tratam especificamente da criação, remoção ou edição de um componente da arquitetura. 


\begin{tabular}{|c|c|c|c|c|}
\hline Verbo(s) & Endpoint & Responsabilidade(s) & Parâmetros & Retorno \\
\hline$[\mathrm{GET}, \mathrm{POST}]$ & /job_scripts & Lista ou cria JobScripts. & $\begin{array}{l}\text { [:strategy, :title } \\
\text { :path, :language, :code, } \\
\text { :defined_at_runtime, ... ] }\end{array}$ & $\begin{array}{l}{[<\mathrm{JobScript}>} \\
<\mathrm{JobScript}>, \ldots]\end{array}$ \\
\hline $\begin{array}{l}\text { [GET, PATCH, } \\
\text { DELETE] }\end{array}$ & /job_scripts/\{:id\} & $\begin{array}{l}\text { Retorna, edita ou remove um } \\
\text { JobScript específico. }\end{array}$ & :id & $<$ JobScript $>$ \\
\hline$[\mathrm{GET}, \mathrm{POST}]$ & /job_templates & Lista e cria JobTemplates. & $\begin{array}{l}{[\text { :job_script_id, :title, }} \\
: \text { capability, ...] }\end{array}$ & $\begin{array}{l}{[<\text { JobTemplate }>,} \\
<\text { JobTemplate }>, . .]\end{array}$ \\
\hline $\begin{array}{l}\text { [GET, PATCH, } \\
\text { DELETE] }\end{array}$ & /job_templates $/\{:$ id $\}$ & $\begin{array}{l}\text { Retorna, edita e remove um } \\
\text { JobTemplate específico. }\end{array}$ & :id & $<$ JobTemplate $>$ \\
\hline GET & /processing_jobs & $\begin{array}{l}\text { Lista todos os } \\
\text { Processing Jobs criados. }\end{array}$ & $\varnothing$ & $\begin{array}{l}{[<\text { ProcessingJob }>,} \\
<\text { ProcessingJob }>, \ldots]\end{array}$ \\
\hline$[G E T$, DELETE $]$ & $/$ processing_jobs/\{:id $\}$ & $\begin{array}{l}\text { Retorna e remove um } \\
\text { ProcessingJob específico. }\end{array}$ & :id & $<$ ProcessingJob $>$ \\
\hline POST & /job_templates/\{:id\}/clone & $\begin{array}{l}\text { Cria um novo } \\
\text { JobTemplate com } \\
\text { os mesmos parâmetros. }\end{array}$ & :id & $<$ JobTemplate $>$ \\
\hline POST & /job_templates/\{:id\}/schedule & $\begin{array}{l}\text { Cria um novo ProcessingJob } \\
\text { que referencie este JobTemplate. }\end{array}$ & : job_template_id & $<$ ProcessingJob $>$ \\
\hline POST & /processing_jobs/\{:id\}/run & Executa o Processing Job criado. & :processing_job_id & $\varnothing$ \\
\hline
\end{tabular}

Tabela 4.2: Lista de endpoints do DataProcessor. 


\subsection{Integração através de Geração de Código}

Os dois principais aspectos utilizados pelo DataProcessor para disponibilizar o processamento distribuído são (1) as interações com os usuários, feito principalmente através dos endpoints listados na Tabela 4.2, e (2) a geração de código Spark nativo. Descrevemos a seguir como sistematizamos essa geração de código e a API disponibilizada para sua extensão. As responsabilidades da geração de código são: (i) gerar o código responsável por definir o processamento dos dados pelo Spark; (ii) gerar o código que recupera os JobTemplates personalizados pelos usuários; e (iii) gerar o código responsável por extrair os dados do InterSCity, que os armazena em um banco de dados MongoDB.

A geração de código feita pelo DataProcessor utiliza a ideia de segmentos, que é uma classificação para as porções do código gerado; essas porções são quatro, sempre nesta ordem: cabeçalho (header), corpo (body), operação (operation) e rodapé (footer). A ideia dos segmentos surgiu pois, recorrentemente viamos trechos de código de mesmo fim atuando em uma mesma sequência. Por exemplo, independente do processamento que o usuário deseje, a importação das dependências ocorre no início do código enquanto o desalocamento dos recursos ocorre no final do código. Na Figura 4.5 listamos os quatro segmentos utilizados e o volume médio de cada um dos segmentos; o cabeçalho costuma ter mais linhas de código que o rodapé.

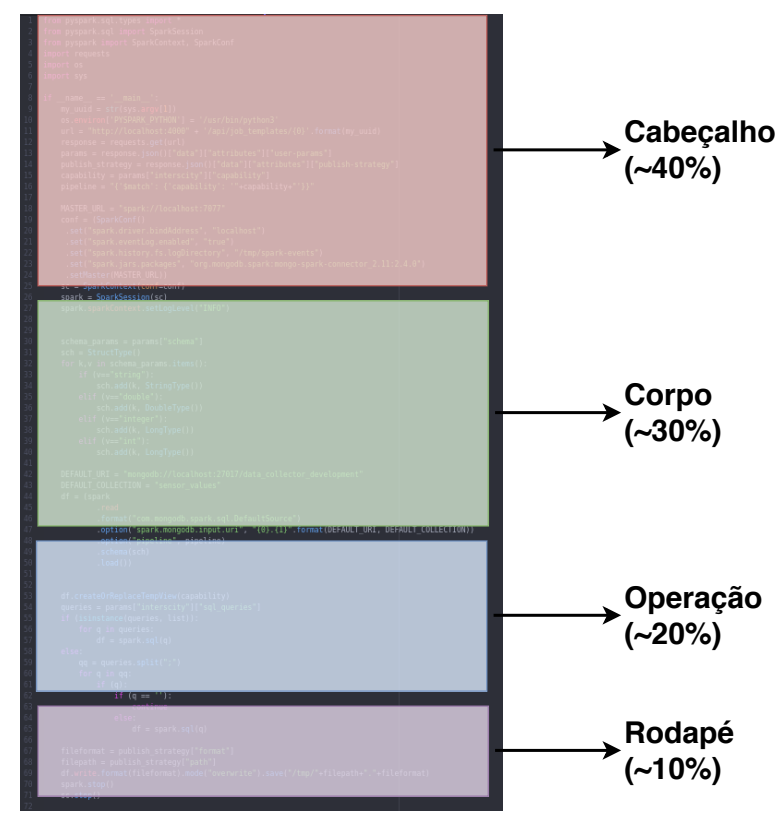

Figura 4.5: Ordem dos segmentos do código gerado e a proporção de código de cada segmento.

Em código, implementamos os segmentos em Elixir através de macros. Disponibilizamos no DataProcessor um módulo chamado CodeGen para ser utilizado como base por outras estratégias de geração de código, por conter implementações padrões para todos os quatro segmentos. O CodeGen utiliza a macro using para que, sempre que um módulo defina a linha __using_- CodeGen, código seja injetado. Assim, caso um usuário precise especificar somente um dos segmentos, é possível aproveitar as implementações presentes no CodeGen. 
O Programa 4.4 ilustra como definir uma estratégia de geração de código com um cabeçalho (header) personalizado para importar pacotes adicionais. A primeira linha define o módulo que contém a estratégia (nesse caso, MyModule) e na linha seguinte aplicamos a macro CodeGen. Com a aplicação da macro, uma série de funções são injetadas em MyModule, de modo que o desenvolvedor só precise sobrescrever o que ele deseja personalizar (nesse caso, o cabeçalho). Por último, na Linha 4, definimos o novo comportamento para o segmento de cabeçalho. Nessa nova versão do cabeçalho retornamos uma string com o código que interage com o pacote Seaborn. Em import seaborn as sns, por exemplo, o JobScript que utilizar a estratégia MyModule terá o seaborn disponível para uso; fazemos uso do seaborn na linha 7, onde a chamada sns. distplot (data=df) imprime a distribuição da variável $d f$. A seguir descrevemos cada um dos quatro segmentos, com exemplos de código. Em alguns casos, separamos um segmento em sub-segmentos menores para melhorar a granularidade de responsabilidades, facilitando a extensibilidade.

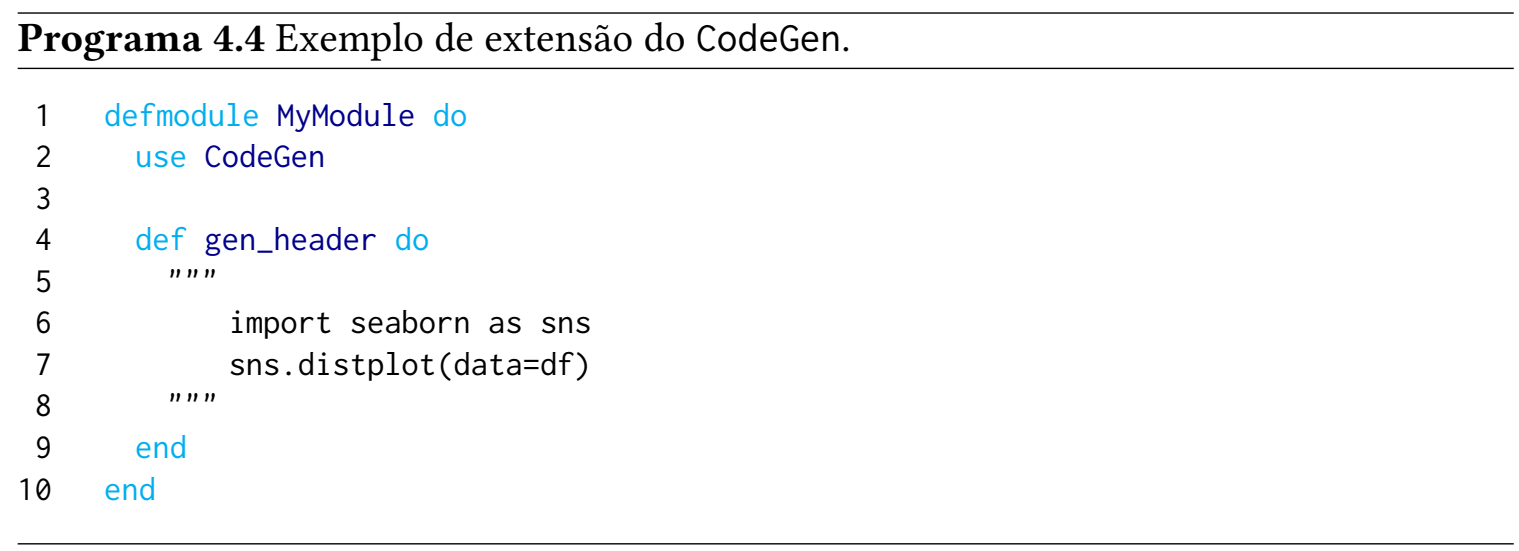

\subsubsection{Segmento Cabeçalho}

O primeiro segmento do código gerado é o cabeçalho, que tem três responsabilidades/sub-segmentos, listados a seguir com a sua respectiva assinatura:

header_commons() A primeira responsabilidade do cabeçalho é a importação das dependências e pacotes utilizados durante o processamento, feito através da rotina header_commons(). Alguns pacotes são obrigatórios, como o pyspark, mas o usuário pode aproveitar este segmento para importar, por exemplo, pacotes que ajudam na visualização de dados, como o Seaborn, ou pacotes que têm diversas operações úteis para a ciência de dados, como o SciKit;

request_template() A segunda responsabilidade do cabeçalho é a integração com o servidor do DataProcessor, através da rotina request_template(). É neste trecho de código que surge a consulta REST <GET, /job_templates/\{:id\}, \{'id' : 5\}>, que recupera os parâmetros definidos pelo usuário no respectivo JobTemplate. Como o request_template() ocorre antes das interações com o Spark, passa a ser possível tratar possíveis erros e inconsistências no JobTemplate antes de iniciar as interações com o cluster. Diferente da maior parte dos sub-segmentos, este provavelmente nunca precisará ser personalizado pelos usuários, dado que sua função é só a recuperação do JobTemplate, algo que deve ocorrer independente do uso desejado; 
spark_config() A última responsabilidade é a configuração inicial do Spark, através da rotina spark_config(). É neste trecho de código que o driver do Spark interage com o master para alocação dos executors e passa a estar pronto para executar o processamento de dados distribuído. De maneira geral, este sub-segmento dificilmente precisará ser modificado e, mesmo que precise, os desenvolvedores precisam o fazer com cautela, pois afeta diretamente a integração entre o Spark e o DataProcessor.

\subsubsection{Segmento Corpo}

O segundo segmento do código gerado é o corpo, que contém duas responsabilidades/sub-segmentos, já feitas através do processamento distribuído com uso do Spark:

mount_schema() A primeira responsabilidade do corpo é gerar o código que define o schema do DataFrame que será utilizado pelo Spark. Nesta etapa, o schema dos dados já encontra-se definido no JobTemplate referente, inferido pelo DataProcessor quando o Processing Job foi instanciado. É importante que este sub-segmento seja disponibilizado para extensão pois, futuramente, caso o Spark passe a adotar novos tipos de dados, um desenvolvedor pode estender a forma de montagem do schema para adicionar suporte ao novo tipo de dado disponível;

retrieve_collector_data() A segunda responsabilidade do corpo é recuperar os dados do MongoDB, ponto crucial da integração entre o InterSCity e o Spark, feito através através de uma consulta direta ao MongoDB com auxílio da API MongoConnector.

\subsubsection{Segmento Operação}

O terceiro segmento do código gerado é o de operação, que contém uma única responsabilidade: definir uma tarefa de processamento dos dados. Alguns exemplos típicos de segmentos de operação são: o trecho de código responsável por treinar um modelo de aprendizagem de máquina, ou por efetuar a limpeza dos dados. Por só ter uma responsabilidade, este segmento não tem sub-segmentos, e disponibiliza a sua extensão através da rotina gen_operation().

\subsubsection{Segmento Rodapé}

O último segmento do código gerado é o de rodapé, que também só apresenta uma responsabilidade: encerrar o processamento dos dados, feito através do fechamento de conexões (com o Spark) e desalocação dos recursos utilizados (principalmente pelo método unpersist() do Spark). A extensão deste segmento é feito através da rotina gen_footer(). 


\subsubsection{Visão geral do código gerado}

Compilamos no Programa 4.5 a representação de todos os segmentos e sub-segmentos utilizados pelo DataProcessor, fiel à implementação feita. Os trechos com \#nope devem ser substituídos por código Spark que executa aquela responsabilidade.

Programa 4.5 Visão geral da esquematização dos segmentos e sub-segmentos.

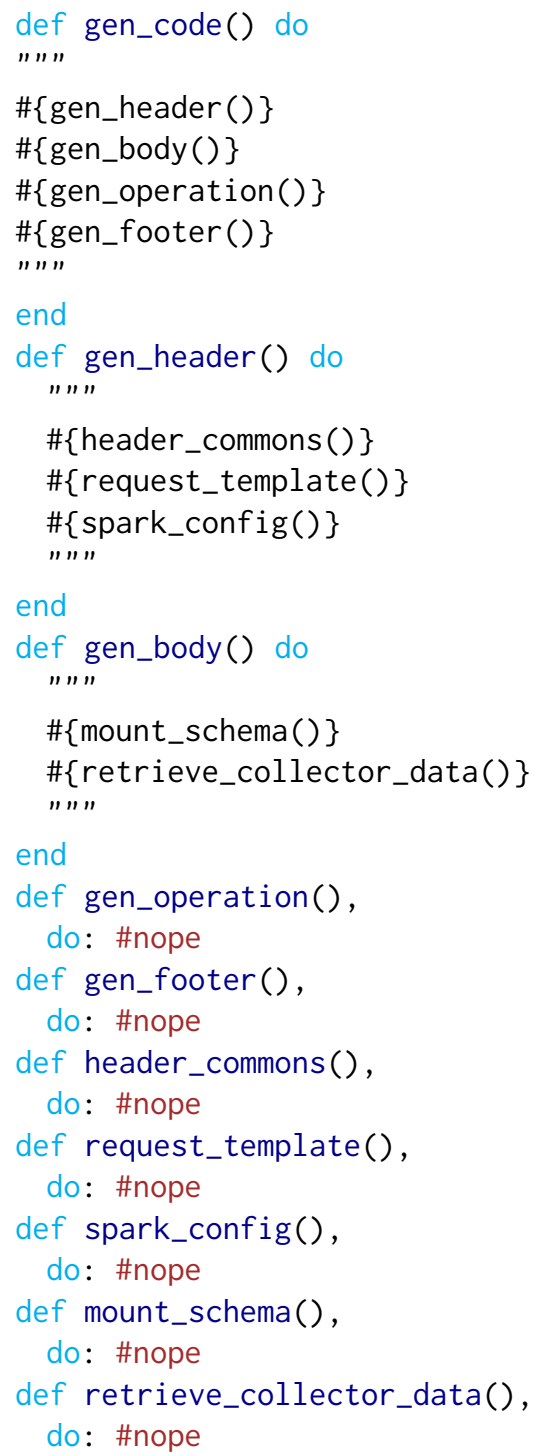

Apresentamos a seguir um exemplo prático de como um desenvolvedor utiliza o DataProcessor para uma tarefa de processamento. 


\subsection{Como visualizar percentis de um recurso armazenado na InterSCity?}

Nesta seção, solucionaremos um cenário que consiste em visualizar o percentil 99 de dados de recursos armazenados na InterSCity, calculados de forma distribuída com a ajuda do DataProcessor. O problema tem um caráter real no contexto de cidades inteligentes: sensores são capazes de gerar grande volume de dados em tempo real, mas a InterSCity, embora disponibilize os dados históricos armazenados, deixa a cargo do usuário o cálculo e processamento desses dados. Assumimos que o DataProcessor, Spark e a InterSCity já encontram-se instalados e configurados corretamente.

Separamos o cenário a ser resolvido em dois sub-problemas: o primeiro é o cálculo das métricas, enquanto o segundo diz respeito à visualização do resultado. Resolvemos o primeiro através de requisições ao DataProcessor, que irá calcular o percentil 99 através de uma consulta SQL processada pelo Spark. Para o segundo sub-problema, carregamos os resultados do processamento com auxílio da biblioteca Pandas ${ }^{9}$ e criamos uma visualização através da biblioteca Seaborn ${ }^{10}$.

Embora o segundo sub-problema dependa do primeiro, antecipamos seu resultado na Figura 4.6: o código do lado esquerdo ilustra como carregar os dados processados pelo DataProcessor em um DataFrame do Pandas e como visualizar os dados com um histograma. No código, importamos os pacotes necessários, criamos um novo DataFrame a partir do caminho 5-6-2019-13-59-52. parquet, que está no padrão de nomes que o DataProcessor utiliza para armazenar os resultados dos processamentos e, por fim, salvamos o gráfico da distribuição com o nome myplot.pdf. Do lado direito está a visualização gerada. No Eixo Y está a densidade de probabilidade das temperaturas e no Eixo $\mathrm{X}$ a temperatura em si. Por exemplo, há uma chance maior de ocorrer uma temperatura entre 20 e 30 graus que entre 30 e 40 graus.
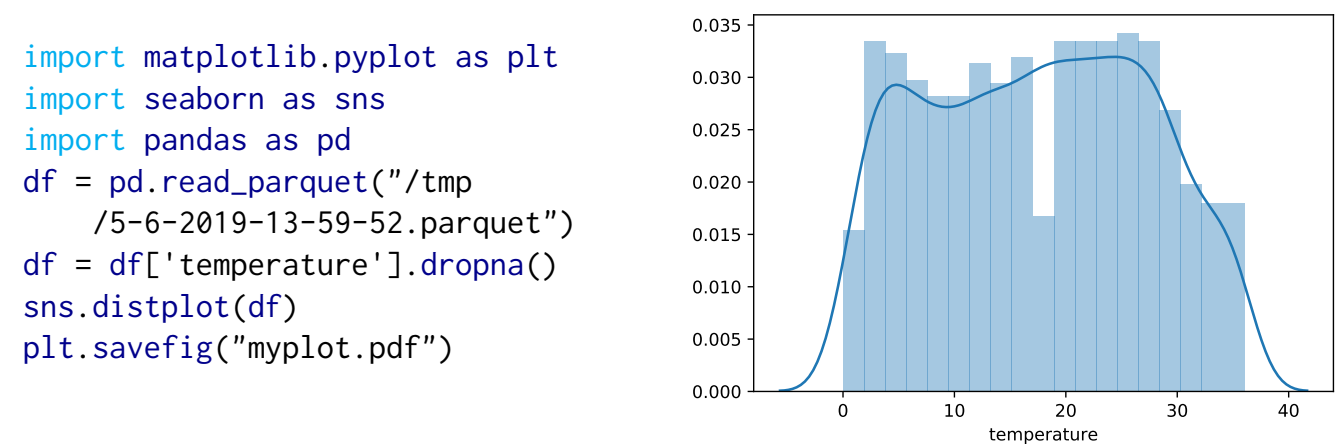

Figura 4.6: Carregamento dos resultados pelo Pandas e visualização através do Seaborn.

Já o primeiro sub-problema pode ser resolvido com auxílio do DataProcessor de ao menos quatro formas. Nas subseções seguintes apresentamos a utilização de cada uma dessas quatro formas, onde:

\footnotetext{
${ }^{9}$ pandas.pydata.org/

${ }^{10} \mathrm{https}$ ://seaborn.pydata.org
} 
- A primeira utiliza a API REST do DataProcessor e faz requisições aos endpoints listados na Tabela 4.2, mas sem qualquer auxílio extra na usabilidade;

- A segunda utiliza um pacote que facilita o uso de APIs que seguem o padrão JSON-API - o pacote JSON-API Client - JAC;

- A terceira utiliza um pacote Python que nós desenvolvemos para abstrair as requisições através de chamadas menos verborrágicas;

- A última, realiza a tarefa através de um serviço de visualização frontend para navegador que desenvolvemos durante este trabalho. Esse serviço consome os dados do DataProcessor e também tira proveito da especificação JSON-API para facilitar seu desenvolvimento.

\subsubsection{Uso por API Rest}

Para a resolução do primeiro sub-problema, devemos executar o fluxo apresentado na Seção 4.4. Contudo, o fluxo apresentado infere que existe um JobScript já criado, o que pode não ser o caso. Para ilustrar mais situações que podem ocorrer durante o uso do DataProcessor, neste exemplo incluímos a definição do JobScript que irá utilizar a estratégia de consulta SQL, feito através da requisição REST <POST, /job_scripts, @parameters>, com os seguintes parâmetros:

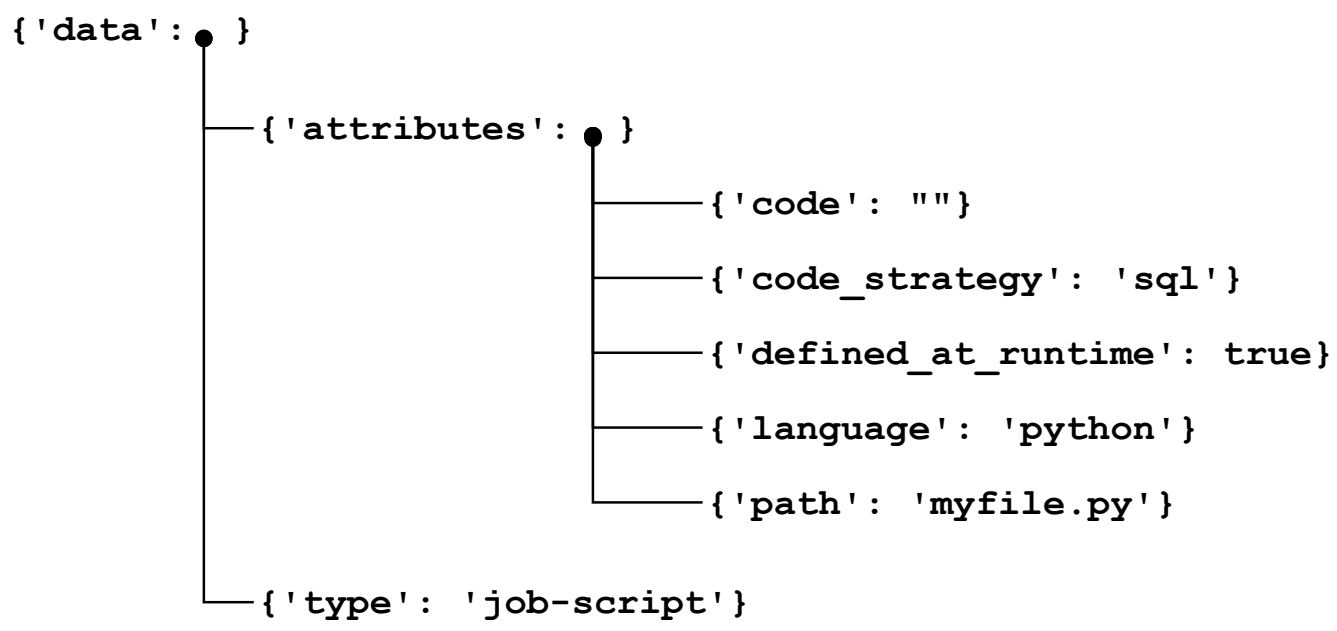

Podemos conferir a lista de JobScripts disponívels no DataProcessor através da requisição <GET, /job_scripts, \{\}>, que neste caso nos retornará:

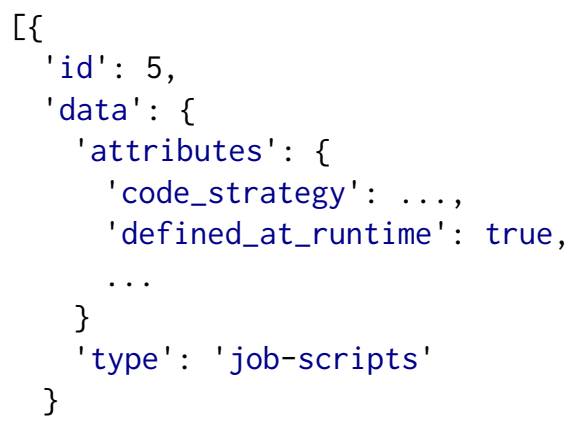




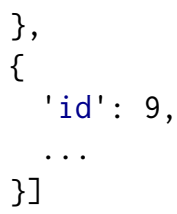

O JobScript criado tem identificador id=5, que utilizaremos nos passos seguintes. De acordo com o fluxo, agora definimos um JobTemplate apropriado, através da requisição <POST, /job_templates, P>, com os seguintes parâmetros P:

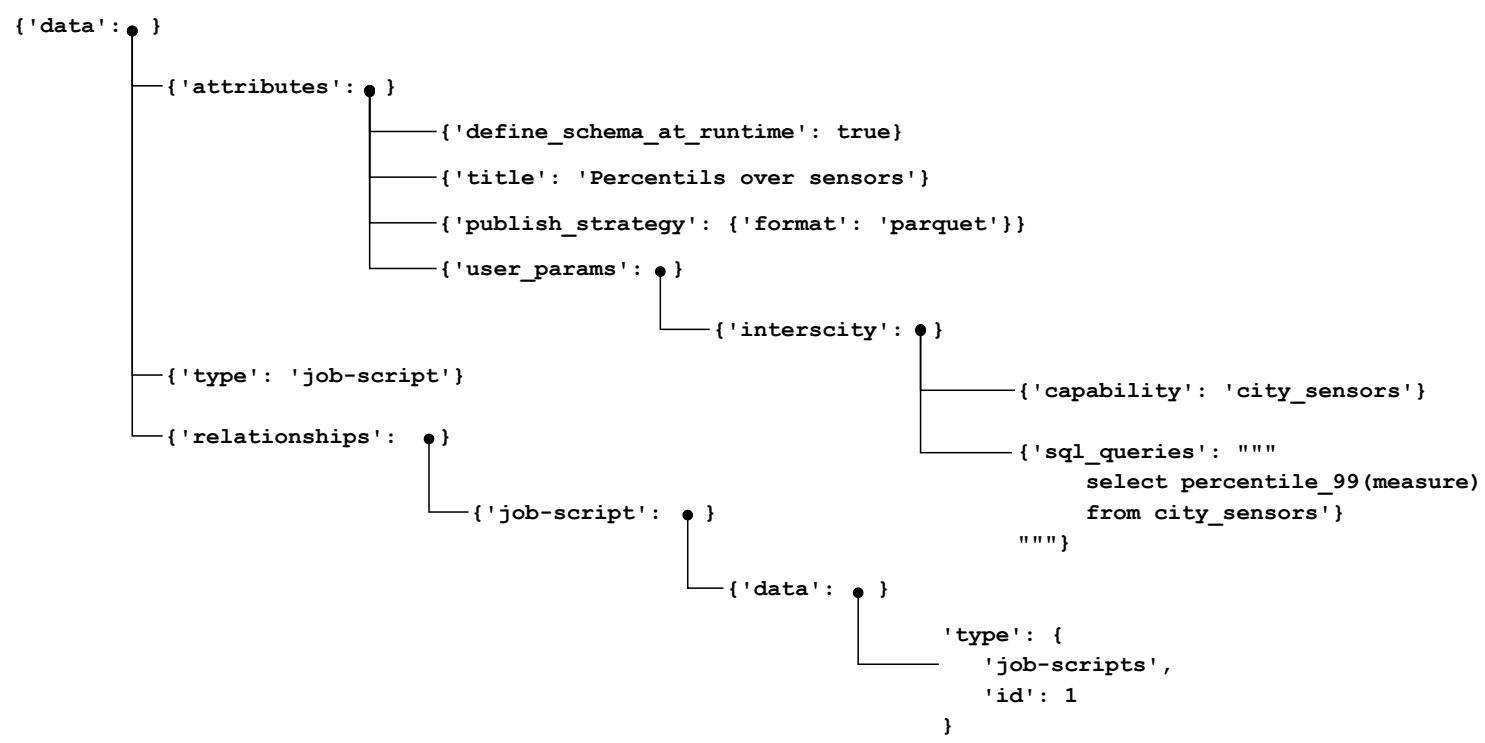

Com o JobTemplate criado, podemos finalmente iniciar o processamento distribuído através dos Processing Jobs. Criamos o ProcessingJob através da requisição

<POST, /api/job_templates/:id/schedule, \{'id': 1\}>,

que dá origem ao Processing Job de id=1. O último passo é iniciar a execução desse ProcessingJob, através da requisição

<POST, /api/processing_jobs/\{:id\}/run, \{'id': 1\}>

Ao final, o Spark deverá processar os dados dos sensores armazenados no InterSCity utilizando os recursos disponíveis e armazenará os resultados no sistema de arquivos do servidor.

\subsubsection{Uso por JSON-API}

O padrão JSON-API traz uma série de benefícios, como suporte à paginação e cache (LEE, 2019), mas trata-se apenas de uma especificação para organização dos dados das requisições REST feitas. Agora, exploramos o seu uso através de um pacote que utiliza a especificação para facilitar o preenchimento dos parâmetros. Em jsonapi.org/implementations/ é disponibilizado uma lista de pacotes que implementam a especificação com o objetivo de facilitar o uso de uma API que o siga, mas focaremos somente no uso do pacote JSON-API Client, que chamaremos de JAC daqui pra frente. 
A API do JAC é um pouco diferente das outras: primeiro, é necessário especificar o schema de todas as estruturas de dados que serão utilizadas (em nosso caso, do JobTemplate, do JobScript e do Processing Job) para a criação da sessão com o servidor (do DataProcessor). Após, para criar um novo JobTemplate, por exemplo, é necessário primeiro criar uma nova instância, preencher seus dados e ao final sinalizar o commit das mudanças, que é o passo que, de fato, envia a requisição REST ao servidor com os dados corretos. O código a seguir define o schema das estruturas do DataProcessor. Um ponto importante é que o schema não sofre qualquer tipo de alteração durante o uso do DataProcessor, mas é um código que precisa ser repetido toda vez que o JAC é utilizado ${ }^{11}$.

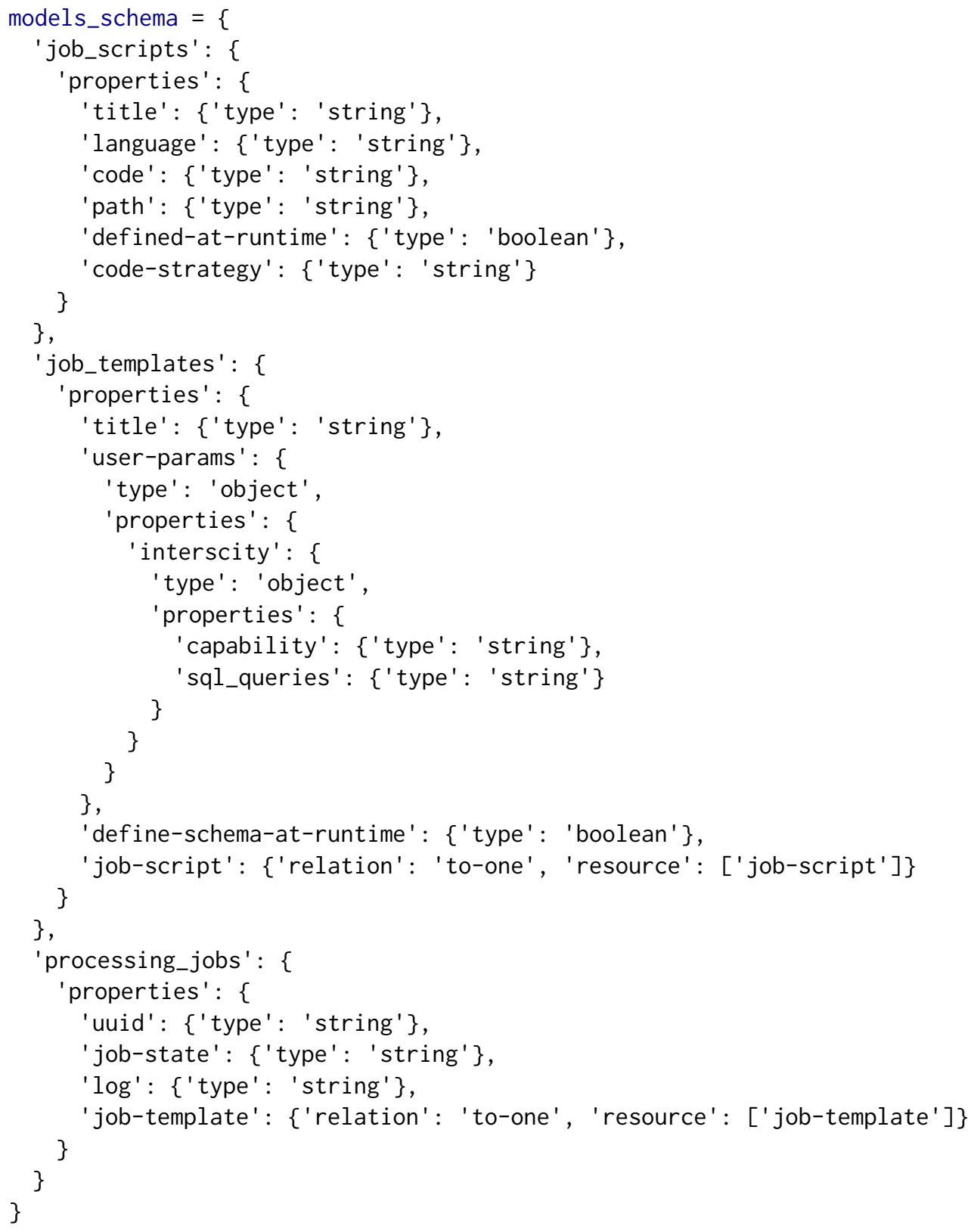

Em seguida, estabelecemos a sessão através do código $s=$ Session(url,

\footnotetext{
${ }^{11}$ A repetição do schema foi o nosso principal motivador para a criação do pacote que apresentamos na Seção 4.6.3.
} 
schema=models_schema). Com a sessão conectada e o schema definido, podemos começar a resolver o sub-problema, que era o nosso objetivo inicial. Seguindo os mesmos passos do uso da API anterior, começamos com a criação do JobScript:

\section{Programa 4.6 Criação do JobScript.}

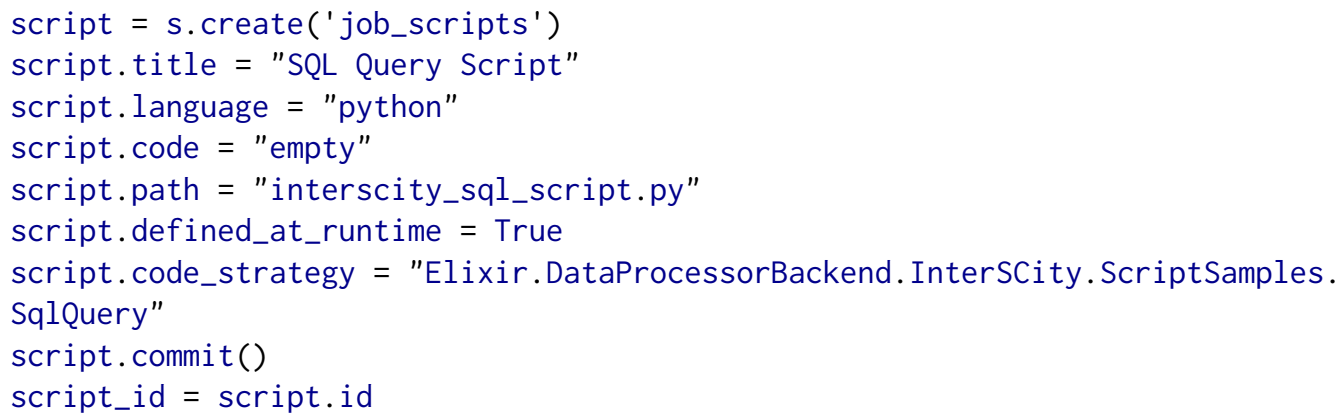

E, em seguida, definimos o JobTemplate

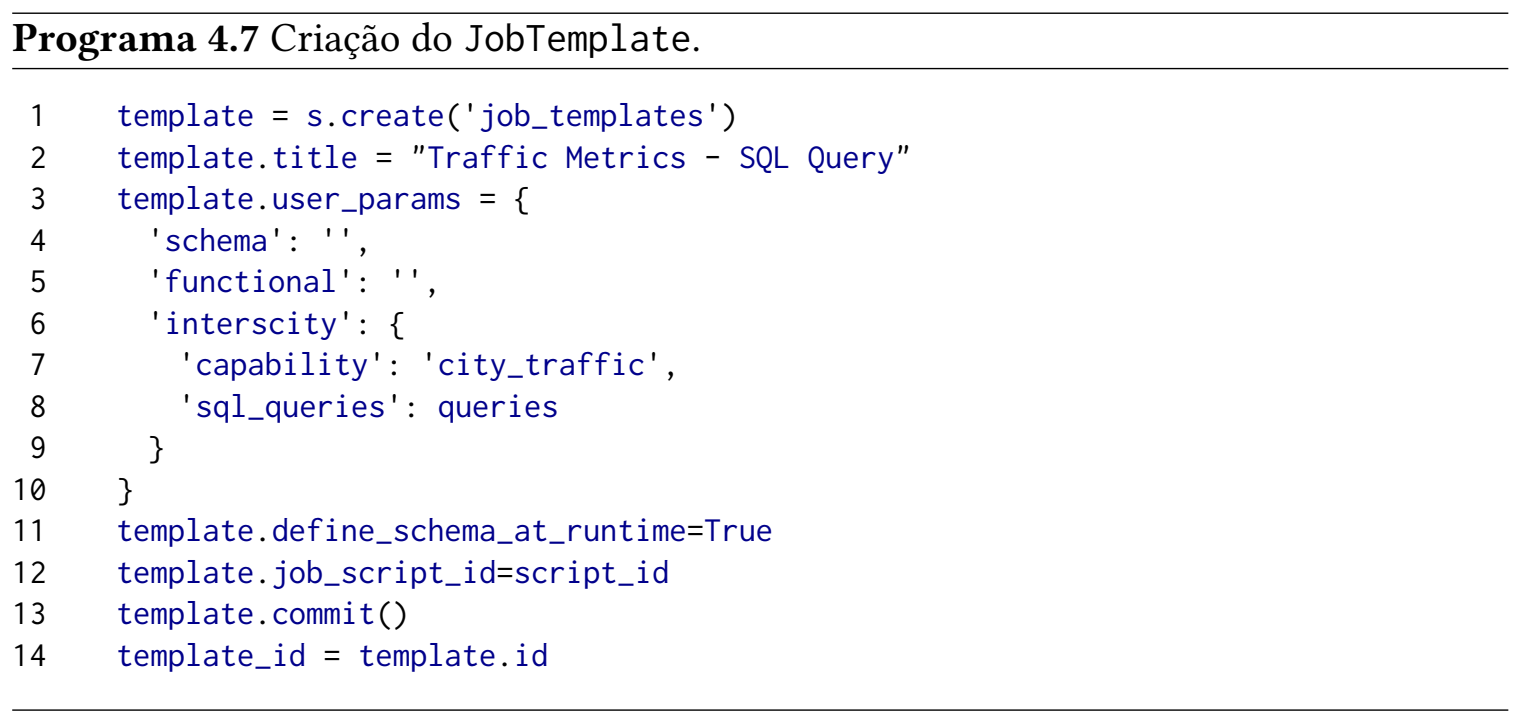

Por fim, finalizamos o sub-problema com a criação e execução do job. Como ambos endpoints não seguem o padrão JSON-API, utilizamos uma requisição REST normal sem o uso do JAC, idêntica á forma com que estávamos fazendo.

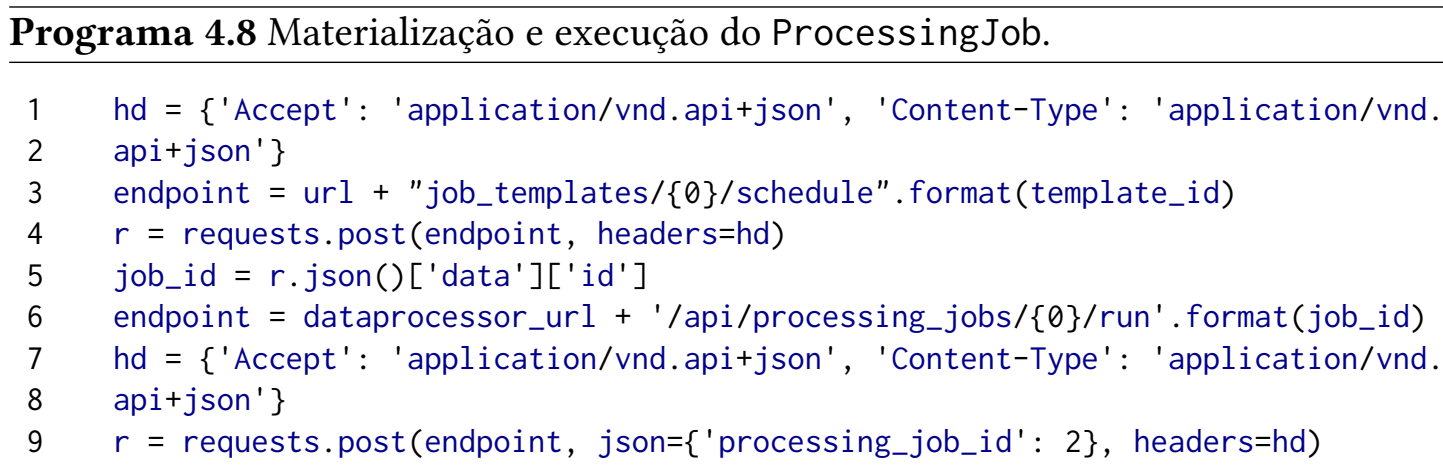




\subsubsection{Uso pelo dataprocessor_client}

Desenvolvemos um pacote Python chamado dataprocessor_client, disponibilizado em github.com/DylanGuedes/dataprocessor_client. O dataprocessor_client, como o nome indica, é um cliente para o DataProcessor que utiliza o JAC internamente para permitir que o usuário não precise se preocupar com a definição do schema apresentada anteriormente, que é verborrágica e repetitiva. O dataprocessor_client tem uma API simples mas sem tantas funcionalidades, que disponibiliza três métodos:

connect() Analisa se o DataProcessor está disponível e, se estiver, cria uma conexão com o servidor, que será utilizada nas outras chamadas.

sql(q, cap) Cria um JobTemplate que encapsula a consulta Q sobre os recursos com a capacidade cap e, em seguida, cria um Processing Job que executa uma consulta SQL utilizando os parâmetros do JobTemplate criado. O retorno do método é o identificador do Processing Job, utilizado no método que vem a seguir.

process(processing_job_id) Inicia o ProcessingJob com identificador processing_job_id.

O Programa 4.9 também resolve subproblema, mas através de uma quantidade menor de linhas de código, por conta do auxílio do pacote dataprocessor_client.

\section{Programa 4.9 Uso do pacote dataprocessor_client.}

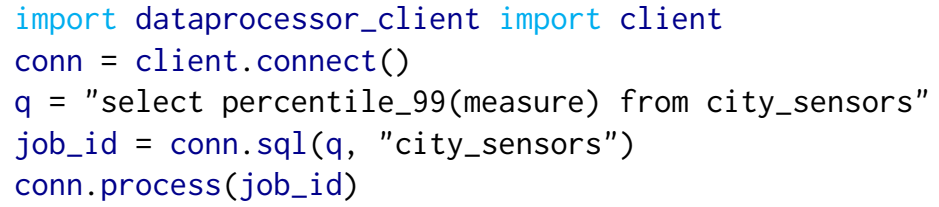

\subsubsection{Uso do serviço dataprocessor-frontend}

Também consideramos disponibilizar uma forma de interação gráfica com o DataProcessor, o que nos levou à implementação de um serviço de frontend para apresentação dos dados, disponibilizado em github.com/dylanguedes/data-processor-frontend. Escrevemos o serviço em Ember JS ${ }^{12}$ e o fato de termos utilizado o padrão JSON-API facilitou seu desenvolvimento, já que o EmberJS conta com uma série de facilidades prontas em cenários em que o servidor backend atende a especificação.

A Figura 4.7 apresenta a tela de criação JobScript, que é a primeira tarefa feita nas outras soluções. Nomeamos o JobScript de Consulta SQL, já que qualquer consulta SQL pode ser feita com seu uso. Marcamos a opção de gerar código em tempo de execução, que significa que toda a lógica da Seção 4.5 será seguida (caso contrário, ela é ignorada e o código no campo Script Code é utilizado no lugar).

\footnotetext{
${ }^{12}$ emberjs.com/
} 
$\equiv$

New Script

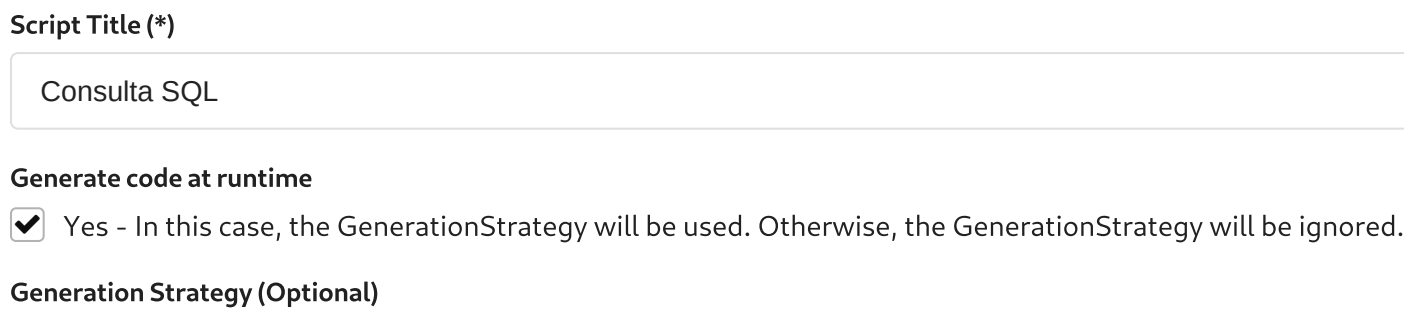

Figura 4.7: Tela de preenchimento dos dados do JobScript.

Na segunda tela, Figura 4.8, preenchemos o JobTemplate. Note que o campo Script recebe como valor o título do JobScript definido na figura anterior - contudo, não é necessário gravar o nome, pois o serviço auto-completa com os nomes possíveis (e, no nosso caso, são poucos). A caixa do terceiro-campo indica que o schema será definido em tempo de execução de criação do ProcessingJob. Caso contrário, é necessário que o usuário especifique todo o schema dos dados.

Na terceira tela, Figura 4.9, criamos o Processing Job através da ação schedule. Outras ações possíveis são a clonagem, que cria um JobTemplate idêntico, e a deleção, que remove o JobTemplate.

Por fim, na quarta tela, Figura 4.10, apresentamos a tela de listagem de Processing Jobs. O ProcessingJob que criamos está com estado unknown pois ainda não foi iniciado. $\mathrm{O}$ JobTemplate e o JobScript apresentam os dados dos JobTemplate e JobScript associados àquele Processing Job e a última ação contém botões responsáveis por diferentes ações. O primeiro executa o ProcessingJob, o segundo não está funcional mas é esper- 


\title{
New Template
}

\author{
Title \\ Percentis de Temperaturas \\ Script
}

Consulta SQL

Define schema at runtime

$\checkmark$ Yes - In this case, the resource schema will be inferred from MongoDB. Otherwise, you must provide the schema through InterSCity params.

Publish Strategy

output .parquet -

\section{Add Template}

Figura 4.8: Tela de preenchimento dos dados do JobTemplate.

\section{$\equiv$}

\section{Percentil de temperatura}

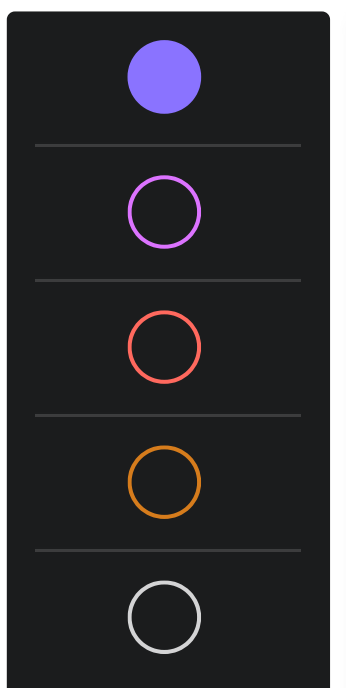

\section{Actions}

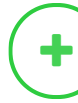

Schedule a new job to process InterSCity's data using this parameters.

Clone this operation to create a new one that has the same parameters.

Delete this query. Forever.

Figura 4.9: Instanciamento de um novo JobScript para o JobTemplate "Percentis de temperatura”. 
ado que execute uma prévia do processamento, o terceiro lista informações e o log do Processing Job e o último botão o remove.

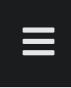

\section{Processing Jobs}

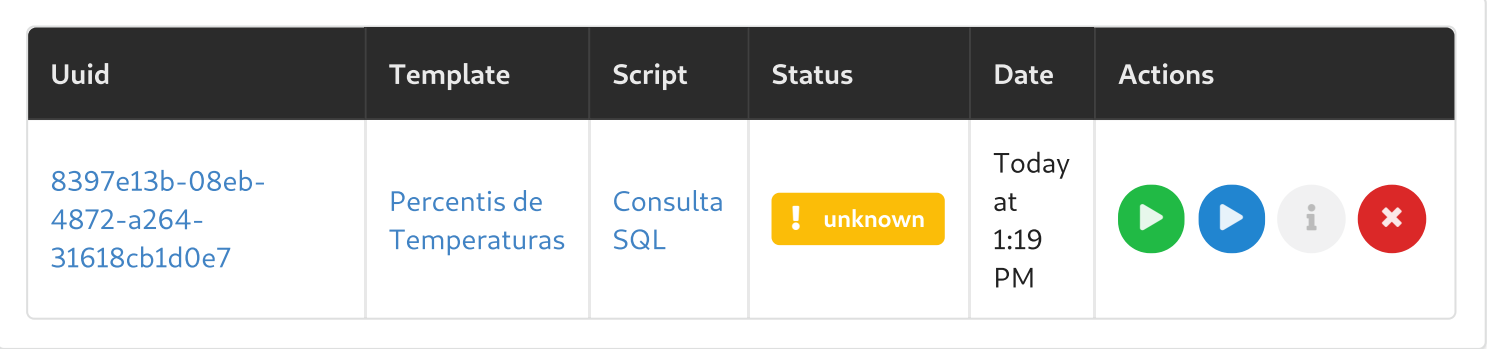

Figura 4.10: $L$ istagem dos Processing Jobs. O botão verde dá início ao Processing Job, que irá lançar um job do Spark para processamento dos dados.

Ao final, assim como das outras formas, os dados processados estarão disponíveis no sistema de arquivos do host em que o servidor do DataProcessor encontra-se em execução.

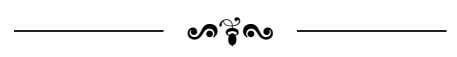

Neste capítulo apresentamos detalhes do DataProcessor. Partimos das definições de mais alto nível, com sua história e requisitos, para definições de mais baixo nível, como quais as tecnologias mais apropriadas e detalhes de sua implementação. Finalizamos com a sistematização da geração de código, que é a forma utilizada pelo DataProcessor para prover o processamento distribuído com boa usabilidade, e com um exemplo de uso, que ilustra como utilizar as diferentes APIs disponíveis. No capítulo seguinte tratamos da avaliação do DataProcessor, que busca quantificar a implementação quanto a três requisitos: usabilidade, extensibilidade e desempenho. Também exploraremos como adicionar novas funcionalidades ao DataProcessor e como o utilizar com outra ferramenta de processamento de dados. 



\section{Capítulo 5}

\section{Avaliação Experimental}

Após o desenvolvimento do DataProcessor, onde colocamos em prática as nossas hipóteses e ideias sobre como deveria ser adicionado suporte para integração distribuída em uma plataforma de cidades inteligentes, passamos para a fase de avaliação, documentada neste capítulo. A nossa avaliação baseia-se em comparações de diferentes pontos de vista entre uma solução que utilize o DataProcessor e uma solução que utilize o Spark diretamente.

Avaliamos o DataProcessor em três frentes, que fazem parte dos quatro requisitos seguidos pelo trabalho e listados na Seção 4.1: usabilidade, extensibilidade e desempenho. Essas avaliações foram exploradas de diferentes formas, onde:

- Avaliamos o desempenho e a usabilidade através de um experimento que utilizou dados simulados gerados pelo simulador InterSCSimulator. A intenção era diagnosticar a degradação de desempenho advinda do uso do DataProcessor, onde desempenho em nosso contexto significa o tempo necessário para finalizar o processamento de uma tarefa; e avaliar a facilidade de uso empregada pelo uso do DataProcessor;

- Avaliamos a extensibilidade através de uma prova de conceito que consiste em estender o DataProcessor com a intenção de definir K centroides de um conjunto de dados com o algoritmo k-Means. O objetivo é demonstrar a flexibilidade do DataProcessor para a adição de funcionalidades não previstas, que julgamos importantes para o uso prolongado de um middleware de integração.

Os experimentos e estudos de caso utilizam dados relacionados ao trânsito por termos à disposição o simulador de trânsito de São Paulo InterSCSimulator e por ser um contexto comum de cidades inteligentes. Começamos a avaliação com um primeiro experimento, que consistiu em calcular métricas de dados do trânsito. 


\subsection{Experimento - Cálculo de métricas do trânsito}

Em São Paulo, a SPTrans ${ }^{1}$ é o órgão do governo responsável pelo incentivo, planejamento e fiscalização do desenvolvimento tecnológico relacionado ao trânsito, o que inclui como responsabilidade a disponibilização dos dados dos ônibus da cidade. Contudo, o único dado disponibilizado é a localização dos veículos no tempo, através da API OlhoVivo².

A Figura 5.1 apresenta quais dados são disponibilizados pela SPTrans. A esquerda da imagem mostra o deslocamento de um ônibus identificado como $0 \times A B C$ pelo caminho $A \leadsto E$, que dura pouco menos de 11 minutos. Do lado direito é apresentado em que formato os dados da imagem são disponibilizados para os desenvolvedores. Pela figura, é possível inferir que o ônibus gastou 33 segundos entre os vértices $C$ e $D$, por exemplo.
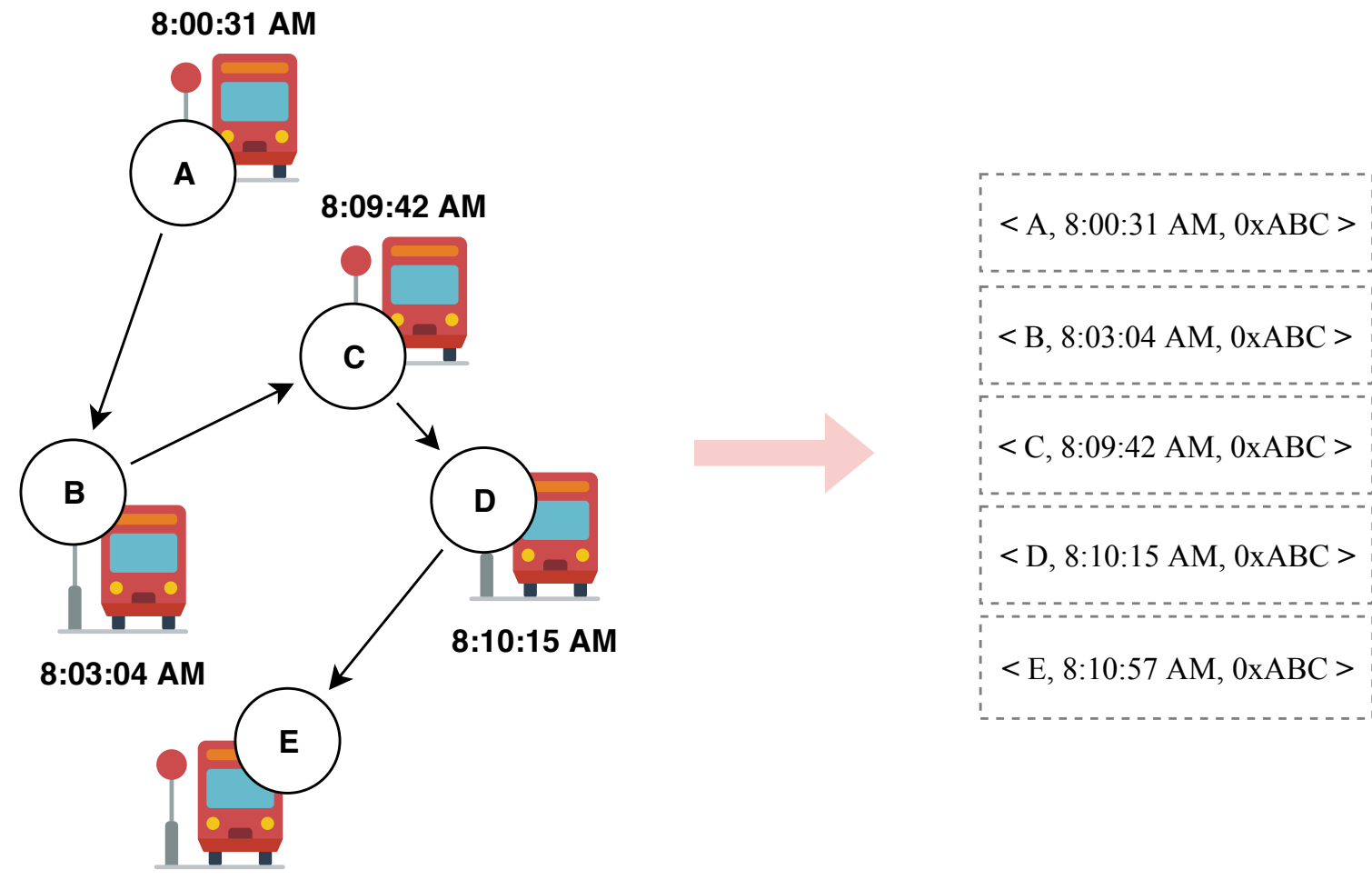

8:10:57 AM

Figura 5.1: Deslocamento do ônibus $0 \times A B C$ sobre o grafo da cidade em um formato semelhante ao fornecido pela SPTrans.

Embora os dados disponibilizados sejam úteis por si só, é possível explorá-los com a intenção de aumentar as possibilidades de uso por aplicações de cidades inteligentes. $\mathrm{O}$ dado apresentado não diz, por exemplo, a velocidade do veículo, tão pouco qual o estado do trânsito: o veículo $0 x A B C$ pode ter demorado mais de 5 minutos no trecho $B \sim C$ pelo fato do trecho estar congestionado, mas outro motivo possível é o fato do trecho simplesmente ser mais longo. Contudo, com a exploração dos dados de ônibus disponibilizados, é possível

\footnotetext{
${ }^{1}$ www.sptrans.com.br/

${ }^{2}$ www.sptrans.com.br/desenvolvedores/api-do-olho-vivo-guia-de-referencia/
} 
calcular desde a velocidade do trecho até métricas dessas velocidades, como a média e o desvio padrão, que podem ser úteis posteriormente para dar origem a novas informações, como: qual a melhor rota para se chegar a um caminho, ou: quanto tempo um ônibus irá demorar para alcançar um determinado ponto de ônibus.

Neste experimento, avaliamos o desempenho e a usabilidade do DataProcessor através do seu uso para o cálculo de desvio padrão e média de velocidade de trechos do trânsito a partir de dados brutos semelhantes aos dados disponibilizados pela SPTrans. Geramos dados realistas da cidade de São Paulo através do simulador de larga escala InterSCSimulator utizando como base dados da pesquisa Origem Destino 2007, armazenamos os dados gerados no banco de dados da plataforma InterSCity com auxílio do ResourceAdaptor e utilizamos o processamento em cluster provido pelo Spark via o DataProcessor. Dado que o nosso principal objetivo com o experimento é avaliar o desempenho e a usabilidade do DataProcessor em relação ao uso direto do Spark, comparamos duas soluções, uma que utiliza o DataProcessor e outra que utiliza o Spark diretamente.

\subsubsection{Definições do Cenário}

Inicialmente, definimos um conjunto de restrições para o experimento com o objetivo de definir fronteiras do que era necessário ou não para que as análises fossem feitas sob um cenário conclusivo. Focamos em três restrições: o volume de dados deveria ser grande o suficiente para justificar o processamento em cluster; os dados deveriam estar armazenados no InterSCity, pois trata-se de um trabalho de integração entre a plataforma e o Spark; e, tanto o Spark quanto o simulador e a plataforma deveriam ser executados em modo distribuído no experimento.

Para cumprir a primeira restrição, definimos que a simulação seria de um dia completo (24 horas) e que simularia 500.000 viagens baseadas na Pesquisa Origem Destino $2007^{3}$. Durante a simulação, a cidade é vista como um grafo onde as ruas são os vértices e seu encontro são as arestas e, a cada transição entre um vértice e outro durante uma viagem, armazenamos em um conjunto de dados qual o veículo referente e que transição de vértices foi essa. O assinatura utilizada por essas transições é <nodeID, tick, uuid>, onde nodeID é o identificador do vértice do grafo, tick é o tempo (em segundos) da simulação em que a transição de vértice ocorreu e uuid é o identificador da viagem.

Ao final, o conjunto de dados ocupou o espaço em disco de $12 \mathrm{~Gb}$, que é um volume de dados suficiente para tirar proveito do processamento distribuído. Poderíamos utilizar mais dados no experimento, mas o volume de dados já era suficiente para avaliar a distribuição das tarefas, de modo que ter mais volume não faria qualquer diferença em nossas análises.

Para a segunda restrição, preparamos o simulador para enviar dados de cada veículo simulado para a instância do RabbitMQ utilizada pela plataforma. Instâncias do DataCollector extraem os dados presentes na fila do RabbitMQ e os escrevem na instância do MongoDB utilizado pela plataforma. A Figura 5.2 ilustra essa comunicação: diversos veículos, em tempo-real, enviam seus dados para uma fila específica do RabbitMQ e diferentes instâncias

\footnotetext{
${ }^{3}$ www.metro.sp.gov.br/pesquisa-od/
} 
do DataCollector, também em tempo real, extraem os dados da fila. Em nossas primeiras tentativas de execução do experimento utilizamos só uma instância do DataCollector, mas a fila do RabbitMQ crescia tão rapidamente que o computador, eventualmente, utilizava toda a memória disponível, causando a interrupção da simulação.

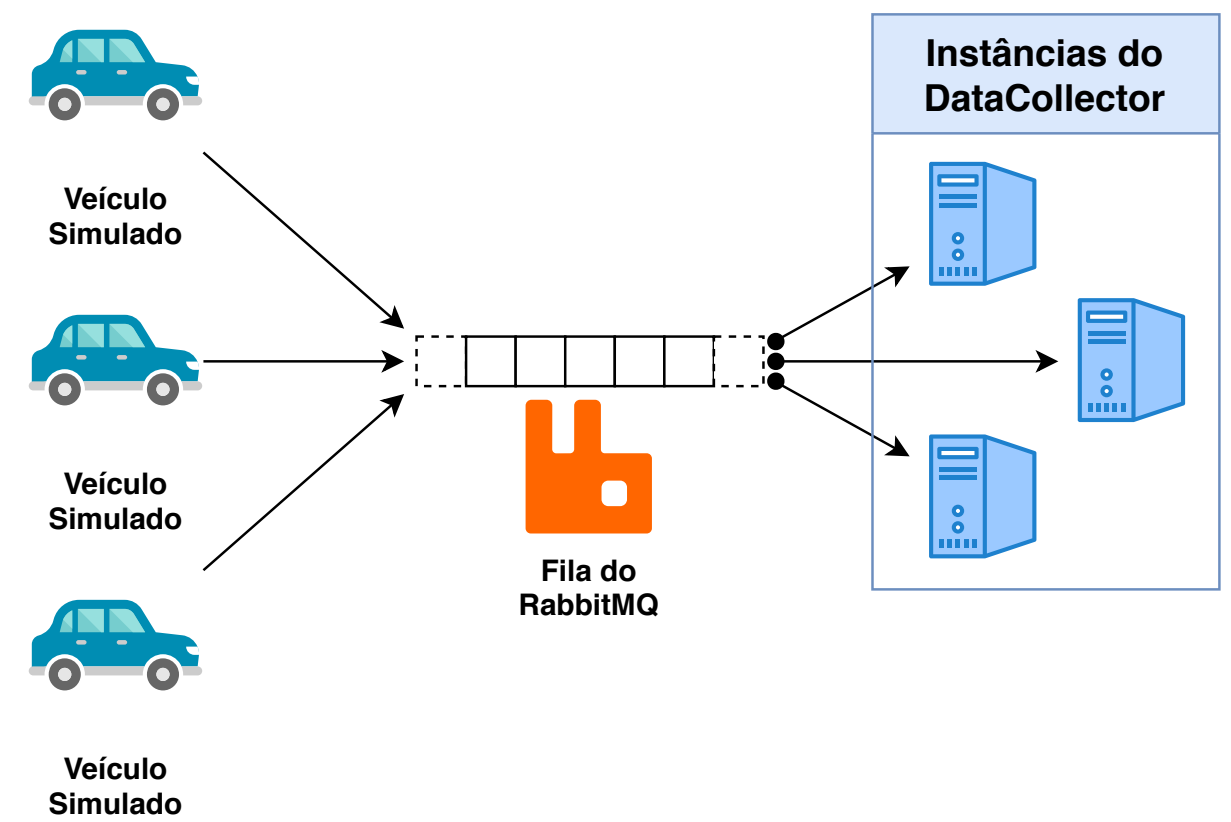

Figura 5.2: Transferência dos dados simulados, gerados pelo InterSCSimulator, para o DataCollector do InterSCity, feito através da API produtor-consumidor do RabbitMQ.

Por fim, para a terceira restrição, executamos os passos presentes nas documentações dos três projetos. Tivemos problemas para executar o simulador de forma distribuída, o que deu origem às contribuições ao InterSCSimulator, descritas no Capítulo 6 e na próxima subseção; com a nova versão do simulador, disponível em github.com/dylanguedes/ interscsimulator-blue, foi possível utilizar diversos computadores em modo distribuído para simular o trânsito de São Paulo.

\subsubsection{Execução da Simulação}

Para a realização do experimento, alguns ajustes foram necessários: (i) escrever os arquivos de entrada da simulação; (ii) aplicar correções ao simulador, onde a mais importante consistia em adicionar suporte à simulação distribuída ao simulador, vide a terceira restrição mencionada; (iii) configurar e preparar uma instância da plataforma InterSCity; e (iv) preparar o DataProcessor e o Spark para processar os dados.

Para definir os arquivos de entrada da simulação, utilizamos como base arquivos anteriores disponíveis no repositório do InterSCSimulator ${ }^{4}$, que já utilizavam como base a pesquisa Origem Destino 2007. Contudo, fizemos algumas adaptações dado o nosso contexto, que resultou em mais algumas contribuições relevantes ao simulador.

\footnotetext{
${ }^{4} \mathrm{O}$ arquivo de viagens utilizado como base encontra-se disponível em: https://github.com/ ezambomsantana/smart_city_model/blob/master/sp_completo/trips.xml
} 
O segundo ajuste teve origem numa tentativa inicial de execução da simulação: a simulação não finalizava com sucesso com as 500.000 viagens quando utilizávamos apenas um computador. Inicialmente, executamos a simulação em modo distribuído sem sucesso, pois o InterSCSimulator utiliza um banco de dados em memória disponibilizado pelo Erlang chamado ETS. As instâncias da ETS não são replicadas entre os nós da simulação, de modo que, caso o Nó A insira um dado chave-valor e o Nó B tente ler essa chave, um erro ocorrerá, pois a chave não estará disponível. Outro problema é que a simulação é interrompida sempre que uma dessincronização é detectada, e várias dessincronizações ocorriam. Consertamos esse último problema ao trocar algumas chamadas de funções e, após os ajustes, a distribuição dos nós da simulação passou a funcionar corretamente.

Por fim, para configurar o Spark e o InterSCSimulator bastou ler e seguir as documentações dos projetos, que ao final resultou nas máquinas do cluster prontas para execução em modo distribuído. Para aumentar a reprodutibilidade do experimento e diminuir o tempo de preparo, automatizamos o processo de configuração através de um script disponível em github.com/DylanGuedes/interscsimulator-blue/blob/master/ansible/computing-node. yml.

Após todos os passos, executamos a simulação em um cluster da NuvemUsp ${ }^{5}$, composto por 17 computadores, que era a maior quantidade possível, num esquema ilustrado na Figura 5.3. Na figura, são mostrados os 3 perfis de nós que utilizamos: os 15 nós de Perfil A (cor amarela) continham 4 Cpus e 8 Gb de memória e hospedaram: os nós da simulação distribuída, instâncias do DataCollector e workers do Spark. O nó de Perfil B (cor azul) continha mais recursos que os outros: 8 Cpus e 16 Gb de memória e nele executamos todos os serviços da plataforma, incluindo o MongoDB e o RabbitMQ, além do driver do Spark. Por fim, o nó de Perfil C (cor vermelha) continha 4 Cpus e 8 Gb de memória e tinha como única tarefa iniciar a simulação, atuando como o driver da simulação. Ao final, os dados estavam disponíveis no MongoDB do InterSCity.

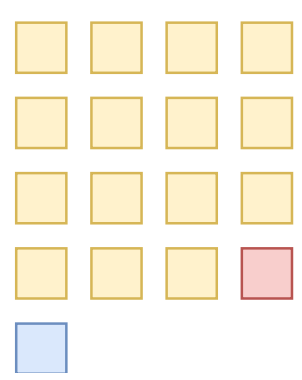

Perfil A

$4 \mathrm{Cpu}, 8 \mathrm{~Gb}$ Memória

SimDiasca, DataCollector, Spark

Perfil B

8 Cpus, 16 Gb Memória

InterSCity, Spark (driver)

Perfil C

4 Cpus, 8 Gb Memória

SimDiasca (driver)

Figura 5.3: Configuração do cluster utilizado.

\subsubsection{Processamento dos Dados}

Neste experimento, o processamento dos dados envolveu extrair os dados da plataforma, que estavam armazenados no MongoDB, e em seguida determinar média e desvio padrão da velocidade dos trechos do tráfego de São Paulo. Dividimos a solução nas seguintes

\footnotetext{
${ }^{5}$ Serviço de nuvem oferecido pela USP. Disponível em: internuvem.usp.br/client/
} 
sub-etapas: (1) agregamos todos os dados referentes a um mesmo veículo e ordenamos esses dados pelo tempo, o que descreve o trajeto do veículo. Na Figura 5.1, por exemplo, o caminho $A \leadsto B \leadsto C \leadsto D \leadsto E$ é dividido em $A \leadsto B, B \leadsto C, C \leadsto D$ e $D \leadsto E$; (2) particionamos os dados utilizando como critério o trecho (dados de mesma origem e mesmo destino ficam na mesma partição) e a janela de horário (de 20 minutos); e (3) finalmente, calculamos as métricas (média e desvio padrão) de cada trecho.

Inicialmente, temos tuplas com três elementos: $\langle\mathrm{A} 1, \mathrm{~A} 2, \mathrm{~A} 3>$, onde $\mathrm{A} 1$ é o identificador de um ponto da cidade, A2 é o tempo da simulação em que o veículo enviou sua localização e A3 é o identificador do veículo.

Após, aplicamos a operação de particionamento sobre os dados das localizações dos ônibus utilizando o identificador do veículo como chave para definir as partições. Assim, cada partição contém todos os dados do caminho percorrido por um mesmo veículo. Esse processamento é ilustrado na Figura 5.4, onde os dados estão no formato $\langle A 1, \quad A 2, \quad A 3\rangle$ e, após serem particionados pelo identificador do veículo, dão origem a 6 partições, uma por veículo. O particionamento ilustrado na figura permite, por exemplo, identificar que o Veículo A levou 25 segundos para migrar do Nó 1 ao Nó 3 da cidade, enquanto o Veículo D levou 14 segundos para ir do Nó 3 ao Nó 1.

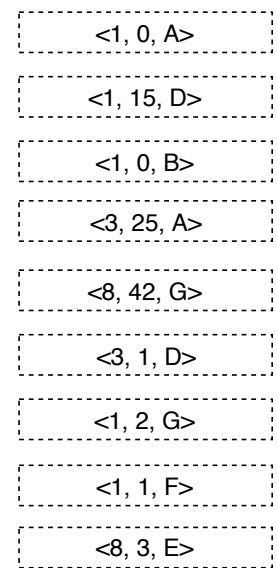

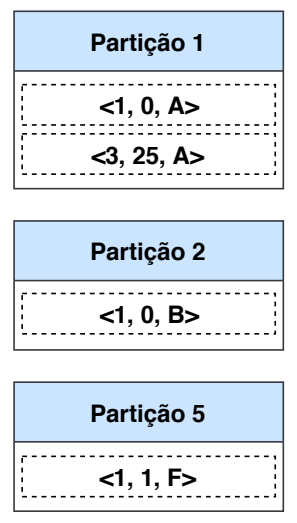
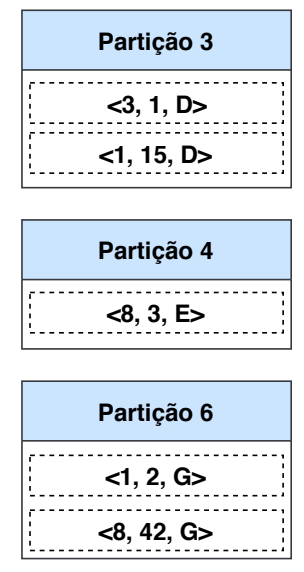

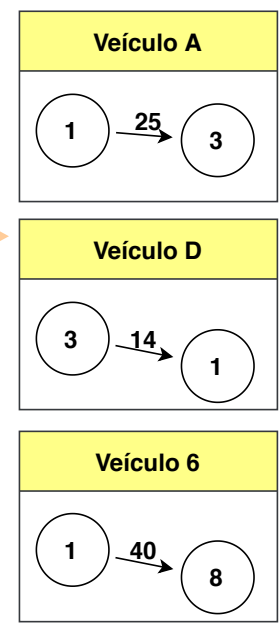

Figura 5.4: Particionamento dos veículos.

Dado que o nosso objetivo era conseguir calcular as velocidades dos trechos, era necessário que em toda tupla da tabela houvesse dois dados: um relativo a origem e outro relativo ao destino. Para que isso fosse possível, era necessário o uso de uma função de janela sobre as partições definidas no passo anterior - a função de janela permite adicionar nas tuplas valores específicos de outras tuplas.

Em nosso caso, por precisarmos adicionar na Tupla X1 valores da Tupla X2, adicionar valores da Tupla X2 na Tupla X3 e assim sucessivamente, utilizamos a função lead ${ }^{6}$. O resultado dessa operação é uma nova tupla, com assinatura $\langle X 1, \quad X 2, \quad X 3, \quad X 4, \quad X 5\rangle$, onde os três primeiros elementos são exatamente os mesmos da tupla inicial, mas dois novos valores surgem: $\mathrm{X} 4$, que é o timestamp da próxima tupla e $\mathrm{X} 5$, que é o nó da próxima

\footnotetext{
${ }^{6}$ São apresentados exemplos de uso em www.postgresqltutorial.com/postgresql-lead-function/
} 
tupla. Com esses valores computados, o resultado são os trechos já divididos, na forma $A \leadsto B, B \leadsto C$, etc. como mencionado no início da seção. A operação que usamos, que tem assinatura lead (col, qtd), é análoga à função sliding, disponível na linguagem Scala e com uso ilustrado no Programa 5.1. O primeiro elemento, que tem valor 1, agora passa a ser um par com os valores 1 e 2 . O segundo elemento, com valor 2 , agora passa a ser um par com os valores 2 e 3 , e assim sucessivamente.

Programa 5.1 Exemplo da função sliding, disponível na linguagem Scala.

1 val a $=\operatorname{Seq}(1,2,3,4,5,6,7,8)$

2 a.sliding(2). tolist

$3 \Rightarrow \operatorname{List}(\operatorname{Array}(1,2), \operatorname{Array}(2,3), \operatorname{Array}(3,4), \operatorname{Array}(4,5), \ldots)$

Após a aplicação da função de janela, toda tupla que descreve os dados do trajeto do ônibus passam a ter a origem e o destino do deslocamento em um intervalo de tempo. Assim, para o cálculo da velocidade, basta calcular a diferença entre duas distâncias no intervalo de tempo: $\delta v=\delta x / \delta t=\left(X_{2}-X_{1}\right) /\left(T_{2}-T_{1}\right)$. Após o cálculo de diferentes velocidades para diferentes trechos, passamos para a etapa final do processamento, que é a divisão dos dados em grupos para que os cálculos de média e desvio padrão dos trechos.

A divisão dos grupos utilizou o seguinte critério: a origem e destino do trecho e o instante de tempo em intervalos de 20 minutos. Por exemplo, todos os dados do Grupo A têm mesma origem e destino (pois se tratam do mesmo trecho) e são medições que ocorreram em uma mesma janela de tempo. Contudo, antes da execução da divisão, arredondamos o tempo dos trechos em janelas de 20 minutos; daí, tanto uma medição às $8 \mathrm{~h} 21$ quanto uma às $8 \mathrm{~h} 23$ tornam-se medições às $8 \mathrm{~h} 20$. Ao final, situações como a comparação do estado de um trecho às 8 h23 e às 21 h00 são evitados, o que traz precisão para o resultado final.

Por fim, após a definição dos grupos, aplicamos funções de agregação. Uma função de agregação aplica uma operação sobre cada grupo e o resultado final é uma tabela onde cada linha descreve um grupo e os valores são os resultados das operações. Uma série de exemplos do que é de como funcionam diferentes funções de agregação estão disponíveis em: www.datacamp.com/community/tutorials/aggregate-functions-sql.

No Programa 5.2 estão as consultas SQL para o processamento de todas as tarefas mencionadas, como o agrupamento, a função de agregação, o particionamento, a função de janela, dentre outras. No total foram necessárias 5 consultas, que estão no formato de um pipeline: a segunda consome o resultado da primeira, a terceira consome o resultado da segunda e assim por diante. As duas soluções, uma que utiliza o DataProcessor e outra que utiliza o Spark diretamente, fazem exatamente as mesmas consultas e com o mesmo código, pois o DataProcessor só abstrai dos usuários a extração e a carga do ETL, como mencionado, mas a transformação, que nesse caso é a consulta, é especificada.

A consulta SQL localizada entre as linhas 1 e 7 do Programa 5.2 particiona os dados por viagens e utiliza a função de janela lead para adicionar os valores T1 e V, explicados anteriormente. Entre as linhas 9 e 12, os dados relativos ao tempo são moldados para o tipo timestamp, pois inicialmente estão em formato string. Entre as linhas 14 e 19 são criadas duas colunas, $\mathrm{H}$ e M, relativos a hora do tick e o minuto, respectivamente. Entre as linhas 21 e 25 é criada a coluna delta, que é a diferença entre os valores T1 e TO, e a M 
relativa aos minutos é arredondada para o múltiplo de 20 igual ou anterior a seu valor. Por exemplo, se a coluna $M$ tem valor 41 ou 59, seu novo valor será 40; se tem valor 25 ou 39, seu novo valor será 20 . Por fim, entre as linhas 27 e 31 ocorre o cálculo das métricas, onde stddev_pop é o desvio padrão e mean é a média.

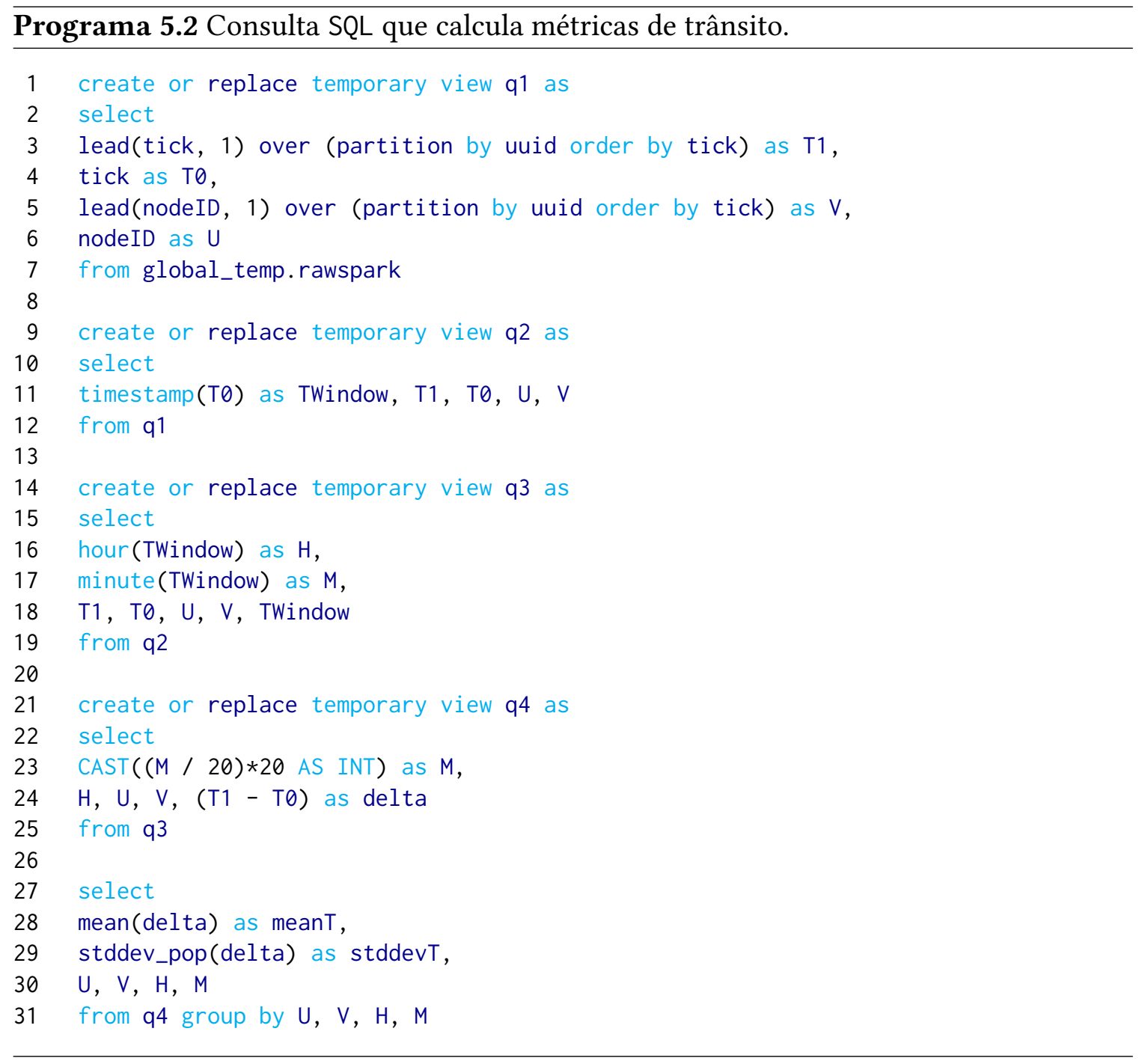

\subsubsection{Resultados}

Após a execução da simulação e o processamento dos dados apresentadas na seção anterior, coletamos os tempos de execução do processamento e as métricas devolvidas pelo próprio Spark para ambas as soluções. O primeiro resultado são os estágios que o Spark definiu para a execução das consultas pelo DataProcessor, apresentado na Figura 5.5. No total foram criados três estágios, onde o primeiro é responsável por extrair dados do MongoDB e transformar os dados, o segundo é responsável por particionar e reorganizar os dados no cluster para a primeira função sobre janela e o terceiro estágio é responsável por um último particionamento para o agrupamento dos dados, aplicação da função de agregação e o armazenamento dos resultados. 


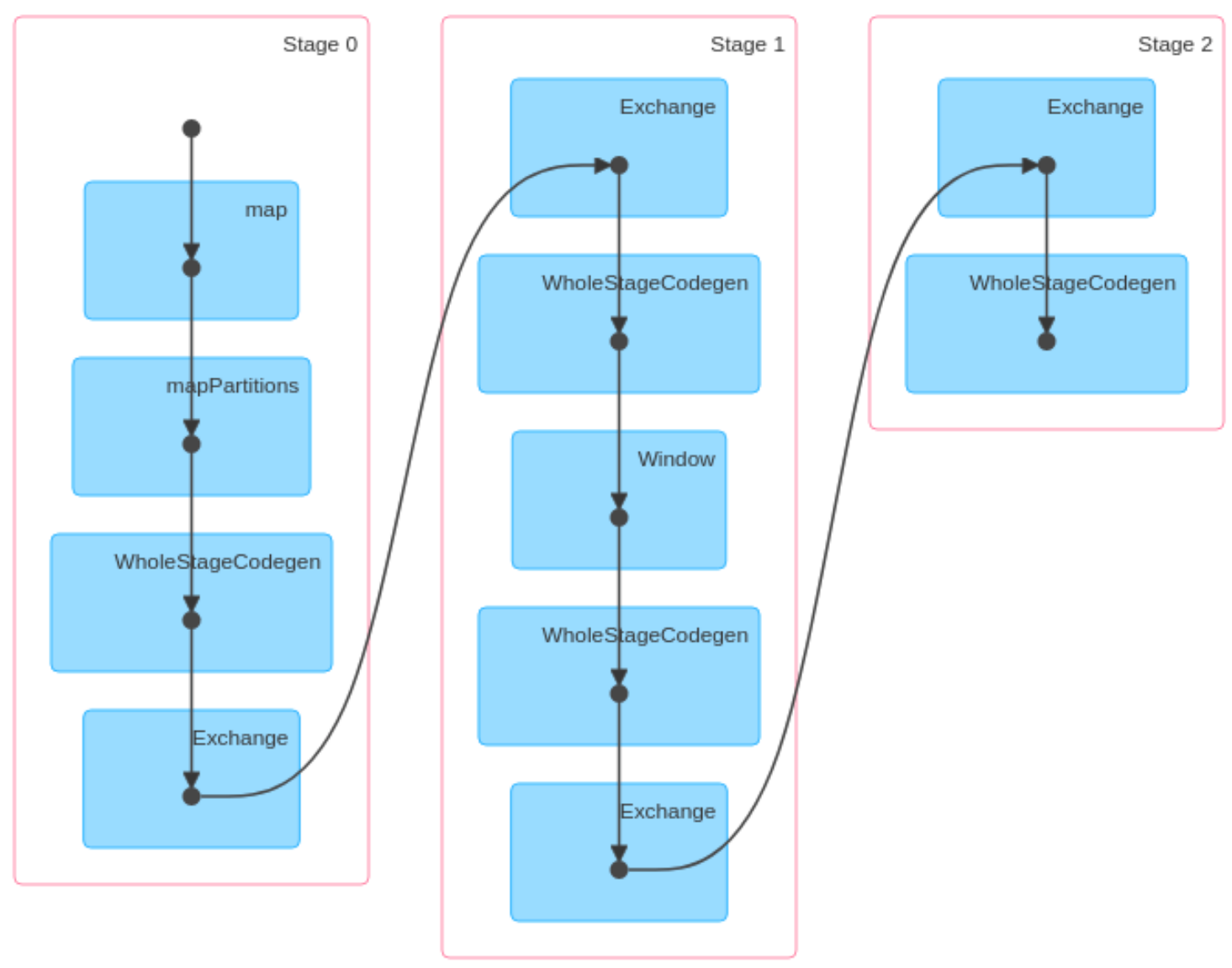

Figura 5.5: Estágios definidos para o código gerado pelo DataProcessor.

A solução que utiliza o Spark diretamente resultou exatamente nos mesmos estágios, já que o código gerado é semelhante ao código Spark utilizado. Além disso, ressaltamos que a proposta do trabalho pode ser vista com uma forma facilitada dos usuários só precisarem especificar a etapa de transformação do pipeline ETL. Como neste experimento a etapa de transformação foi a mesma entre as duas soluções, a separação de estágios ser a mesma indica que os dois códigos finais foram bem parecidos.

Após, apuramos métricas e estatísticas que o Spark disponibiliza sobre as tarefas de processamento, apresentadas na Tabela $5.1^{7}$. Durante a execução, conforme a tabela, os três estágios ao todo deram origem a 507 tarefas (tasks). Como os estágios foram os mesmos e o cluster utilizado também foi o mesmo, o número de tarefas entre as duas soluções são iguais, conforme esperado. A duração do processamento também é semelhante, que é o esperado, mas não foi exatamente o mesmo porque diversos fatores afetam o desempenho do cluster. A Figura 5.6 apresenta as diferenças no tempo de processamento entre ambas as soluções, que mostra quão similar foram os resultados do ponto de vista do processamento feito pelo Spark.

Ao final, a solução que utilizou o DataProcessor demorou $t_{1}=209.387 \mathrm{~s}$, enquanto

\footnotetext{
${ }^{7} \mathrm{O}$ Spark disponibiliza outras métricas, mas nos atemos às métricas relativas ao tempo necessário para o processamento dos dados, que é a mesma métrica que temos como requisito.
} 


\begin{tabular}{|c|c|c|c|c|c|c|c|c|}
\hline \multirow[t]{2}{*}{ Solução } & \multirow[t]{2}{*}{ Estágio } & \multicolumn{6}{|c|}{$\begin{array}{c}\text { Duração do } \\
\text { Processamento }\end{array}$} & \multirow{2}{*}{$\begin{array}{c}\text { Tarefas } \\
\text { Êxito/Total }\end{array}$} \\
\hline & & Total & Mín & $25 p$. & Mediana & $75 p$. & Máx. & \\
\hline Spark & \multirow{2}{*}{0} & $47 \mathrm{~s}$ & $3 \mathrm{~s}$ & $13 \mathrm{~s}$ & $20 \mathrm{~s}$ & $28 \mathrm{~s}$ & $40 \mathrm{~s}$ & \multirow{2}{*}{$107 / 107$} \\
\hline $\begin{array}{c}\text { Data } \\
\text { Processor }\end{array}$ & & $54 \mathrm{~s}$ & $2 \mathrm{~s}$ & $12 \mathrm{~s}$ & $18 \mathrm{~s}$ & $30 \mathrm{~s}$ & $46 \mathrm{~s}$ & \\
\hline Spark & \multirow{2}{*}{1} & $8 \mathrm{~s}$ & $0.7 \mathrm{~s}$ & $1 \mathrm{~s}$ & $1 \mathrm{~s}$ & $4 \mathrm{~s}$ & $6 \mathrm{~s}$ & \multirow{2}{*}{$200 / 200$} \\
\hline $\begin{array}{c}\text { Data } \\
\text { Processor }\end{array}$ & & $8 \mathrm{~s}$ & $0.7 \mathrm{~s}$ & $1 \mathrm{~s}$ & $1 \mathrm{~s}$ & $4 \mathrm{~s}$ & $6 s$ & \\
\hline Spark & \multirow[t]{2}{*}{2} & $3 \mathrm{~s}$ & $0.2 \mathrm{~s}$ & $0.4 \mathrm{~s}$ & $0.6 \mathrm{~s}$ & $2 \mathrm{~s}$ & $2 \mathrm{~s}$ & \multirow{2}{*}{$200 / 200$} \\
\hline $\begin{array}{c}\text { Data } \\
\text { Processor }\end{array}$ & & $3 s$ & $0.2 \mathrm{~s}$ & $0.3 \mathrm{~s}$ & $0.5 \mathrm{~s}$ & $2 \mathrm{~s}$ & $2 \mathrm{~s}$ & \\
\hline
\end{tabular}

Tabela 5.1: Métricas retornadas pelo Spark após o processamento dos dados.
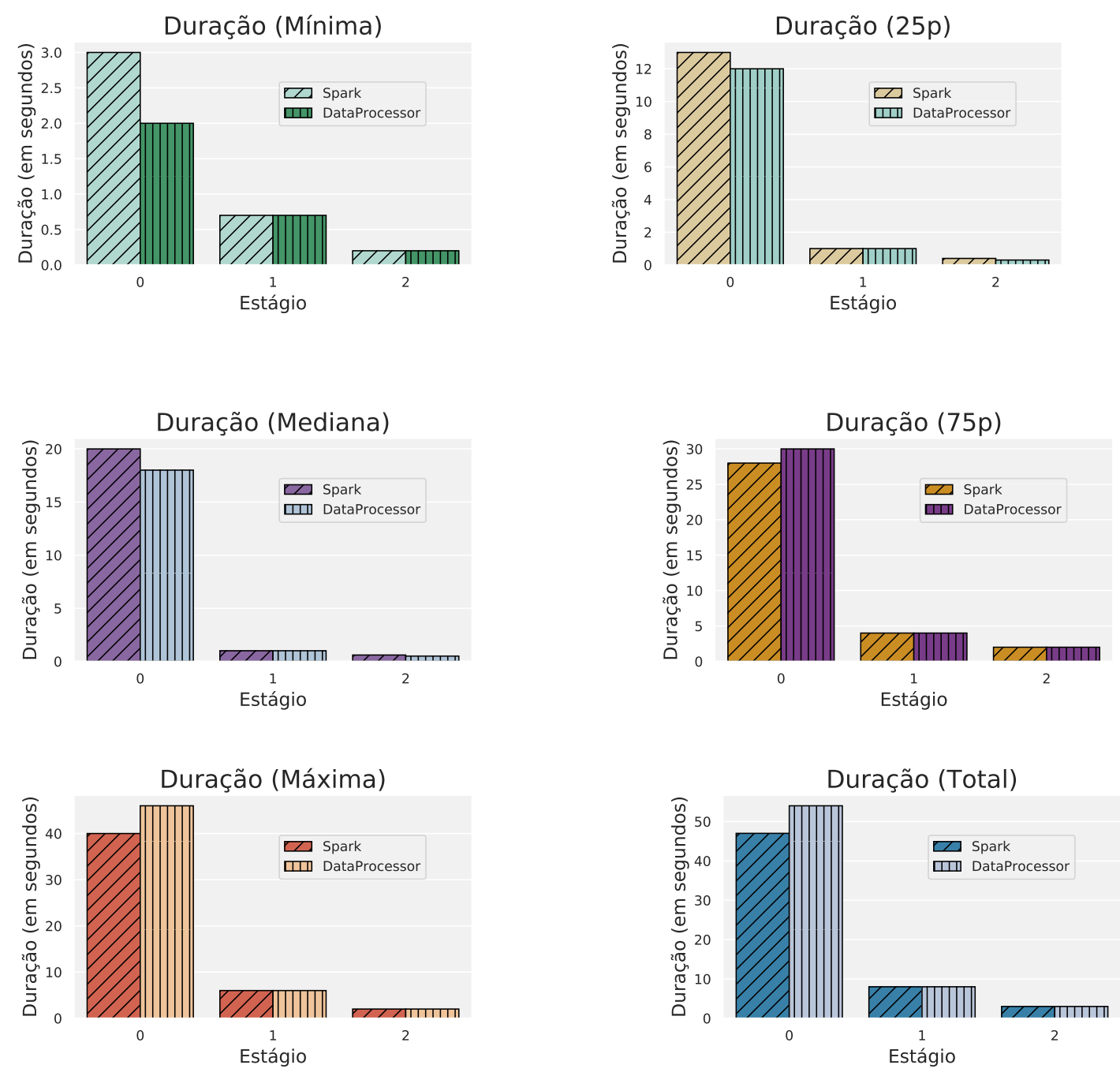

Figura 5.6: Tempo de processamento - DataProcessor vs. Spark. 
a solução que utilizou o Spark diretamente demorou $t_{2}=57.817 \mathrm{~s}$, uma diferença de $t 1-t 2=209.387-57.817=151.57 s$, ou 2.51 minutos.

\subsubsection{Análise de Desempenho}

$\mathrm{Na}$ análise de desempenho, avaliamos o overhead presente na utilização do DataProcessor. Conforme os resultados listados na Seção 5.1.4, a utilização do DataProcessor adicionou ao tempo total de execução da tarefa quase 3 minutos. Os motivos para esse tempo adicional são:

- O tempo necessário para que a requisição do usuário seja recebida e atendida pelo DataProcessor;

- O tempo necessário para a geração do código Spark;

- Após o Spark iniciar a execução do código, o código gerado recupera os parâmetros definidos pelo usuário através de uma requisição ao DataProcessor, que retornará um JobTemplate que contém os parâmetros encapsulados. Assim, também existe um tempo necessário para que o DataProcessor envie uma requisição para recuperação do JobTemplate;

- O tempo até que o Spark devolva o log de processamento para o DataProcessor, que posteriormente o armazenará no banco de dados.

De maneira geral, faz sentido que ocorra o acréscimo no tempo total de processamento da tarefa, pois são várias requisições e serializações adicionais. Contudo, embora um acréscimo de 3 minutos pareça muito, é importante ressaltar que entre os motivos que levam ao overhead, nenhum deles varia conforme o volume de dados. Isso significa que, caso você esteja trabalhando com 100 Petabytes de dados armazenados no InterSCity, ou com 1 Gigabyte, o overhead resultante do uso do DataProcessor será o mesmo.

Portanto, quanto maior o volume de dados, mais irrelevante é o overhead causado pelo DataProcessor. No cenário em que executamos o experimento, que utilizou cerca de 12 $\mathrm{Gb}$, os quase 3 minutos adicionais fizeram uma diferença significativa, já que a execução do Spark em si demorou menos que isso. Contudo, com volumes muito maiores, que são a regra e não a exceção, a demora adicional é irrelevante, que é exatamente o cenário em que se espera a utilização desse tipo de ferramenta.

\subsubsection{Análise de Usabilidade}

Nesta análise, comparamos a facilidade de uso entre as duas soluções que executam as consultas SQL listadas na Subseção 5.1.3. Faremos essa análise por uma perspectiva quantitativa, onde analisamos a quantidade de linhas a mais necessárias (ou não) para uso do DataProcessor. Durante a comparação, analisamos tanto porções separadas das duas soluções, quanto o código completo que possibilita o processamento dos dados. 


\section{DataProcessor}

Todo o código produzido nesta análise está em linguagem Python, embora qualquer linguagem que tivesse uma forma de executar requisições REST servisse. Também, aproveitamos o fato do DataProcessor seguir a especificação JSON-API e utilizamos o pacote JAC, o mesmo utilizado em 4.6.2.

A primeira porção do código que utiliza o DataProcessor está listada no Programa 5.3 e cuida da sessão de comunicação entre o cliente e o servidor e define o schema dos dados das entidades. Essa porção de código, independente do processamento que será feito pelo DataProcessor, é executada sempre da mesma forma - exceto quando o usuário está utilizando outro pacote para interagir, que não o JAC.

A segunda porção, presente no Programa 5.4, define o JobScript que descreve as consultas SQL. O usuário deve preencher parâmetros simples, como qual a linguagem do código (no caso do DataProcessor, trata-se da linguagem Python na maior parte das vezes), e outros mais avançados, como qual a estratégia utilizada para gerar código, mas ressaltamos que, novamente, essas definições são altamente reutilizáveis. Caso você deseje executar uma consulta SQL no InterSCity, independente de qual consulta será executada ou qual capacidade da plataforma você deseje utilizar como entrada, o mesmo JobScript pode ser reutilizado.

A porção de código presente no Programa 5.5 trata o conjunto de definições específicas de cada uso do DataProcessor. No código, é definido o JobTemplate que define que a capacidade city_traffic será a analisada, que o schema dos dados do InterSCity podem ser inferidos, que a consulta SQL que deve ser processada está armazenada na variável queries e que o JobScript responsável pela geração o código é o apresentado no Programa 5.4. Nós omitimos as consultas SQL nas soluções pois: (I) o código das consultas é o mesmo nas duas soluções, então não faz diferença nas análises e (II) o código avaliado ficaria mais poluído, o que atrapalha as explicações.

A porção final está apresentada no Programa 5.6 e trata a criação de um Processing Job que referencie o JobTemplate definido no Programa 5.5 e a sua execução. Separamos em uma porção pois, embora o identificador do JobTemplate possa variar, esse código é reutilizável independente da sua tarefa: se você deseja executar alguma tarefa através do DataProcessor, basta copiar esse exato código e substituir o identificador do JobTemplate pelo identificador que você recebeu.

Utilizamos o tokei ${ }^{8}$ para determinar a quantidade de linhas de código, que apontou um total de 72 linhas para o código Python que realiza a tarefa através do DataProcessor ${ }^{9}$. Contudo, ressaltamos que a primeira porção deverá ser repetida sempre, independente da tarefa a ser executada, e só ela contempla 42 linhas de código. A segunda porção, que contém 9 linhas de código, também é reutilizável e deverá ser repetida da mesma forma caso se deseje executar uma consulta SQL. Por fim, a última porção também é reutilizável e deverá ser repetida exatamente da mesma forma independente do uso desejado, só devendo ser alterado o id do JobTemplate, que contempla mais 7 linhas. Ou seja, independente

\footnotetext{
${ }^{8}$ github.com/XAMPPRocky/tokei

${ }^{9}$ Essa quantidade é sem contar a quantidade de linhas da consulta SQL. Retiramos essa quantidade porque a mesma consulta é executada com as duas soluções (Spark e DataProcessor).
} 
Programa 5.3 Porção 1 do código-fonte que processa as métricas através do

\section{DataProcessor.}

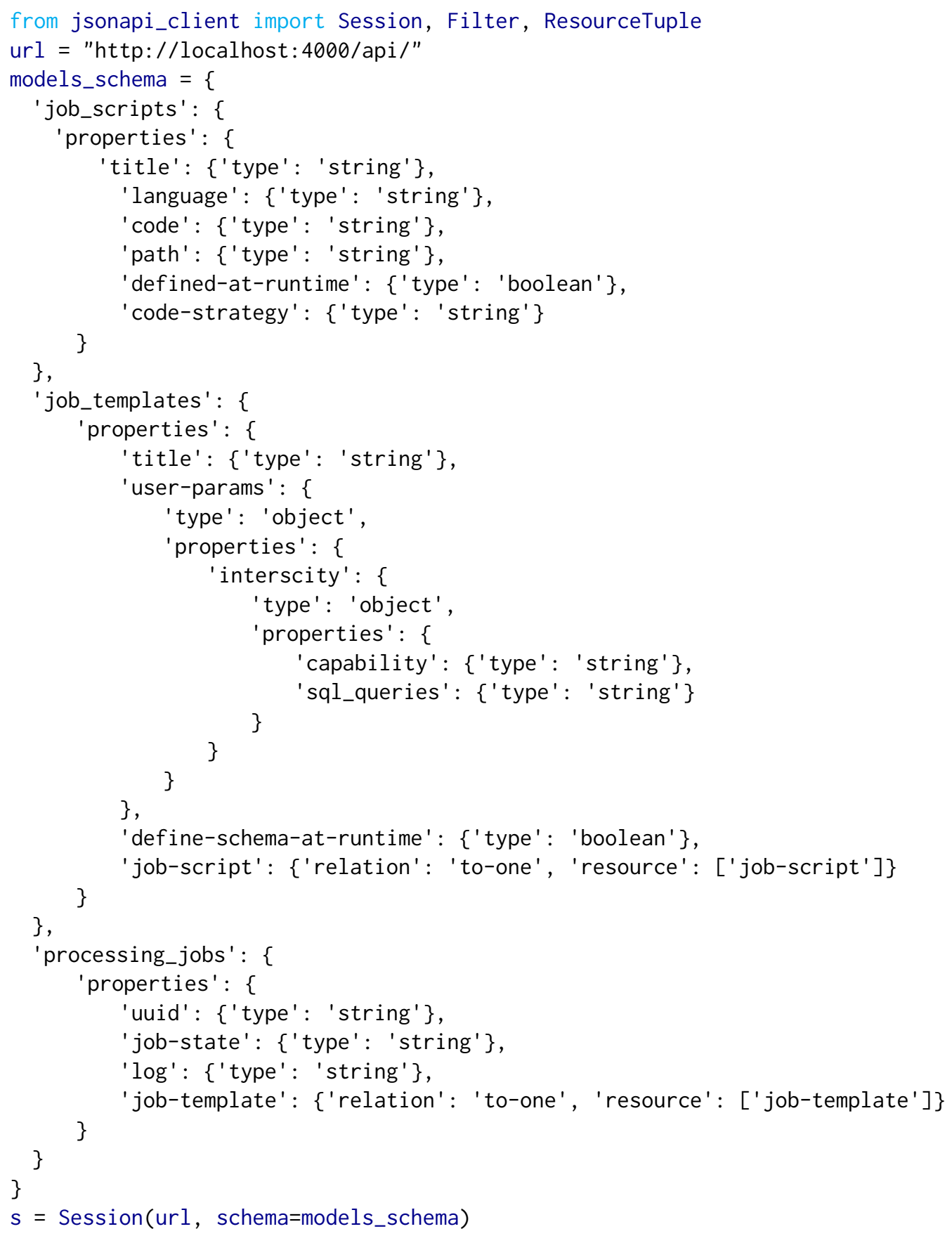


Programa 5.4 Porção do código que define um JobScript do DataProcessor.

\section{Programa 5.5 Definição do JobTemplate utilizado para o processamento pelo}

\section{DataProcessor.}

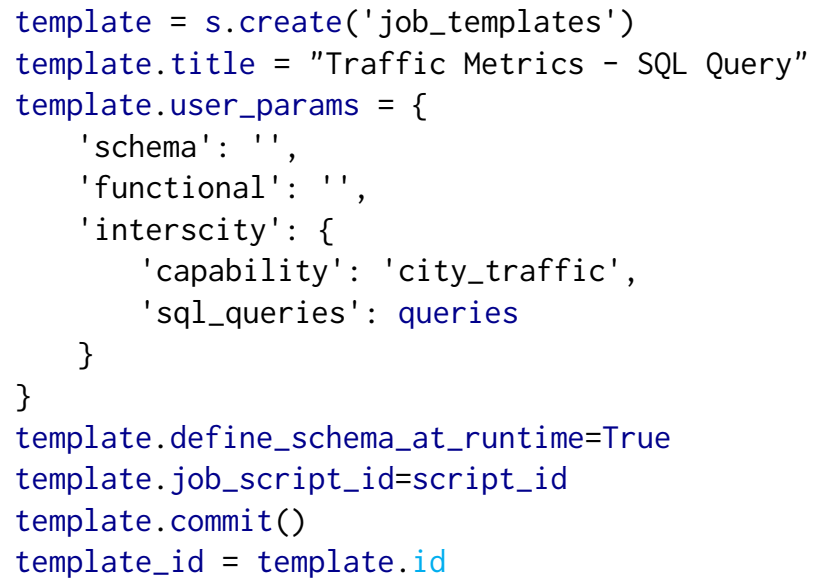

Programa 5.6 Última porção do Código-fonte utilizado para o processamento pelo DataProcessor.

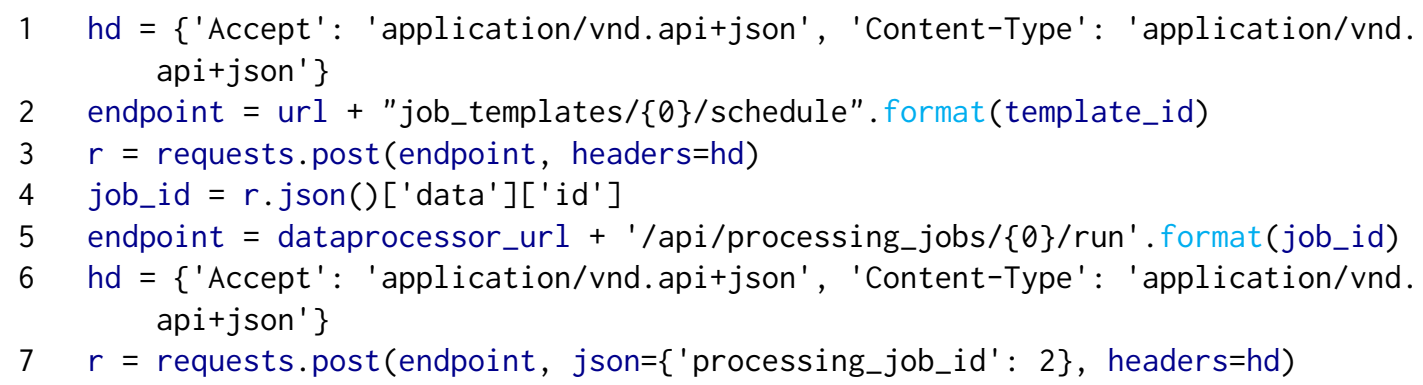


do seu uso, dessas 72 linhas, 72-(42+7) deverão ser copiadas, sobrando 23. Dessas 23, se você deseja executar uma consulta SQL, 7 linhas deverão ser copiadas, sobrando 23-7 = 16 linhas. Ou seja, na maior parte das vezes para uma consulta SQL, só é necessário escrever, de fato, 16 linhas, e na maior parte das vezes para qualquer solução, só são necessárias 23 linhas.

\section{Spark}

Separamos o código Spark em duas porções, onde a primeira cuida do preparo e não executa nenhum processamento de fato, enquanto a segunda cuida do processamento e do desalocamento dos recursos. No Programa 5.7 são definidos parâmetros essenciais como: qual o endereço do master do cluster, qual versão específica do Python deve ser utilizada, a localização da instância do MongoDB utilizado pelo DataProcessor, dentre outros parâmetros.

\section{Programa 5.7 Primeira porção do código-fonte utilizado para o processamento sem o DataProcessor.}

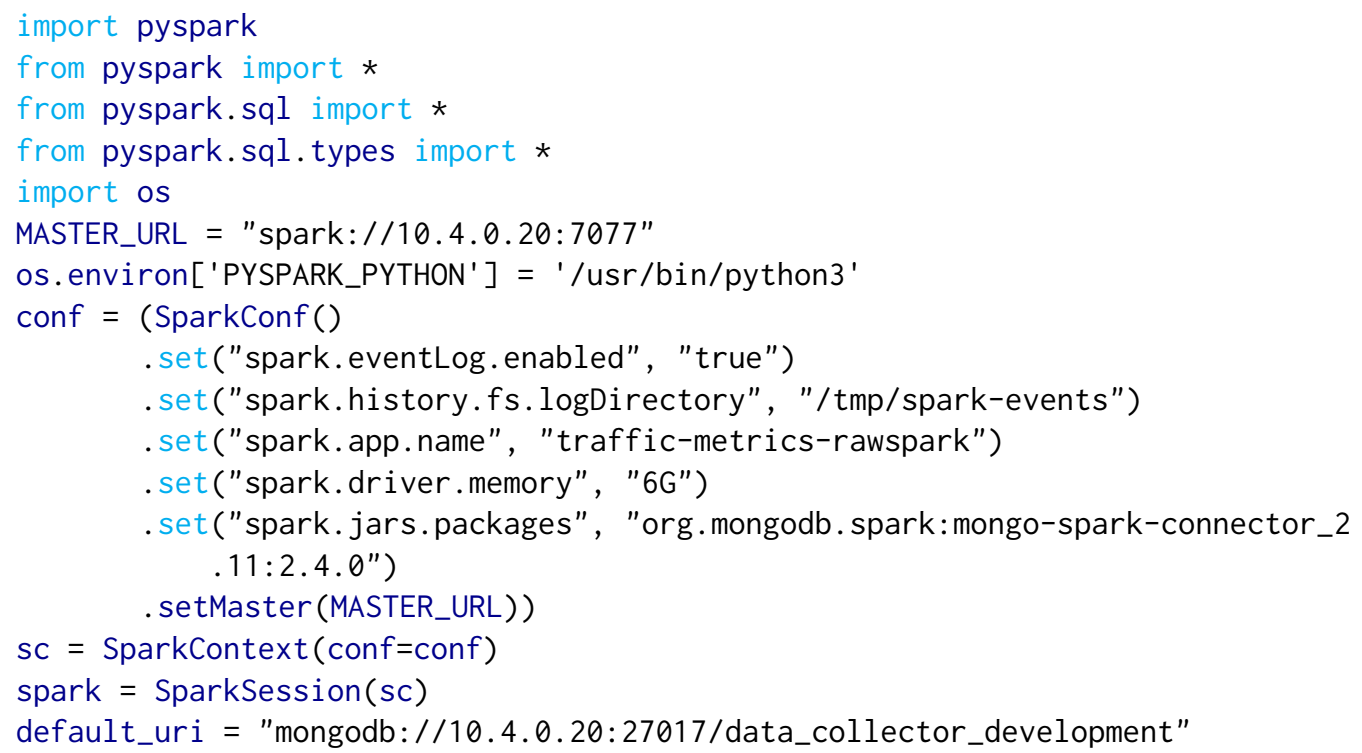

Na segunda e última porção, apresentada no Programa 5.8, é definido a entrada do processamento, que contempla a capacidade da plataforma, o schema dos dados (inferidos pelo InterSCity), qual o formato da entrada, qual a tarefa que será executada e como salvar os dados processados. A primeira porção do código, assim como no caso do DataProcessor, é totalmente reaproveitável: independente do processamento que você quer executar no Spark, só é necessário escrever a primeira porção uma vez. Essa segunda, não. Caso seja outra capacidade, é necessário alterar todo o schema dos dados, qual o formato você deseja salvar e qual a tarefa processada, por exemplo.

Através do sloc, a solução que não utiliza o DataProcessor resultou em 39 linhas, bem menos que as 72 linhas iniciais do DataProcessor. Observando mais detalhadamente, com a remoção das linhas que são sempre repetidas de ambos, o uso do DataProcessor requer que 


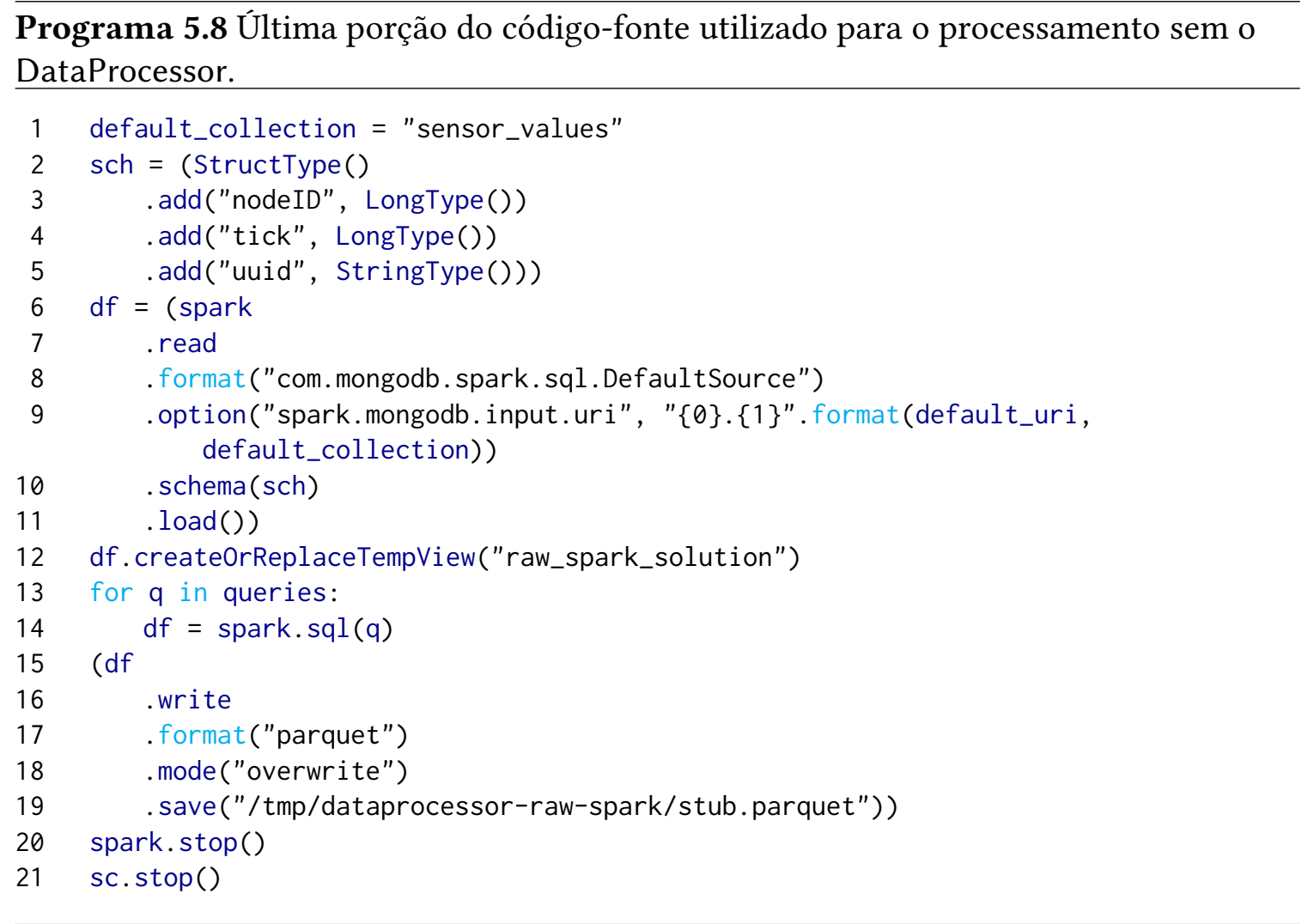

você desenvolva 23 linhas, enquanto sem o utilizar você precisa definir $39-17=22$ linhas, ou seja, uma quantia muito similar entre as duas soluções (22 vs 23). Portanto, a quantidade relevante de linhas que você precisa definir para usar o DataProcessor será, na maioria dos casos, uma quantidade parecida ao que você precisaria definir no Apache Spark (isso para consultas SQL, que é o exemplo que utilizamos). Ou seja, com o DataProcessor você ganha acesso ao mesmo processamento distribuído do Spark mas através de uma API que só precisa de conhecimento comum através de requisições REST e sem que seja necessário que você escreva uma maior quantidade de linhas.

\subsection{Exemplo de Uso - Separar Pontos da Cidade em Regiões}

Analisamos a extensibilidade do DataProcessor através de um estudo de caso que consiste na resolução do seguinte problema, através de processamento distribuído:

\section{A partir de pontos de trechos de viagens, quais pontos melhor agrupam os trechos?}

Em outras palavras, estamos interessados em poder definir pontos-chaves em um mapa da cidade, onde um ponto-chave é um ponto que é próximo de uma grande quantidade de veículos. Algumas aplicações da solução desse problema são: quais os pontos com mais potencial para se instalar postos de gasolina? Em quais locais instalar departamentos de 
trânsito?

Uma forma de resolver o problema é através do uso de um algoritmo que encontra centroides que melhor descrevem um conjunto de dados, como o k-Means, que utilizaremos na solução. Neste exemplo, utilizamos novamente os dados simulados pelo InterSCSimulator, que gera um conjunto de dados onde cada entrada tem o formato <nodeID, tick, uuid>, sendo o nodeID o vértice da cidade, tick o tempo da simulação (em minutos) e uuid o identificador da viagem. Embora a origem dos dados sejam viagens completas de pessoas pela cidade de São Paulo, neste problema iremos interpretá-los como viagens de veículos, o que não muda o caráter do problema.

Separamos a resolução do problema via DataProcessorem três partes: primeiro, adicionamos ao DataProcessor novos segmentos que permitem utilizar o Spark para definir um modelo k-Means; em seguida, mostramos como o usuário, após essa extensão do DataProcessor, resolve o problema e utiliza os resultados calculados; e por fim, avaliamos o processo de adição da funcionalidade ao DataProcessor, com uma discussão sobre a quantidade de código e a complexidade envolvida na adição do novo segmento.

\subsubsection{Adição da estratégia que permite a clusterização}

Pela definição apresentada na Subseção 4.5.3, a adição do k-Means encaixa-se bem com o segmento de operação. Dessa forma, adicionamos o trecho que gera o código que calcula os centroides dos dados utilizando o Spark através de uma nova estratégia que define os segmentos de operação e de cabeçalho, com auxílio do módulo CodeGen. De acordo com a documentação do Spark ${ }^{10}$, para calcular o k-Means de um DataFrame só é necessário definir a coluna features, que deve estar disponível no DataFrame fornecido. Como trata-se de um campo parametrizável, em nossa implementação esperamos a sua definição através de argumentos definidos pelo usuário, de modo que usuários possam definir diferentes features mesmo através do mesmo segmento. Esses campos são esperados no campo user_params.

O Programa 5.9 lista o código fonte da estratégia. Mais uma vez, nos apoiamos no macro __use __ CodeGen, que injeta comportamento padrão para os quatro segmentos; depois, sobrescrevemos o segmento de operação para processar os dados com o k-Means. Para essa estratégia em específico, também sobrescrevemos o sub-segmento responsável pela importação dos módulos - isso porque o k-Means precisa de módulos específicos do SparkML, como o VectorAssembler. Além disso, salvamos dois resultados: o modelo em si, que pode servir para cálculos futuros mas reaproveitando o treinamento feito em uma dada iteração, mas também o cálculo das centroides em si.

${ }^{10}$ Disponível em: spark.apache.org/docs/latest/ml-clustering.html\#k-means 


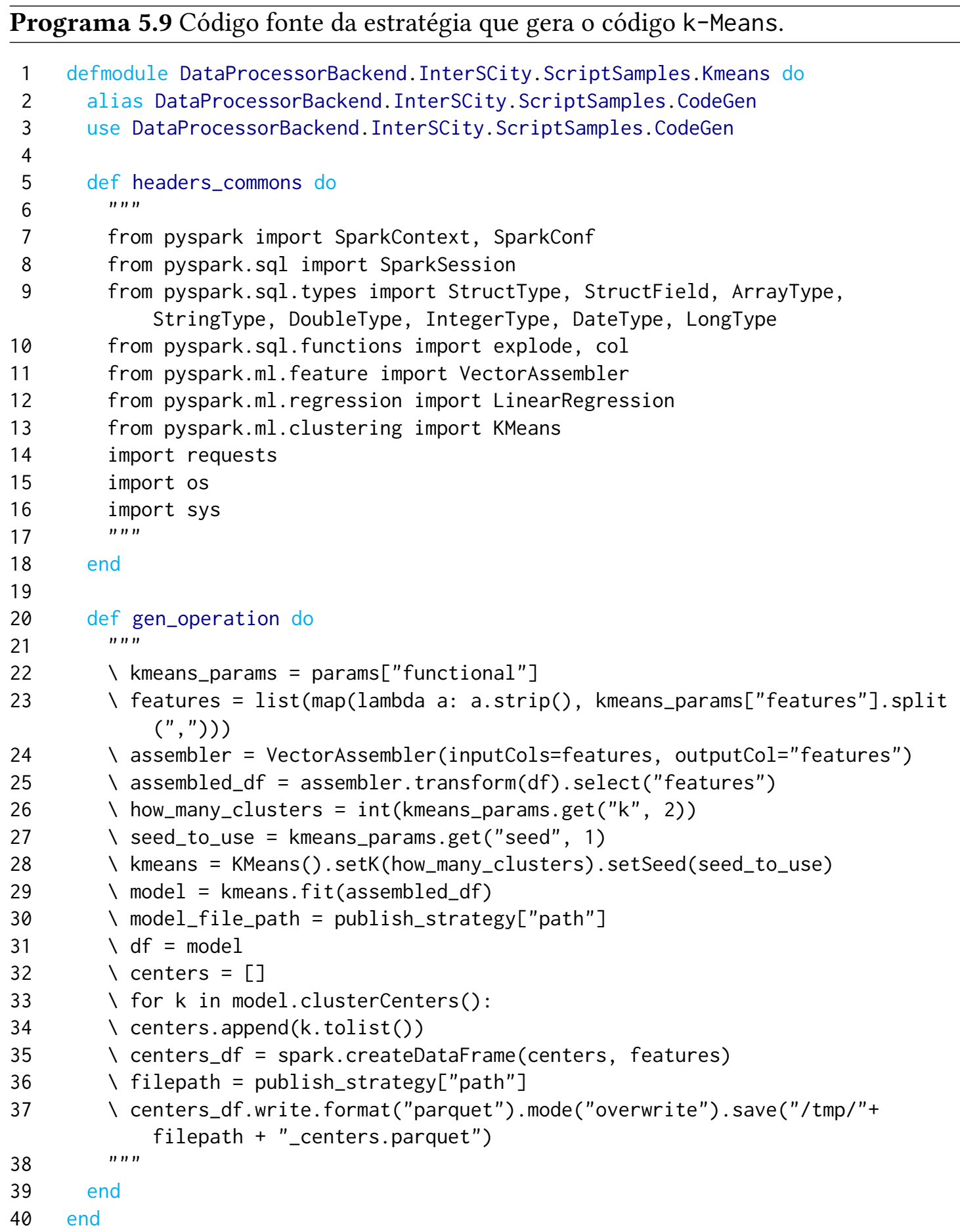




\subsubsection{Utilização}

Na seção anterior, estendemos o DataProcessor para adicionar suporte ao k-Means. Agora, como podemos utilizá-lo para resolver nosso problema original, que era definir as regiões que melhor agrupam as viagens? A adição do k-Means ao DataProcessor nos permite definir o modelo k-Means, mas ainda precisamos utilizá-lo para definir a região das viagens. Dessa forma, criaremos um Processing Job no DataProcessor que treina o modelo com os dados simulados pelo InterSCSimulator descritos anteriormente e armazenaremos as centroides definidas pelo modelo em um arquivo. Seguimos as mesmas tarefas vistas na Subseção 4.6.2, iniciando pela definição do JobScript ${ }^{11}$. O Programa 5.10 define um JobScript feito para utilização do k-Means.

Programa 5.10 Cria o JobScript responsável por executar o k-Means.

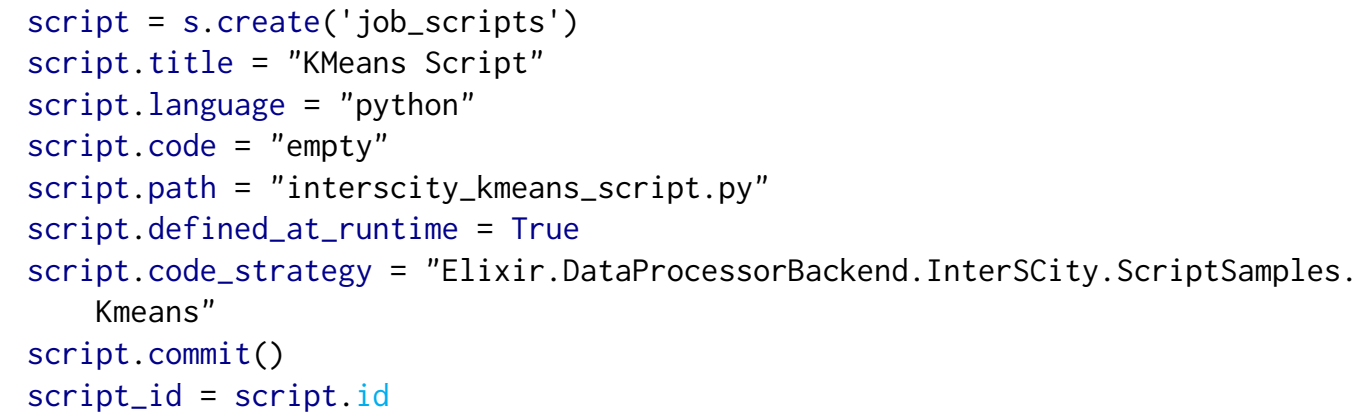

Agora, de acordo com o fluxo, devemos definir um JobTemplate que faça referência ao JobScript que acabamos de criar. Definimos o JobTemplate no Programa 5.11.

Programa 5.11 Cria o JobTemplate responsável por calcular o k-Means dos dados de tráfego da cidade.

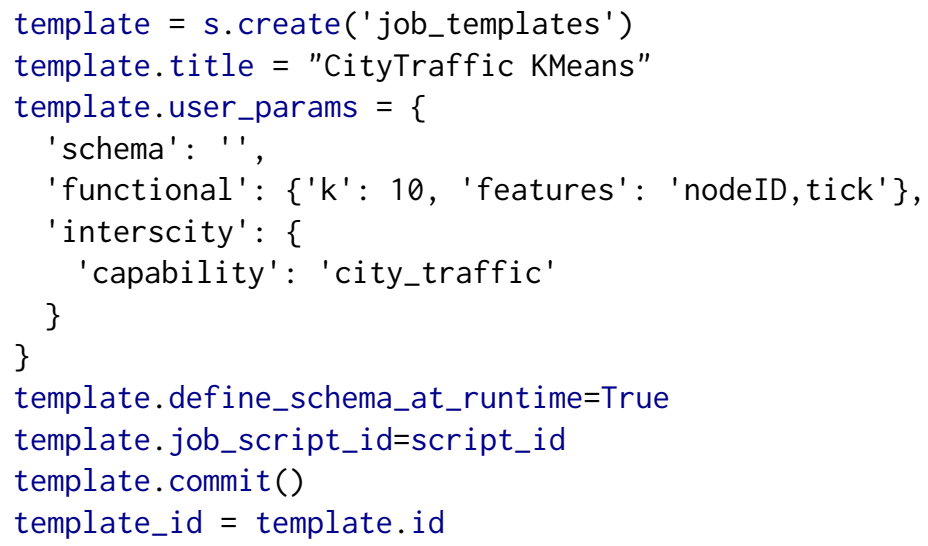

Por fim, basta criarmos um novo Processing Job que referencie o JobTemplate que acabamos de criar e iniciá-lo. O Programa 5.12 cuida da criação e início do Processing Job, que ao final tornará disponível os centroides em um em arquivo em formato parquet, que

\footnotetext{
${ }^{11}$ Omitimos a definição da sessão do JAC, já que o código é exatamente o mesmo
} 
pode ser carregado pelo Pandas através da chamada read_parquet. No Programa 5.13 está o código responsável por carregar os dados do processamento no Pandas, que posteriormente pode ser utilizado para gerar visualizações ou explorado por outras ferramentas do ecossistema de ciência de dados.

Programa 5.12 Criação do Processing Job que tem referencia para o JobTemplate que configura o k-Means.

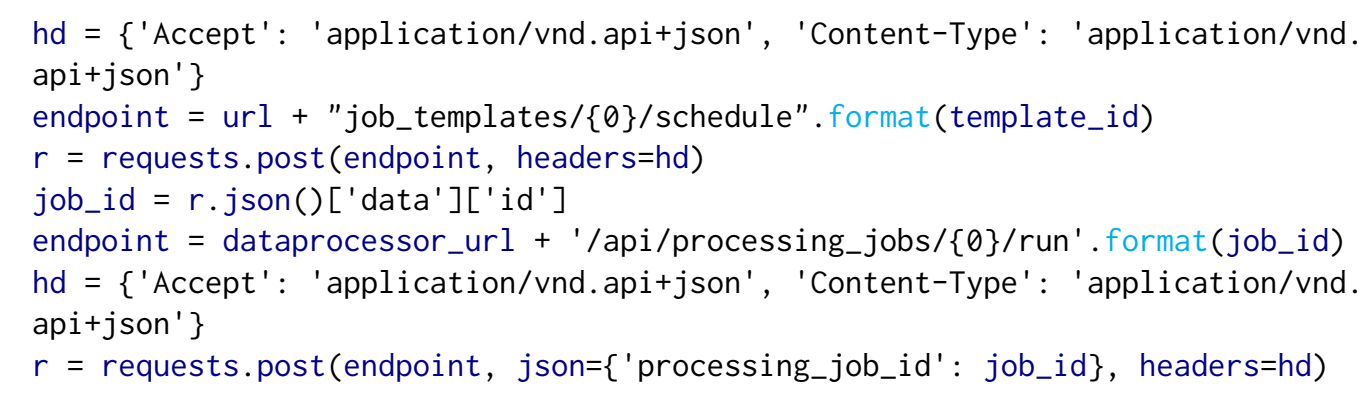

Programa 5.13 Como carregar um resultado do processamento em formato parquet no Pandas.

1 import pandas as pd

$2 \mathrm{df}=$ pd.read_parquet ("/tmp/kmeans_carros_centers.parquet")

\subsubsection{Análise de Extensibilidade}

De maneira geral, a extensibilidade do DataProcessor apresentada no Programa 5.9 gira em torno da macro __use_-_ e na sobrescrita dos sub-segmentos/segmentos desejados. Assim, a extensão do DataProcessor nesse caso precisa de, no mínimo, 4 linhas essenciais e mais 4 linhas para cada segmento/sub-segmento que será sobrescrito. Ou seja, uma quantidade baixa para permitir a extensão de uma grande quantidade de cenários. Contudo, notamos duas limitações quanto à extensibilidade:

A primeira limitação relevante da extensibilidade do DataProcessor é a ordem, que é sempre fixa. Embora a ordem atual contemple muitos cenários, talvez em algum cenário mais específico pode ser relevante que algum segmento ocorra em ordem diferente da atual (cabeçalho, corpo, operação e rodapé, nesta ordem).

A segunda limitação relevante é a sobrescrita do cabeçalho, que atualmente precisa que um usuário especifique todos os pacotes que queira-se importar caso ele precise de algum não disponível na implementação padrão. Por exemplo, se um usuário deseja importar algum módulo do pacote time, já que esse pacote não está disponível na implementação padrão, é necessário que o sub-segmento seja importado e que todos os outros pacotes (além do time) sejam importados nessa nova implementação. O DataProcessor não possibilita, por exemplo, uma forma de só importar o pacote time, que é o único que não estava presente anteriormente. 
Em todo caso, ambas as limitações só facilitariam a extensibilidade, mas não impedem o uso do DataProcessor em algum cenário específico. Na primeira limitação, por exemplo, bastaria o usuário trocar os nomes das implementações. Exemplo: se é desejado que o segmento operação venha antes do corpo, basta implementar o segmento operação no corpo e vice-versa. Na segunda limitação, ocorre uma replicação a mais no código mas ainda assim o DataProcessor estaria sendo estendido para contemplar o novo pacote desejado. Portanto, o DataProcessor pode ser estendido para uma grande gama de operações e usos não esperados com a adição de poucas linhas (menos de 10) e de forma bem padronizada - estendendo os segmentos/sub-segmentos disponibilizados.

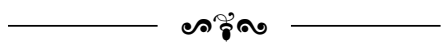

Neste capítulo vimos qual o potencial e as possíveis limitações do DataProcessor, onde começamos com uma análise de desempenho e usabilidade feitos a partir de um experimento que utilizou dados simulados. Em seguida, analisamos como estender o DataProcessor para adicionar suporte a funcionalidades não previstas. No próximo capítulo apresentamos as nossas conclusões quanto ao método que identificamos para permitir a integração de processamento distribuído em cidades inteligentes e como mitigar as limitações observadas durante as análises. Classificamos as limitações em trabalhos futuros que contemplam tanto a exploração de desafios mais científicos, quanto a exploração de desafios mais técnicos. 



\section{Capítulo 6}

\section{Conclusões}

Neste trabalho apresentamos uma arquitetura para processamento distribuído de Big Data integrada a uma plataforma de cidades inteligentes. Essa arquitetura tem como diferencial uma maior atenção a três requisitos: extensibilidade, desempenho e usabilidade. Após uma revisão geral sobre os trabalhos da área, concluímos que a maior parte dos trabalhos não dão atenção principalmente à a extensibilidade, o que dificulta seu reuso em um contexto diferente, e para a usabilidade, o que dificulta o uso por desenvolvedores sem profundo conhecimento em ferramentas específicas.

Implementamos a arquitetura como um microsserviço para a plataforma de cidades inteligentes InterSCity. O nome desse novo microsserviço é DataProcessor e permite que desenvolvedores da plataforma possam processar dados de sensores de maneira distribuída, através da ferramenta Apache Spark, mas sem que precisem aprender Spark. Os usuários escolhem algumas das estratégias de processamento pré-definidas, personalizam essas estratégias e escalonam tarefas que processam os dados. Caso seja necessário uma estratégia não pensada, disponibilizamos formas de estender o DataProcessor.

Avaliamos a extensibilidade, desempenho e usabilidade do DataProcessor através de um experimento que utilizou o simulador de larga escala InterSCSimulator. Nesse experimento, simulamos um cenário de trânsito da cidade de São Paulo para gerar dados que foram processados pelo DataProcessor. Os resultados indicam que: o desempenho atingido com o uso DataProcessor é semelhante ao desempenho atingido utilizando somente o Spark, portanto o DataProcessor traz facilidade de uso mas sem que ocorra prejuízo relevante no desempenho; que sua utilização não aumenta a quantidade de linhas necessárias para se executar uma tarefa de processamento distribuído; e que é possível estender o DataProcessor para adicionar novas tarefas de processamento com poucas linhas de código.

Por fim, este trabalho resultou nas seguintes contribuições, que são tanto técnicas quanto científicas:

- Uma arquitetura de integração de processamento distribuído em plataformas de cidades inteligentes, com foco em desempenho, usabilidade e extensibilidade;

- Um serviço que integra e facilita o processamento distribuído para plataformas de cidades inteligentes, chamado DataProcessor, que implementa a arquitetura da 
contribuição anterior na plataforma de cidades inteligentes InterSCity. Através desse serviço, desenvolvedores podem executar consultas SQL utilizando múltiplos computadores em cluster utilizando dados da plataforma;

- Discussões sobre o estado-da-arte em computação intensiva em dados e processamento de Big Data em cidades inteligentes, desde as principais técnicas até os principais trabalhos;

- Contribuições ao código fonte do simulador de cidades inteligentes InterSCSimulator, como a a adição ao suporte de simulações distribuídas, que permite que ocorram simulações maiores e que essas finalizem mais rápido. Dentre outras contribuições, ressaltamos a otimização de rotinas, que permitiram que as simulações pudessem ser executadas em um menor tempo. Uma dessas otimizações foi o cache de caminhos; em versões anteriores do simulador, caso mil viagens saíssem da mesma origem e mesmo destino, o menor caminho com essa origem e destino seria calculado mil vezes. Na versão atual, esse cálculo ocorre uma única vez.

Nesse contexto, uma série de melhorias podem ser aplicadas ao trabalho com objetivo de o estender, permitindo seu uso em mais cenários. Algumas das melhorias têm cunho mais científico, enquanto outras são mais técnicas. Dentre as mais relevantes, ressaltamos:

Avaliação com usuários A avaliação com usuários reais pode ser utilizada de diversas formas para demonstrar os efeitos do DataProcessor em diferentes contextos. Um exemplo de trabalho futuro é pedir que um grupo de alunos adicione uma nova tarefa de processamento ao DataProcessor e avaliar seu desempenho para realização da tarefa.

Explorar processamento em fluxo Embora o DataProcessor permita sua extensão para adição de processamento em fluxo, esse tipo de processamento está fora do escopo deste trabalho. Do ponto de vista da arquitetura, talvez mudanças sejam necessárias, pois enquanto no processamento em lote não há necessidade de interação após o processamento ser concluído, no processamento em fluxo pode ser interessante que o desenvolvedor interaja com o DataProcessor de maneira contínua.

Adição de políticas para atuadores $\mathrm{Na}$ arquitetura do DataProcessor, seria interessante pensar em formas de integrar a adição de políticas que determinariam ações a ser feitas em atuadores. O InterSCity já conta com suporte a atuadores, o que facilita, mas ainda assim seria necessário que a arquitetura comportasse formas de adicionar essa atuação de forma integrada.

Integração de logs Outra contribuição interessante seria a integração de tudo gerado pelo DataProcessor em conjunto com outros serviços do InterSCity. Essa agregação é interessante pois seu processamento pode servir para detectar situações problemáticas, tanto do lado da plataforma quanto do lado dos sensores da cidade.

Ativação/desativação do microsserviço Atualmente, todos os microsserviços do InterSCity são ativados em conjunto. Uma contribuição interessante seria permitir que o DataProcessor fosse desativado enquanto os outros serviços continuariam ativados. A motivação para essa funcionalidade é que, após o usuário instalar o DataProcessor, mesmo que ele não queira o utilizar, o Spark continua em execução, 
o que consome recursos de forma desnecessária.

Experimentos com múltiplos usuários Em nossos experimentos, somente um usuário utilizou o DataProcessor ao mesmo tempo. Um outro trabalho futuro interessante seria um experimento onde vários usuários utilizassem o serviço ao mesmo tempo, o que ajudaria a explorar falhas e inconsistências, principalmente por questões de concorrência e disputa de recursos.

Integração com outras ferramentas Embora a arquitetura do DataProcessor não utilize funcionalidades específicas do Spark, uma forma de garantir que a arquitetura não é dependente de tecnologias específicas seria a sua implementação com outras ferramentas, ou a adição de suporte a outra ferramenta na implementação atual do DataProcessor.

Facilitar a adição de código Python Atualmente, para estender o DataProcessor é necessário que o desenvolvedor escreva código Python em uma string dentro de código fonte Elixir. Uma adição interessante ao DataProcessor seria permitir que o novo código Python fosse desenvolvido em um arquivo a parte com extensão do Python, possibilitando a utilização de editor específico para Python. 



\section{Referências}

[Apache Spark RDD Documentation 2019] Apache Spark RDD Documentation. 2019. URL: http://spark.apache.org/docs/latest/rdd-programming-guide.html (acesso em 07/07/2019) (citado nas pgs. 9, 13).

[Amini et al. 2017] S. Amini, I. Gerostathopoulos e C. Prehofer. "Big data analytics architecture for real-time traffic control”. Em: 2017 5th IEEE International Conference on Models and Technologies for Intelligent Transportation Systems (MT-ITS). Jun. de 2017, pgs. 710-715. DOI: 10.1109/MTITS.2017.8005605 (citado na pg. 24).

[Al Nuaimi et al. 2015] Eiman Al Nuaimi, Hind Al Neyadi, Nader Mohamed e Jameela AL-JARoodi. “Applications of big data to smart cities". Em: Fournal of Internet Services and Applications 6.1 (dez. de 2015), pg. 25. ISSN: 1869-0238. DoI: 10.1186/ s13174-015-0041-5 (citado nas pgs. 14, 21, 27).

[Araujo et al. 2019] Victor Araujo, Karan Mitra, Saguna Saguna e Christer Åhlund. "Performance evaluation of fiware: a cloud-based iot platform for smart cities". Em: Journal of Parallel and Distributed Computing 132 (mai. de 2019). DOI: 10.1016/ j.jpdc.2018.12.010 (citado na pg. 22).

[BABAr e Arif 2017] Muhammad BABAr e Fahim Arif. "Smart urban planning using Big Data analytics to contend with the interoperability in Internet of Things". Em: Future Generation Computer Systems 77 (2017), pgs. 65-76. ISSN: 0167739X. DOI: 10.1016/j.future.2017.07.029 (citado na pg. 1).

[BAppalige 2014] Sachin Bappalige. An introduction to Apache Hadoop for big data. 2014. URL: https://opensource.com/life/14/8/intro-apache-hadoop-big-data (citado na pg. 15).

[BATista et al. 2016] Daniel Macêdo BATista et al. "Interscity: addressing future internet research challenges for smart cities”. Em: 2016 7th International Conference on the Network of the Future (NOF). Nov. de 2016, pgs. 1-6. DOI: 10.1109/NOF.2016. 7810114 (citado nas pgs. 1, 2, 18, 21).

[BraAms 2018] Boudewijn BraAms. "Predicate pushdown in parquet and databricks spark”. Em: 2018 (citado na pg. 9). 
[Carbone, Katsifodimos et al. 2015] Paris Carbone, Asterios Katsifodimos et al. "Apache flink ${ }^{\mathrm{TM}}$ : stream and batch processing in a single engine". Em: IEEE Data Eng. Bull. 38 (2015), pgs. 28-38 (citado na pg. 16).

[Carbone, Ewen et al. 2017] Paris Carbone, Stephan Ewen et al. "State management in apache flink: consistent stateful distributed stream processing”. Em: Proc. VLDB Endow. 10.12 (ago. de 2017), pgs. 1718-1729. ISSN: 2150-8097. DOI: 10.14778/3137765. 3137777. URL: https://doi.org/10.14778/3137765.3137777 (citado na pg. 16).

[Cheng et al. 2015] B. Cheng, S. Longo, F. Cirillo, M. Bauer e E. Kovacs. "Building a big data platform for smart cities: experience and lessons from santander". Em: 2015 IEEE International Congress on Big Data. Jun. de 2015, pgs. 592-599. DOI: 10.1109/BigDataCongress.2015.91 (citado na pg. 22).

[Chintapalli et al. 2016] Sanket Chintapalli et al. "Benchmarking streaming computation engines: storm, flink and spark streaming”. Em: 2016 IEEE International Parallel and Distributed Processing Symposium Workshops (IPDPSW). Mai. de 2016, pgs. 1789-1792. DOI: 10.1109/IPDPSW.2016.138 (citado na pg. 15).

[C. H. Costa et al. 2015] Caio H. Costa, João Vianney B. M. Filho, Paulo Henrique M. Maia e Francisco Carlos M. B. Oliveira. "Sharding by hash partitioning". Em: Proceedings of the 17th International Conference on Enterprise Information Systems - Volume 1. ICEIS 2015. Barcelona, Spain: SCITEPRESS - Science e Technology Publications, Lda, 2015, pgs. 313-320. ISBN: 978-989-758-096-3. DOI: 10.5220 / 0005376203130320 (citado nas pgs. 7, 8).

[C. Costa e Santos 2016] C. Costa e M. Y. Santos. "Basis: a big data architecture for smart cities”. Em: 2016 SAI Computing Conference (SAI). Jul. de 2016, pgs. 1247-1256. DOI: 10.1109/SAI.2016.7556139 (citado na pg. 23).

[Chambers e Zaharia 2018] Bill Chambers e Matei Zaharia. Spark: The Definitive Guide: Big Data Processing Made Simple. O’Reilly, 2018 (citado nas pgs. 11-13).

[Dean e Ghemawat 2004] Jeffrey Dean e Sanjay Ghemawat. "Mapreduce: simplified data processing on large clusters”. Em: OSDI'04: Sixth Symposium on Operating System Design and Implementation. San Francisco, CA, 2004, pgs. 137-150 (citado na pg. 15).

[Esposte et al. 2017] Arthur M. Del Esposte, Fabio Kon, Fábio M. Costa e Nelson Lago. "Interscity: a scalable microservice-based open source platform for smart cities". Em: SMARTGREENS. 2017 (citado nas pgs. 1-3, 18, 30).

[FOWLER 2014] Martin FOWLER. Microservices. 2014. URL: https://martinfowler.com/ articles/microservices.html (citado nas pgs. 16, 18).

[García-Gil et al. 2017] Diego García-Gil, Sergio Ramírez-Gallego, Salvador García e Francisco Herrera. "A comparison on scalability for batch big data process- 
REFERÊNCIAS

ing on apache spark and apache flink”. Em: Big Data Analytics 2.1 (mar. de 2017), pg. 1. ISSN: 2058-6345. DOI: 10.1186/s41044-016-0020-2 (citado na pg. 16).

[Gandomi e Haider 2015] Amir Gandomi e Murtaza Haider. "Beyond the hype: big data concepts, methods, and analytics". Em: International fournal of Information Management 35.2 (2015), pgs. 137-144. ISSN: 0268-4012. DOI: https://doi.org/10. 1016/j.ijinfomgt.2014.10.007. uRL: http://www.sciencedirect.com/science/article/ pii/S0268401214001066 (citado na pg. 21).

[Khan, Anjum e Kiani 2013] Zaher Khan, Ashiq Anjum e Saad Liaquat Kiani. "Cloud based big data analytics for smart future cities". Em: 2013 IEEE/ACM 6th International Conference on Utility and Cloud Computing. Dez. de 2013, pgs. 381-386. DOI: 10.1109/UCC.2013.77 (citado na pg. 23).

[Khan, Anjum, Soomro et al. 2015] Zaher Khan, Ashiq Anjum, Kamran Soomro e Muhammad Atif TAHIR. "Towards cloud based big data analytics for smart future cities”. Em: Journal of Cloud Computing (2015). ISSN: 2192-113X. DOI: 10.1186/ s13677-015-0026-8. URL: https://doi.org/10.1186/s13677-015-0026-8 (citado na pg. 23).

[Kleppmann 2017] Martin Kleppmann. Designing Data-Intensive Applications: The Big Ideas Behind Reliable, Scalable, and Maintainable Systems. O’Reilly Media, 2017. ISBN: 9781491903100 (citado nas pgs. 5, 6, 8, 21).

[LEE 2019] Jeremiah LEE. Pragmatic design with FSONAPI.org. 2019. URL: https://www. youtube.com/watch?v=3jBJOga4e2Y (acesso em 07/07/2019) (citado na pg. 45).

[M. Del Esposte et al. 2019] Arthur de M. Del Esposte et al. "Design and evaluation of a scalable smart city software platform with large-scale simulations". Em: Future Generation Computer Systems 93 (2019), pgs. 427-441 (citado na pg. 3).

[MA e Liang 2015] S. MA e Z. LiANG. "Design and implementation of smart city big data processing platform based on distributed architecture". Em: 2015 10th International Conference on Intelligent Systems and Knowledge Engineering (ISKE). Nov. de 2015, pgs. 428-433. DOI: 10.1109/ISKE.2015.7 (citado na pg. 23).

[Myкhalyк 2019] Dmytro Myкhalyk. Spark DataSkew Problem. 2019. url: https:// dataengi.com/2019/02/06/spark-data-skew-problem/ (citado na pg. 8).

[NAIR 2018] Sujith Jay NAIR. Broadcast Hash Joins in Apache Spark. 2018. urL: https: //sujithjay.com/spark/broadcast-joins (acesso em 07/07/2019) (citado nas pgs. 10, $11)$.

[Osman 2019] Ahmed M. Shahat Osman. "A novel big data analytics framework for smart cities”. Em: Future Generation Computer Systems 91 (2019), pgs. 620-633. ISSN: 0167-739X. DOI: https://doi.org/10.1016/j.future.2018.06.046. URL: http: //www.sciencedirect.com/science/article/pii/S0167739X17307446 (citado nas pgs. 6, 23). 
[Pu et al. 2019] Qifan Pu, Shivaram Venkataraman e Ion Stoica. "Shuffling, fast and slow: scalable analytics on serverless infrastructure”. Em: 16th USENIX Symposium on Networked Systems Design and Implementation (NSDI 19). Boston, MA: USENIX Association, 2019, pgs. 193-206. ISBN: 978-1-931971-49-2. URL: https://www.usenix. org/conference/nsdi19/presentation/pu (citado na pg. 9).

[Santana et al. 2017] Eduardo Felipe Zambom Santana, Ana Paula Chaves, Marco Aurelio Gerosa, Fabio Kon e Dejan S. Milojicic. "Software platforms for smart cities: concepts, requirements, challenges, and a unified reference architecture". Em: ACM Comput. Surv. 50.6 (nov. de 2017), 78:1-78:37. ISSN: 0360-0300. DOI: 10.1145/3124391 (citado na pg. 2).

[Sodt e Maravić 2018] Rita Sodt e Igor Maravić. Data Processing Pipelines. 2018. UrL: https://landing.google.com/sre/workbook/chapters/data-processing/ (citado na pg. 3).

[Storimer 2013] Jesse Storimer. Nobody understands the GIL. 2013. urL: www . jstorimer.com/blogs/workingwithcode/8085491-nobody-understands-the-gil (citado na pg. 31).

[Toshniwal et al. 2014] Ankit Toshniwal et al. "Storm@twitter". Em: Proceedings of the 2014 ACM SIGMOD International Conference on Management of Data. SIGMOD '14. Snowbird, Utah, USA: ACM, 2014, pgs. 147-156. ISBN: 978-1-4503-2376-5. DOI: 10.1145/2588555.2595641 (citado na pg. 15).

[Villanueva et al. 2013] F Villanueva, Maria Santofimia, D Villa, Jesus Barba e Juan Carlos López. "Civitas: the smart city middleware, from sensors to big data". Em: jul. de 2013, pgs. 445-450. DOI: 10.1109/IMIS.2013.80 (citado na pg. 21).

[Warren e Karau 2017] Rachel Warren e Holden Karau. High Performance Spark: Best Practices for Scaling and Optimizing Apache Spark. O’Reilly, 2017 (citado na pg. 14).

[XIN et al. 2013] Reynold S. XIN et al. "Shark: sql and rich analytics at scale". Em: Proceedings of the 2013 ACM SIGMOD International Conference on Management of Data. SIGMOD '13. New York, New York, USA: ACM, 2013, pgs. 13-24. ISBN: 978-1-4503-2037-5. DOI: 10.1145/2463676.2465288. uRL: http://doi.acm.org/10.1145/ 2463676.2465288 (citado nas pgs. 10, 11).

[Zaharia, Chowdhury, Franklin et al. 2010] Matei Zaharia, Mosharaf Chowdhury, Michael J. Franklin, Scott Shenker e Ion Stoica. "Spark: cluster computing with working sets". Em: Proceedings of the 2Nd USENIX Conference on Hot Topics in Cloud Computing. HotCloud'10. Boston, MA: USENIX Association, 2010, pgs. 10-10 (citado na pg. 31).

[Zaharia, Chowdhury, Das et al. 2012] Matei Zaharia, Mosharaf Chowdhury, Tathagata DAs et al. "Resilient distributed datasets: a fault-tolerant abstraction for in-memory cluster computing”. Em: Proceedings of the 9th USENIX Conference on 
Networked Systems Design and Implementation. NSDI'12. San Jose, CA: USENIX Association, 2012, pgs. 2-2 (citado nas pgs. 15, 23).

[Zaharia 2014] Matei Zaharia. "An Architecture for Fast and General Data Processing on Large Clusters". Tese de dout. EECS Department, University of California, Berkeley, fev. de 2014. uRL: http://www2.eecs.berkeley.edu/Pubs/TechRpts/2014/ EECS-2014-12.html (citado na pg. 12).

[Zaman et al. 2017] Ibna Zaman, Kayvan Pazouki, Rose Norman, Shervin Younessi e Shirley ColEman. "Challenges and opportunities of big data analytics for upcoming regulations and future transformation of the shipping industry". Em: Procedia Engineering 194 (2017). 10th International Conference on Marine Technology, MARTEC 2016, pgs. 537-544. ISSN: 1877-7058 (citado na pg. 2). 